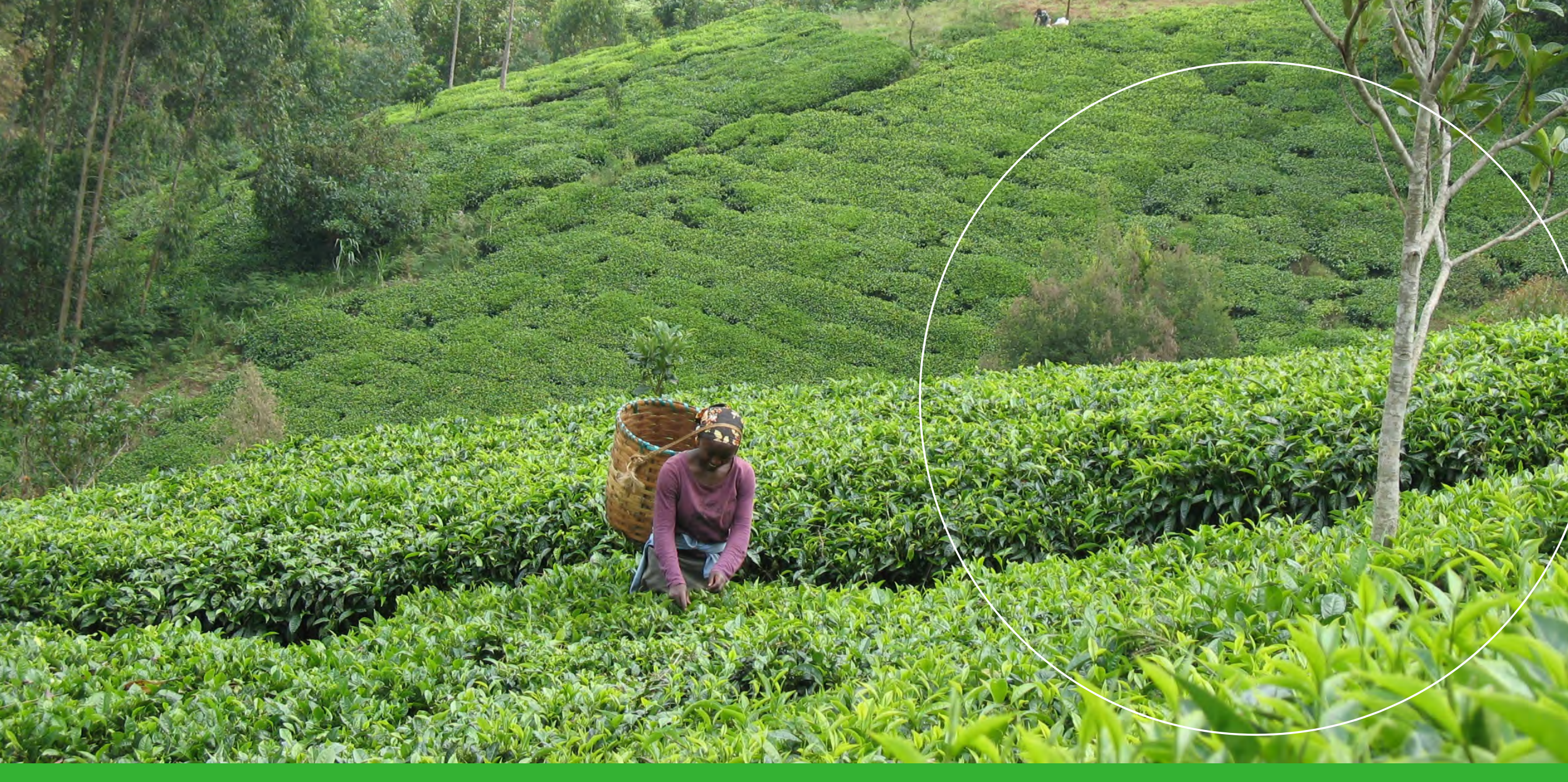

\title{
Final impact evaluation of Farmer Field School implementation in the smallholder tea sector in Kenya, 2009-2016
}




\section{Table of contents}

Acronyms

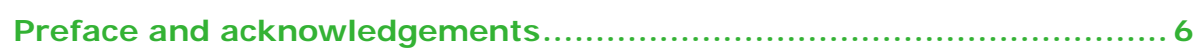

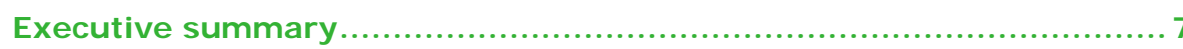

Farmer Field Schools in Kenya, from pilot to scale ................... 13

The FFS programme for smallholder tea producers in Kenya ............. 13

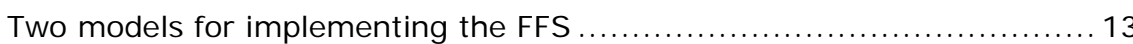

FFS participation is expected to increase incomes by improving farming practices, productivity and quality, and by diversifying income ......... 13

Rainforest Alliance certification is also expected to positively influence practices, productivity and incomes, and its criteria have been incorporated into the FFS curriculum ....

FFS farmers are expected to share what they learnt with other farmers, resulting in spillover effects.....

Spillover effects will differ between collection centres as the share of FFS farmers is between $5 \%$ and $50 \%$ per collection centre......

KTDA perceived the upscaling process as a positive experience, though dropout rates have increased and sometimes it suffered from a shortage of demonstration material....

Most farmers are satisfied with the FFSs and how they are set up, and non-participants are lining up to join an FFS ......................... 17

Evaluating the impact of the FFS programme, 2006-2016 .............. 17

Methodology for measuring the impact of the FFS programme......... 19

Study design to evaluate the impact of the tea programme $\ldots \ldots \ldots \ldots \ldots \ldots 19$

Indicators for programme and impact evaluation ......................... 20

Farmers were interviewed from six factories and two programme periods 20 Large differences in the share of FFS participants in total factory population in the six factories studied
I mpact of TESA-led FFS between 2009- 2013 and long-term trends

in green leaf productivity 26

Implementation of TESA-led Farmer Field Schools 2009-2013 ...............26

Farmers were very satisfied with FFS implementation ....................26

FFS participation increased knowledge of Good Agricultural Practices......26

FFS farmers also improved the implementation of GAPs compared to

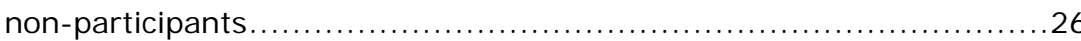

FFS farmers apply more fertilisers, which is considered to be generally beneficial as application rates were previously too low ..................27

Green leaf productivity increases because of FFS participation .............27

An initial increase in green leaf incomes for FFS farmers, but between 2011 and 2013, incomes decrease for all farmers because of a huge

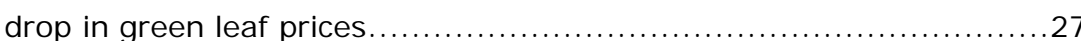

FFS farmers diversify their income sources between 2011 and $2013 \ldots \ldots .28$

But household incomes and income earned per person per day remain low

FFS farmers report livelihood improvements between 2011 and $2013 \ldots \ldots 28$

Overall positive results of FFS implementation, though the green leaf price has had a major influence on profitability and incomes, and tea farmers remain poor.

In the factory data, we find similar trends in green leaf productivity per hectare between FFS participants and other farmers in their factories. But the early FFS participant has a higher productivity per hectare than the average farmer in their factory catchment.....................28

Professionalisation of tea farmers, 2013- 2015........................ 31

Knowledge of good tea practices increased for both FFS and comparison

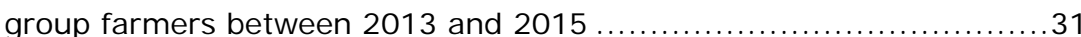


Comparison group farmers were also trained by TESAs and all farmers had been trained in order to get Rainforest Alliance certification prior to starting with an FFS

Older farmers and farmers with larger farms are more likely to increase their knowledge, while there is no difference in the knowledge increase between men and women....

FFS farmers more likely to make management decisions based on what they learn in FFS trainings than the comparison group .................. 32

Farmers value FFS most for learning how to improve tea practices, increase productivity and diversify income......................... 33

But farmers were already implementing many good tea practices at baseline, and FFS farmers hardly improved .......................... 33

This suggests diminishing returns in training and adoption ................ 33

Other trainings on good tea practices and spillover effects may explain why the comparison group improved without participating in an FFS .. 34

FFS participants confirm that spillover effects have led them to

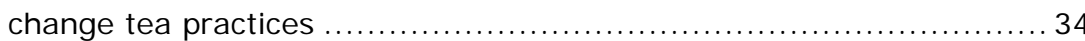

Farmers with larger families are more likely to have improved their production and environmental practices, and we also found regional differences in implementation often than with the comparison group, but the frequency of sharing

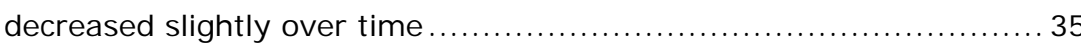

Green leaf productivity and quality, 2013-2015 . .37

Green leaf productivity differs between regions and factories: it generally increased between 2010 and 2012, after which it decreased on average

Productivity decrease is lower for FFS participants than for nonparticipants of two factories between J uly 2012 and June $2015 \ldots \ldots \ldots 37$

Productivity increase is associated with the region farmers are based in .. 37

The quality of green leaf decreased slightly in terms of rejected green leaf at leaf collection centres ....................................... 39

There was little change in the share of different grades of made black

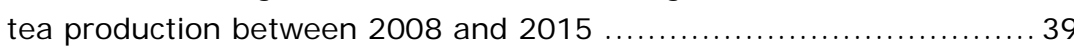

Profitability of green leaf and other crops, 2013-2015 ................ 42 Green leaf prices dropped in the period July 2011 to J une 2014, but increased again after June 2014
Green leaf profitability: decrease in profitability of tea per hectare, for both FFS and non-FFS farmers.....

Decrease in production costs mainly caused by reduction of labour used

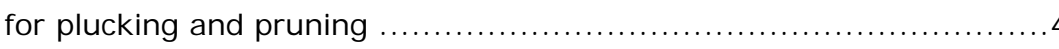

Green leaf profitability per hectare is higher than profitability for maize

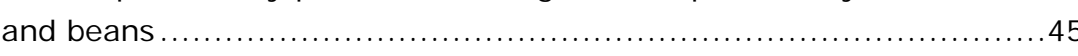

I ncome and income diversification, 2013-2015........................47

Household income fell by $25 \%$ over the period 2013-2015 for all farmers, from USD1,099 to USD744 per year, which translates to amounts well below the USD1.25/day poverty line

It is a challenge for tea farmers to earn a good income from tea as farm sizes are small, have significantly decreased over time and farmers with smaller-sized farms have lower productivity..............4

All farmers increased their income from sources other than tea although not with statistical significance due to a wide variance .................47

All farmers reduced their dependency on green leaf for income ............48

Social effects of Farmer Field Schools, 2013-2015 ....................... 50

The relationship between FFS farmers and KTDA has improved because FFSs allow KTDA to have more in-depth discussions with FFS group

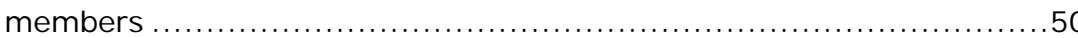

Women's leadership capacity improved because of the FFS according to KTDA staff. Women in particular bring innovation to food production activities and value addition.

Better health thanks to improved waste management practices and the introduction of 'central sprayers', which have especially benefited

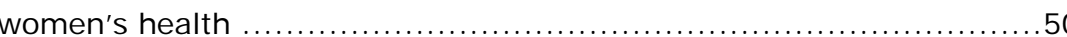

Farmers and KTDA staff report that the FFS programme has had a positive effect on food and nutrition security ........................ 5

Embedding and institutionalisation of FFS within KTDA .............. 53

FFS have been upscaled within the KTDA factory system .................5

All three parties contributed to the programme's results. Funding by IDH and Unilever has led to FFSs being implemented more rapidly than would have been the case without their funding...................53 The FFS approach has been embedded and institutionalised at the KTDA

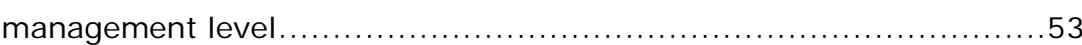

Half of the farmers continue with FFS group activities after graduation ....53 
But graduate FFS group activities take place at least monthly in $70 \%-90 \%$ of the cases. Older graduates meet more often than recent graduates 54 Various activities are carried out by farmers who graduated from FFS groups..... 54

Conclusions and recommendations .................................... 57

Upscaling FFS implementation between 2009 and $2016 \ldots \ldots \ldots \ldots \ldots \ldots \ldots . \ldots \ldots$

The FFS programme increased green leaf productivity between 2009 and 2013 and increased incomes between 2009 and $2011 \ldots \ldots \ldots \ldots . \ldots 5$

A decrease in green leaf prices has negatively affected green leaf profitability between 2011 and 2013 and tea farmers remain poor .... 57

All farmers increased knowledge levels between 2013 and 2015 but adoption did not change, probably because of already high levels at baseline.

Green leaf quality decreased slightly in terms of rejected green leaf at the leaf collection centres for all farmers (2013-2015)

Green leaf productivity decreased for all farmers between 2013 and 2015, but FFS participants experienced a significantly smaller decrease than non-participants....

Combined with lower green leaf prices, this resulted in lower green leaf profitability between 2013 and 2015
Average household income fell over the period 2013-2015 for all farmers, from USD1,099 to USD744 per family per year, which is well below the poverty line....

It is a challenge for tea farmers to earn a good income from green leaf as farm sizes are small and have decreased over time, and smaller-sized farms are associated with lower productivity per hectare......

KTDA and farmers acknowledge that between 2013 and 2015 the FFSs improved the relationship between KTDA and the farmers, and also improved farmers' health, nutrition and the position of women .....

All three parties contributed: funding by IDH and Unilever has led to FFSs being implemented more rapidly than would have been the case without their funding.....

The FFS approach has been embedded and institutionalised at the KTDA management level, but half of the FFS farmers discontinue activities

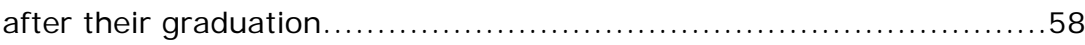

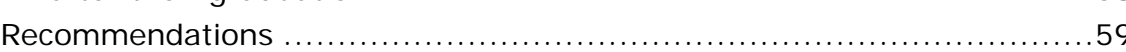

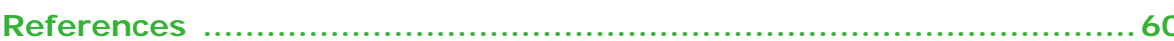

Appendices . .61

4 | Wageningen Economic Research | Final impact evaluation of Farmer Field School implementation in the smallholder tea sector in Kenya, 2009-2016 


\section{Acronyms}

DiD

FFS

FSC

Farmer-assisted FFS

GAP

IDH

KES

KTDA

PSM

RA

TESA

TESA-led FFS difference-in-difference

Farmer Field School

Field Services Coordinator

FFS facilitated by TESAs, who are assisted in the FFS organisation by FFS graduates

Good Agricultural Practice

The Sustainable Trade I nitiative

Kenya shilling

Kenya Tea Development Agency

Propensity score matching

Rainforest Alliance

Tea Extension Services Assistant

FFS organised and facilitated by TESAs 


\section{Preface and acknowledgements}

Farmer Field Schools (FFSs) are a popular education and extension approach around the globe. Co-funded by the UK government's Department for International Development (DFID), the Kenya Tea Development Agency (KTDA) and Lipton implemented the Sustainable Agriculture Project, which introduced pilot FFSs in four KTDA-managed factories in 2006. The purpose was to make tea production more sustainable by encouraging the adoption of Good Agricultural Practices (GAPs) in the tea value chain as well as improving green leaf profitability and the livelihoods of smallholder growers.

Based on the good results from the pilot phase in 2006, the partnership between KTDA, Unilever and IDH launched their Sustainable Tea Programme in 2009 with the aim of reaching all 65 processing factories belonging to the 54 KTDA tea factory companies. Upscaling the FFSs in this phase was mainly led by Tea Extension Service Assistants (TESAs). An impact evaluation of the TESA-led FFS was done in 2014.

In order to reach more farmers and leaf collection centres from every KTDA processing plant, KTDA, Unilever and IDH launched their Embedding Sustainability Programme in 2013, which introduced a new upscaling phase that enabled FFS graduate farmers to help initiate and run FFS activities (farmer-assisted FFS). They are doing this with guidance from TESAs.

Now that the FFS programme has been thoroughly upscaled and embedded in the entire KTDA factory and management system, KTDA, Unilever and IDH are evaluating the overall tea programme. They commissioned Wageningen Economic Research to conduct this study.

In this report, we present an update of the impact evidence on the TESA-led FFSs which we evaluated before between 2009 and 2013. But the main focus of the report is the evaluation of the farmer-assisted FFSs between 2013 and 2015. As the factories had obtained Rainforest Alliance (RA) certification before these farmer-assisted FFSs started and farmers were also trained by TESAs, this enabled us to assess whether the farmer-assisted FFS approach had value in addition to such trainings and RA certification. It also enabled us to analyse whether this approach is as effective as the TESA-led FFS approach, especially in situations where factories had also undergone RA certification. And it made it possible to analyse trends in green leaf yield over time, including long after the first FFS farmers had graduated.

We thank KTDA, Unilever and IDH for their trust in us to carry out this study and to provide valuable information, insights and inputs to facilitate and improve our work. We sincerely appreciate the support and cooperation from KTDA factory staff and management from Kinoro, Litein, Ndima, Nyankoba, Gachege and Mudete factories, who assisted us in our work and provided a large amount of factory data. We are grateful in particular to Mr. Peter Mbadi from KTDA for his tremendous effort in ensuring that we get the right data and information on time.

We are indebted to the enumerators and data entry clerks for the hard work they put into collecting and processing primary data. Our special gratitude goes to Mr. Davies Onduru from ETC-East Africa for managing the primary data collection process and for assisting us with his excellent knowledge and extensive experience of the developments in the tea sector since 2006 . Finally, we also thank Rainforest Alliance for providing us with information on Rainforest Alliance certification of the KTDA factories between 2009 and 2014.

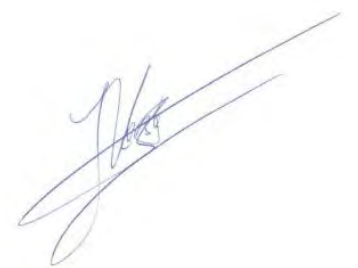

Prof.dr.ir. Jack van der Vorst General Director Social Sciences Group Wageningen University \& Research 
The FFS programme for smallholder tea producers in Kenya, from pilot to scale

The use of Farmer Field Schools (FFSs) as an extension method was introduced in 2006 by the Kenya Tea Development Agency (KTDA), the management agency that represents 560,000 smallholder tea producers. Motivated by the good results from a pilot project with 24 FFSs in 2008, KTDA introduced the FFS programme to all 54 KTDA factory companies between 2009 and 2016. This was done in partnership with Unilever, IDH (the Sustainable Trade Initiative) and the Netherlands Embassy in Nairobi. The tea programme achieved 3,436 FFSs by J une 2016, reaching 86,020 farmers in total and $15 \%$ of all farmers connected to KTDA on average. By the end of 2016, 72,816 farmers had graduated including 38, 783 women (53\%). In total, an estimated number of 45,849 women participated in the FFS programme. See Figure E. 1 on next page.

Evaluating the impact of the FFS programme, 2006-2016

This study evaluates the impact of the whole tea programme (2006-2016) and tracks changes in adoption, green leaf productivity, profitability and household income. A summary is given of the results of two evaluation studies on the impact of FFS implemented by Tea Extension Services Assistants (TESAs) between 2009 and 2013 (the TESA-led FFS model). But we specifically focus on the impact of the farmer-assisted FFS model between 2013 and 2015 at the farm level, the results of which we have often compared to the performance of the first two years of the TESA-led FFS (2009-2011). We also assess the embedding and institutionalisation of FFSs at KTDA, including a future outlook for FFS implementation at KTDA. Finally, recommendations are provided for future work with smallholder tea producers within the KTDA factory system.
Two models for FFS implementation between 2006 and 2016 Following the pilots and first implementation in TESA-led Farmer Field Schools between 2009 and 2012, KTDA, Unilever and IDH launched the programme's 'embedding phase' (2012-2016). In this phase, FFS graduates assisted TESAs in the organisation of FFS, for which they were reimbursed. This enabled the TESAs to implement more FFSs per person per year, from two to about six FFSs per TESA. This latter model is called the Farmer-assisted FFS, and both KTDA Field Services Coordinators (FSCS) and TESAs have noted that the quality of the implementation of these FFSs is comparable to the first FFS model.

The FFS programme increased the adoption of Good Agricultural Practices and green leaf productivity between 2009 and 2013 and helped to increase green leaf incomes between 2009 and 2011 TESA-led FFS trainings improved knowledge and adoption of Good Agricultural Practices (GAPs), which increased farmers' productivity per bush between 2009 and 2013 by $30 \%$, compared to $15 \%$ for non-FFS farmers. This has helped to increase incomes between 2009 and 2011. Moreover, FFS participants actively shared the knowledge they acquired with other farmers, resulting in significant spillover effects.

A decrease in green leaf prices negatively affected green leaf profitability between 2011 and 2013, though FFS farmers experienced less of a decline. Tea farmers remain poor Even though green leaf productivity increased between 2009 and 2013, a decrease in green leaf prices resulted in lower profitability per hectare and lower incomes from green leaf for all tea farmers between 2011 and 2013. FFS farmers experienced less decline of profitability than farmers in the comparison group. Increases in income from other sources did not offset this green leaf income decrease, so farmers remained poor with a typical income of less than USD2 from green leaf per family per day. 
Figure E.1 The implementation of the FFS programme; number of FFSs implemented and numbers of farmers trained, cumulative over time

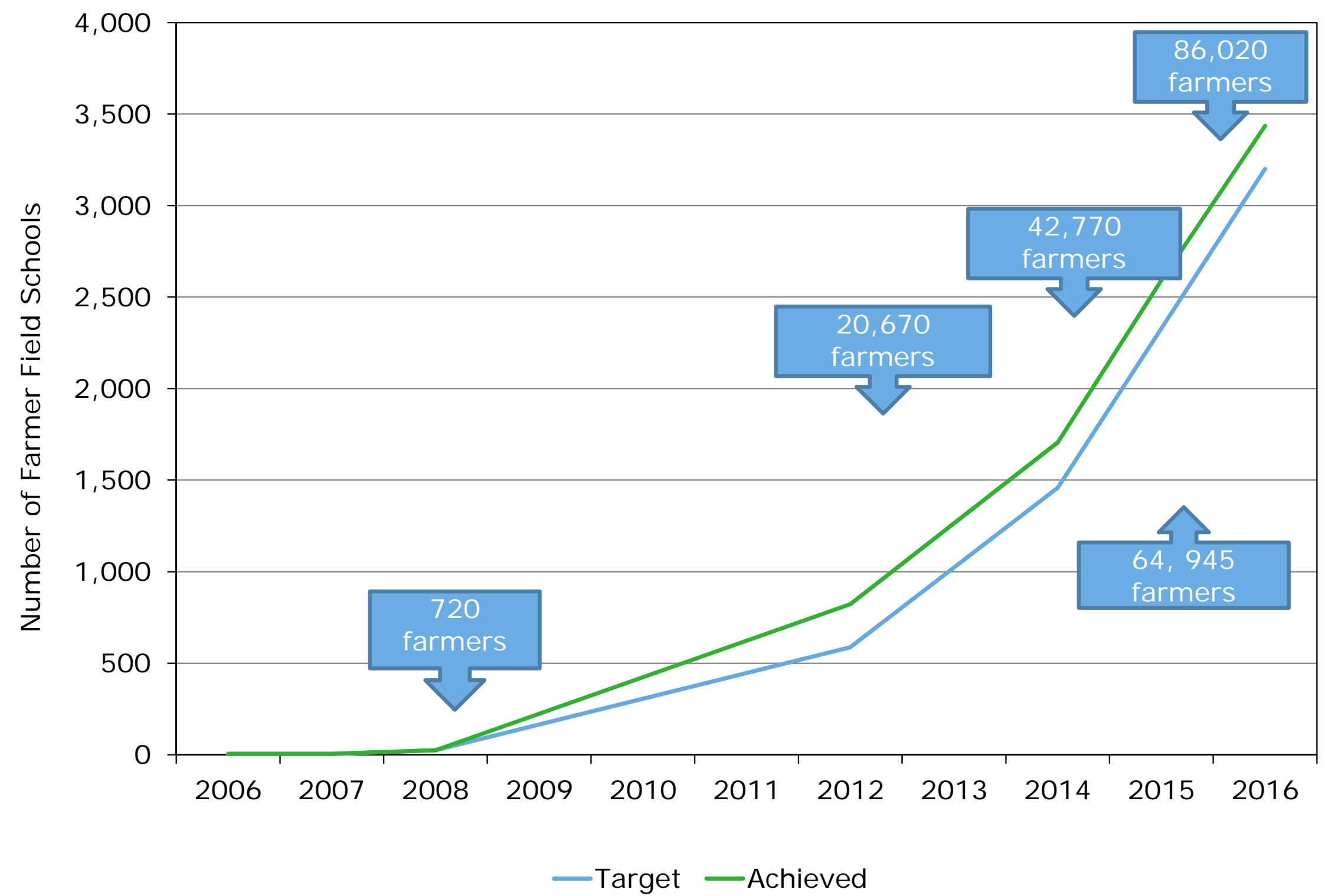

8 | Wageningen Economic Research | Final impact evaluation of Farmer Field School implementation in the smallholder tea sector in Kenya, 2009-2016 
All farmers increased knowledge levels between 2013 and 2015 but adoption did not change, probably because of already high levels at baseline

Over the period 2013-2015, the knowledge of good tea practices increased for both FFS and comparison group farmers. Furthermore, the adoption rates were already quite high at the baseline situation. This may be attributable to the fact that both groups of farmers had been trained by TESAs before the FFSs were implemented, and also to RA certification in 2013. It appears that FFS training on top of these earlier trainings for the group of farmers in question has a limited impact. This could indicate that there are diminishing returns in training and adoption: farmers who already participated in other trainings reach a point where participating in an extra training does not lead to additional knowledge levels or behavioural change by the farmer.

Green leaf productivity decreased for all farmers between 2013 and 2015, but FFS participants experienced a significantly smaller decrease than non-participants

While the knowledge of GAPs increased and their adoption remained stable, average green leaf productivity decreased between 2013 and 2015 because of unfavourable climatic conditions. Interestingly, the productivity of non-FFS farmers showed a much steeper decline than the productivity of FFS farmers. This might indicate a higher resilience of FFS farmers to changes in climatic conditions.
Figure E.2 Green leaf productivity per hectare July 2012-J une 2015

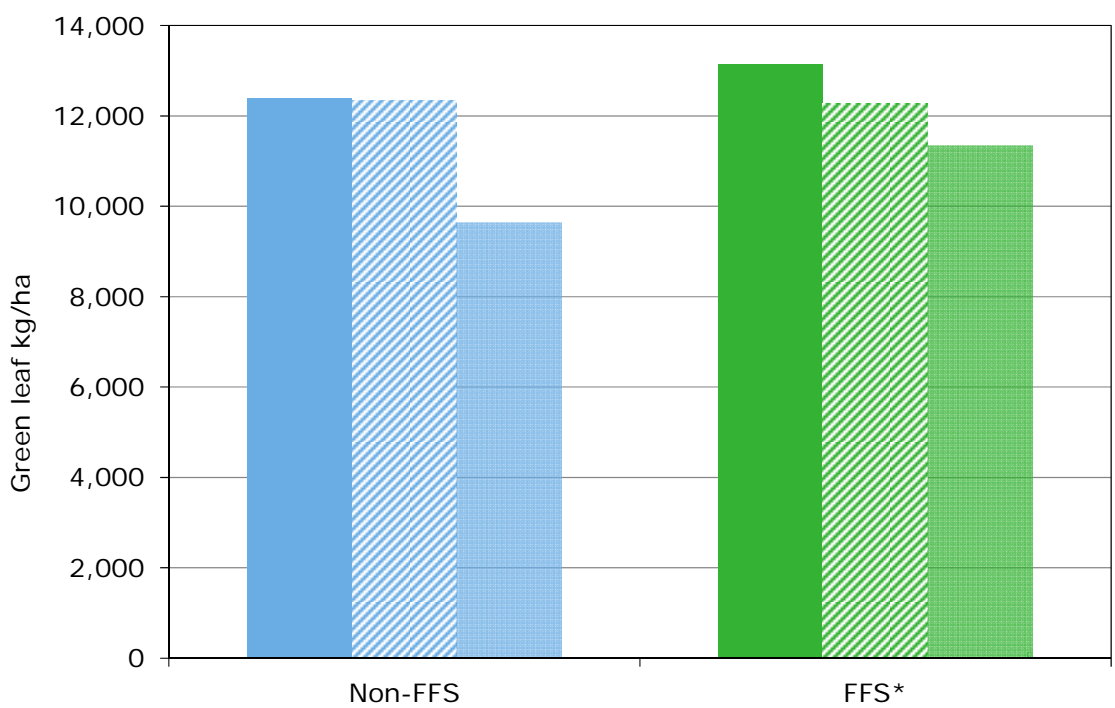

-July 2012-J une 2013 \%July 2013-J une 2014 嘼July 2014-J une 2015

* Significant difference in evolution over time between FFS and non-FFS farmers based on difference-in-difference analyses.

Combined with lower green leaf prices, this resulted in lower green leaf profitability between 2013 and 2015

Green leaf prices dropped in the period 2012-2015, after a steady increase in the period 2008-2013. Combined with declining tea productivity, this resulted in a decrease in green leaf profitability between 2013 and 2015, for both FFS and non-FFS farmers. Interestingly, production costs decreased as well during that period, mainly as a result of a reduction of labour used for plucking and pruning. Apart from climatic effects, the decrease in productivity could be explained in part by farmers reducing their labour investments in green leaf production because of unattractive tea prices. 
Average household income fell over the period 2013-2015 for all farmers, from USD1,099 to USD744 per family per year, which is well below the poverty line

As a result of the decline of green leaf productivity and the drop in prices for green leaf during the period 2013-2015, the income from green leaf fell by $45 \%$ for non-FFS farmers and $40 \%$ for FFS farmers in that period. Income from other sources increased for all farmers, though not significantly so.

Examples of new income sources were dairy and poultry farming, tomato and cabbage production and nurseries for tree seedlings. Other income sources that contributed to the increased diversification are business and services activities. But the average household income declined for both FFS and nonFFS farmers by $25 \%$, from USD1,099 to USD744 per family per year. This is well below the poverty line, and is largely due to the relatively small size of most farmers' farms (on average 0.21 ha in 2015).

It is a challenge for tea farmers to earn a good income from green leaf as farm sizes are small and have decreased over time, and smallersized farms are associated with lower productivity per hectare Farm sizes have decreased significantly from 0.25 ha to 0.21 ha between 2008 and 2015. According to KTDA this is the case because plots are being divided among the children when a parent passes away. These new households earn less from green leaf because they have less land available. Also, smaller-sized farms are associated with lower productivity per hectare, which might explain why households are spending less time on tea as they now need to have additional income-generating activities. It is very difficult for tea farmers to earn a good income from tea if prices do not increase. If the trend of decreasing farm sizes continues, famers will face an even bigger challenge.

KTDA and farmers acknowledge that between 2013 and 2015 the FFSs improved the relationship between KTDA and the farmers, and also improved farmers' health, nutrition and the position of women The FFS implementation between 2013 and 2015 resulted in a range of social effects according to KTDA staff and farmers that participated in focus group discussions. Regular interaction with the FFS improved relations between KTDA and FFS farmers. In particular, farmers now know how prices are established, and thus complain less that green leaf prices are too low. Also, women's leadership capacity improved due to the FFS activities as women started innovating more in food production and value adding activities.
Moreover, farmers' health improved due to better waste management practices and the introduction of central sprayers, which especially reduced the number of women applying crop protection products. Farmers and KTDA staff also report that the FFS programme had a positive effect on food and nutrition security. The participants of FFS focus groups indicated that there have been clear improvements in the quantity of food, due to increased yields of maize, beans and vegetables. Also, FFS famers indicated that the diversity of food in their diets had increased, for example due to a higher intake of vegetables and fruits. Non-FFS participants did not indicate any such changes.

Figure E.3 Perceived changes in quantity and quality of diet (2013-2015) ( $\mathrm{N}=36$ for FFS, and 60 for non-FFS farmers)

FFS

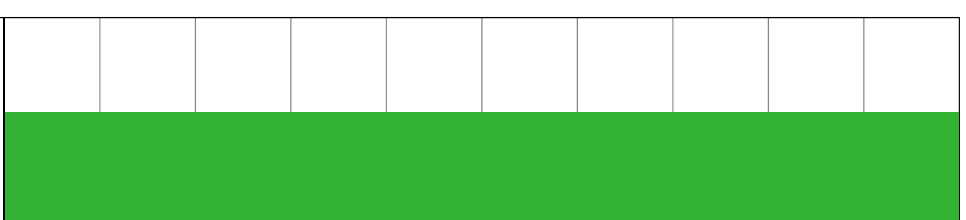

Non-FFS

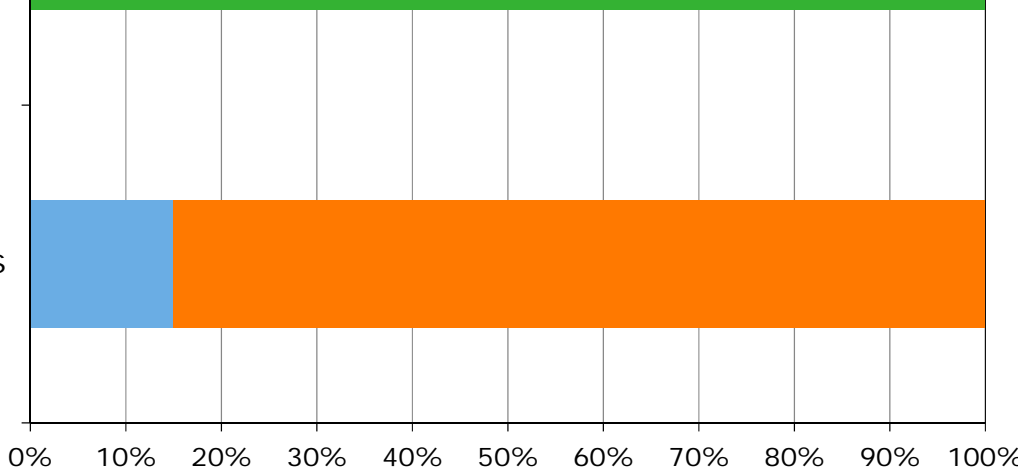

Improved $=$ Constant

10 | Wageningen Economic Research | Final impact evaluation of Farmer Field School implementation in the smallholder tea sector in Kenya, 2009-2016 
All three parties contributed: funding by IDH and Unilever has led to FFSs being implemented more rapidly than would have been the case without their funding

The impact of the Embedding Sustainability Programme can be attributed in large part to the three funders contributing to the programme. The funding of the programme was equally distributed between KTDA, Unilever and IDH. The co-funding of Unilever and IDH played a key role in upscaling the FFS approach. KTDA would also have implemented the FFS without IDH and Unilever support, but at a much slower pace.

The FFS approach has been embedded and institutionalized at the KTDA management level, but half of the FFS farmers discontinue activities after their graduation

KTDA staff in all parts of the organisation consider the FFS to be an important and effective extension methodology. Over the coming years, the FFS implementation will continue, though at a slower pace than in the last few years as KTDA fully funds the implementation itself and farmer graduates will no longer assist the TESAs in organising the FFS. KTDA management has gained one extra staff member to implement the FFS programme. This enhances the sustainability of the continued implementation of FFS at KTDA from the KTDA management level.

There is one point that needs to be addressed in order to increase the embeddedness of the FFS within the KTDA extension strategy: about $50 \%$ of the farmers indicated they had discontinued activities since graduation. Time and money constraints, a lack of commitment and insufficient coordination are mentioned as the main reasons for discontinuing FFS activities. A more active way of engaging FFS farmer graduates would perhaps go further in

guaranteeing the sustainability of these FFS group graduates. This could also help to address the production problems that many of these FFS graduates are facing.

\section{Recommendations}

Based on the results of this evaluation, we recommend the following

1. Explore ways of managing the fact that tea plots are getting smaller and smaller plots tend to be less productive. We should learn from similar developments occurring in other sectors.

2. Focus the implementation of FFSs on those farmers who still stand to substantially improve their tea practices. This is likely to have a bigger impact, and would therefore increase the efficiency of FFS implementation because similar investments would generate more impact.

3. Explore which topics and themes can offer added value in addition to previous trainings attended by FFS farmers.

4. Continue the training on nutrition and diversification, as it contributes to resilience and food security. Explore ways of increasing the activities of farmers who have graduated from FFSs with their FFS groups, to address production problems and continue to experiment with innovations. 


\section{Farmer Held Schools in Kenyt?}

from pilotgors ald:

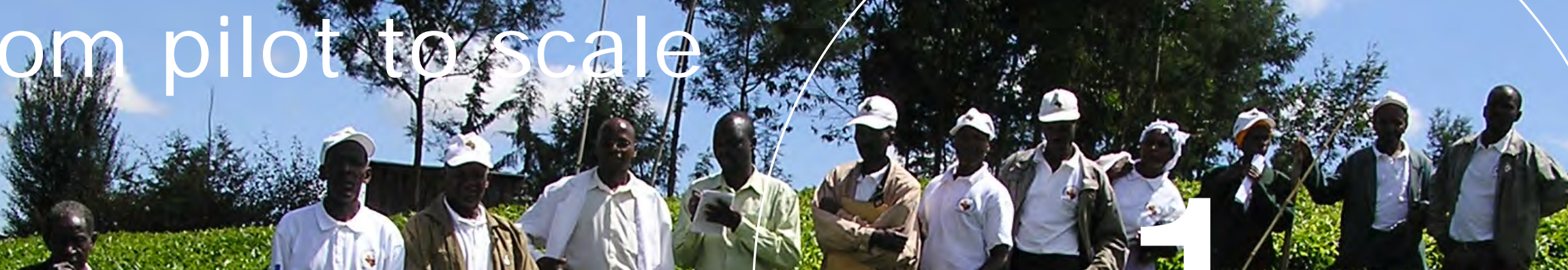

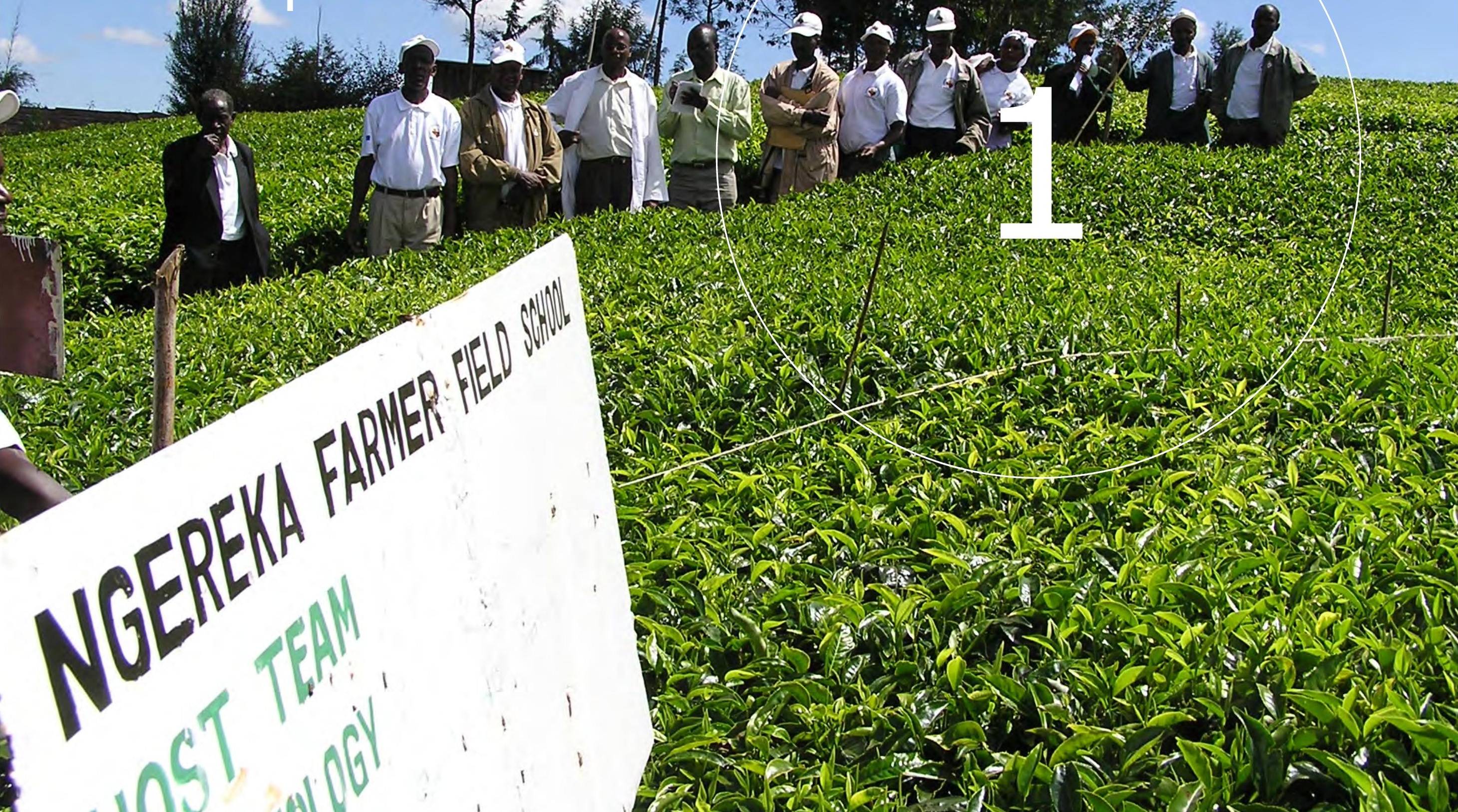




\section{Farmer Field Schools in Kenya, from pilot to scale}

The FFS programme for smallholder tea producers in Kenya

The use of Farmer Field Schools (FFSs) as an extension method was introduced in 2006 by the Kenya Tea Development Agency (KTDA), the management agency that represents 560,000 smallholder tea producers. Motivated by the good results from a pilot project with $24 \mathrm{FFSs}^{1}$ in 2008, KTDA introduced the FFS programme to all 54 KTDA factory companies between 2009 and 2016. This was done in partnership with Unilever, IDH (The Sustainable Trade Initiative) and the Netherlands Embassy in Nairobi. The tea programme aimed to implement 3,200 FFSs by the end of the programme, and achieved 3,436 FFSs by J une 2016 , reaching 86,020 farmers in total and $15 \%$ of all farmers connected to KTDA on average (see Figure 1.1 on next page). By the end of 2016, 72,816 farmers had graduated including 38, 783 women (53\%). In total, an estimated number of 45,849 women participated in the FFS programme. ${ }^{2}$ The average number of participants per FFS decreased slightly from 31 in 2012 to 27 in 2016. KTDA Field Service Coordinators (FSCs) indicated that in later years the rate of school dropout was higher than in the first years in which the participation rate was $100 \%$.
Two models for implementing the FFS

The first FFSs were implemented by the KTDA tea extension staff (TESA-led FFS, 2006-2012). In the programme's embedding phase (2013-2016), FFS graduates assisted the TESAs in facilitating the FFS group meetings, and were reimbursed for their time spent. This enabled the TESAs to implement more FFSs per person per year (from 2 to 5 or 6 per TESA). This latter model is called the Farmer-assisted FFS, and both KTDA Field Services Coordinators (FSCS) and TESAs have noted that the quality of the implementation of these FFSs are the same as the first FFS model. This is because the TESAs remain responsible for the FFS and its curriculum. The impact of the TESA-led FFS was already evaluated in 2014. ${ }^{3}$

FFS participation is expected to increase incomes by improving farming practices, productivity and quality, and by diversifying income

The FFS programme aims to professionalise farmers in such a way that they improve their green leaf productivity and quality and diversify their activities in order to increase green leaf profitability and total household income. See Figure 1.2 on page 15.

\footnotetext{
1 In partnership with DFiD and Lipton.

2 This was calculated based on the percentage of women graduates (53\%)
}

3 More information about the implementation of the FFS and the evaluation of the TESA-led FFS model can be found in Waarts et al., 2012 and Waarts et al., 2014. See the references section for links to these reports. 
Figure 1.1 The implementation of the FFS programme; number of FFSs implemented and numbers of farmers trained, cumulative over time

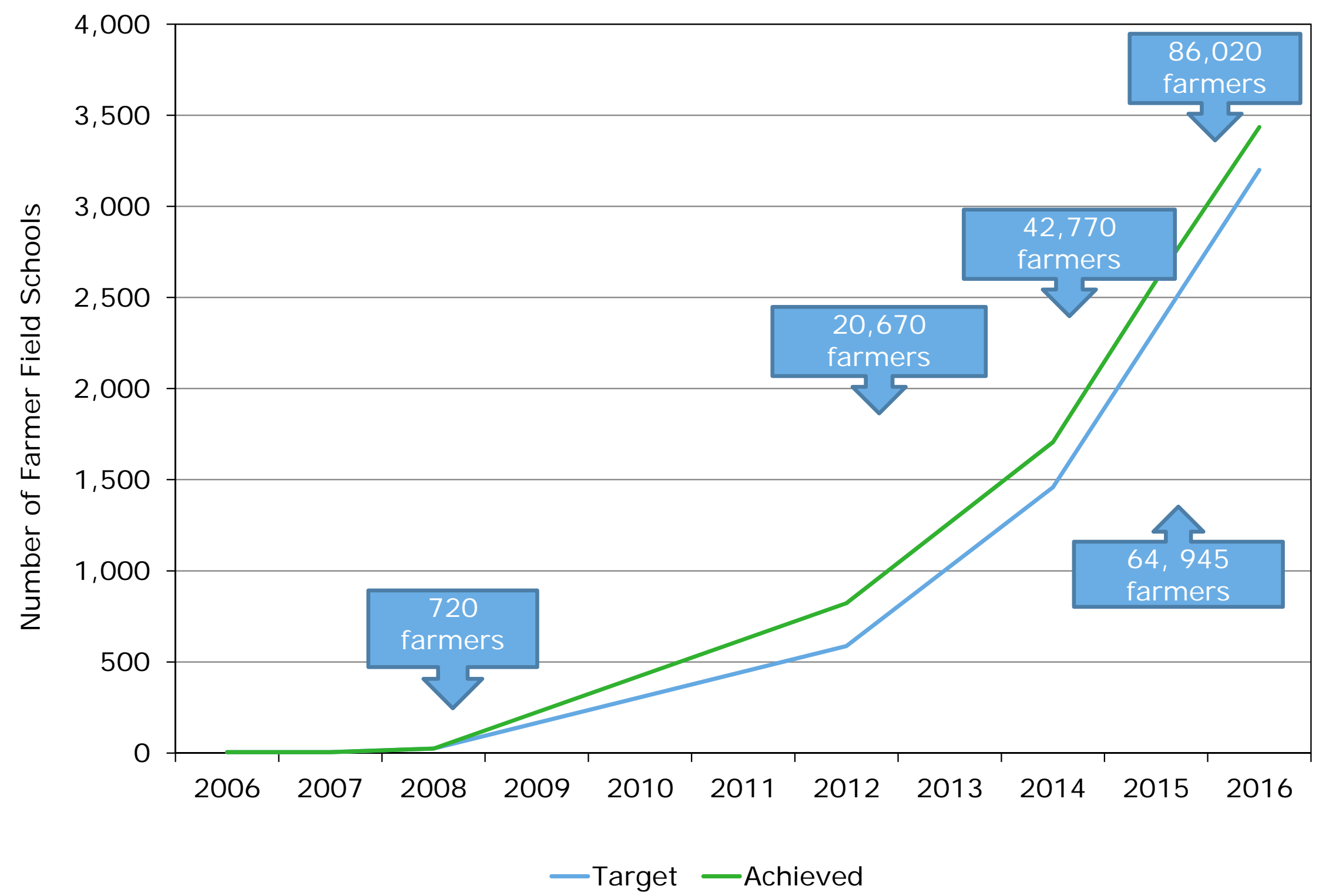

14 | Wageningen Economic Research | Final impact evaluation of Farmer Field School implementation in the smallholder tea sector in Kenya, 2009-2016 


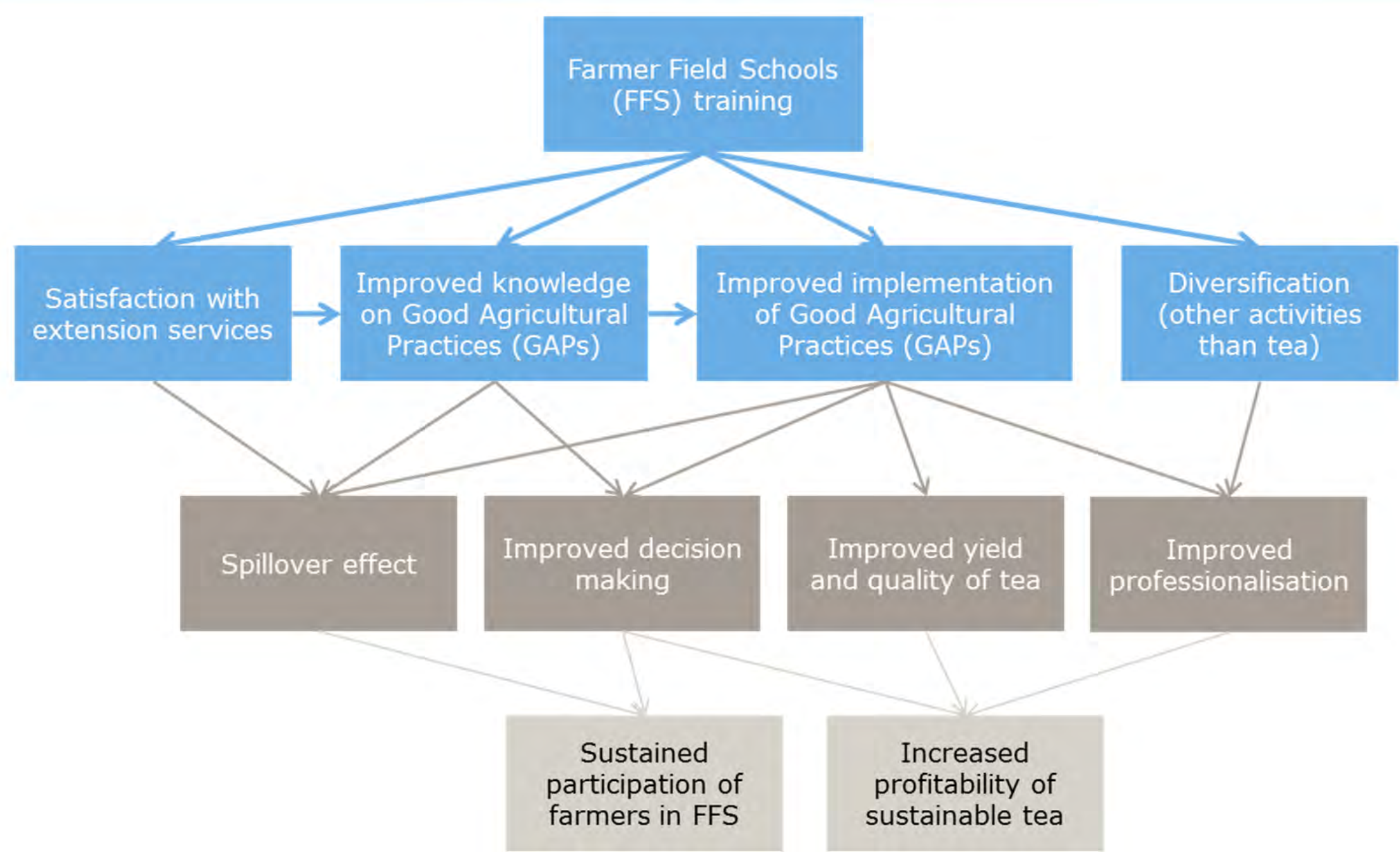


Rainforest Alliance certification is also expected to positively influence practices, productivity and incomes, and its criteria have been incorporated into the FFS curriculum

In addition to the implementation of FFS, KTDA has decided to obtain Rainforest Alliance (RA) certification for all its factories, a certification process that started in 2009. In 2014, all 54 factory companies, including 66 processing factories, were RA certified. RA certification was funded by the DFID-Lipton-KTDA project in 2009-2010 (6\% of factories), by IDH in 2011-2014 (45\% of the factories), by the KTDA-Unilever-IDH programme in 2014 (14\% of the factories) and by other initiatives in $2011-2013$ (35\% of the factories) ${ }^{4}$.

KTDA staff expects that the activities and requirements for RA certification will help to change farmers' practices and improve productivity and incomes. RA certification was facilitated because the FFS programme was already implemented. RA certification takes place at a different scale, as all farmers connected to a factory are trained and certified in one period, while on average $15 \%$ of all farmers have participated in an FFS. In 2011, RA certification criteria were taken up in the FFS curriculum, combining the two training programmes for FFS participants.

FFS farmers are expected to share what they learnt with other farmers, resulting in spillover effects

One of the tea programme's assumptions is that FFS farmers and graduates will share what they have learnt with other farmers. One FFS was implemented per coded leaf collection centre, in order to have a relatively equal spread of the FFS programme over the entire area where KTDA operates. The programme thus tries to facilitate the transfer of knowledge on tea management practices between as many farmers as possible.

Spillover effects will differ between collection centres as the share of FFS farmers is between $5 \%$ and $50 \%$ per collection centre The average number of farmers connected to a coded leaf collection centre is 300. As an FFS has on average 30 participants, this means that on average $10 \%$ of the farmers have been trained. However, there is a wide variance around this average. KTDA staff indicated that the range of farmers supplying a leaf collection centre is between 60 and 600 . This means that between $5 \%$ and $50 \%$ of farmers per coded leaf collection centre has been trained.

\section{Figure 1.3 Cumulative number of Rainforest Alliance certified factories}

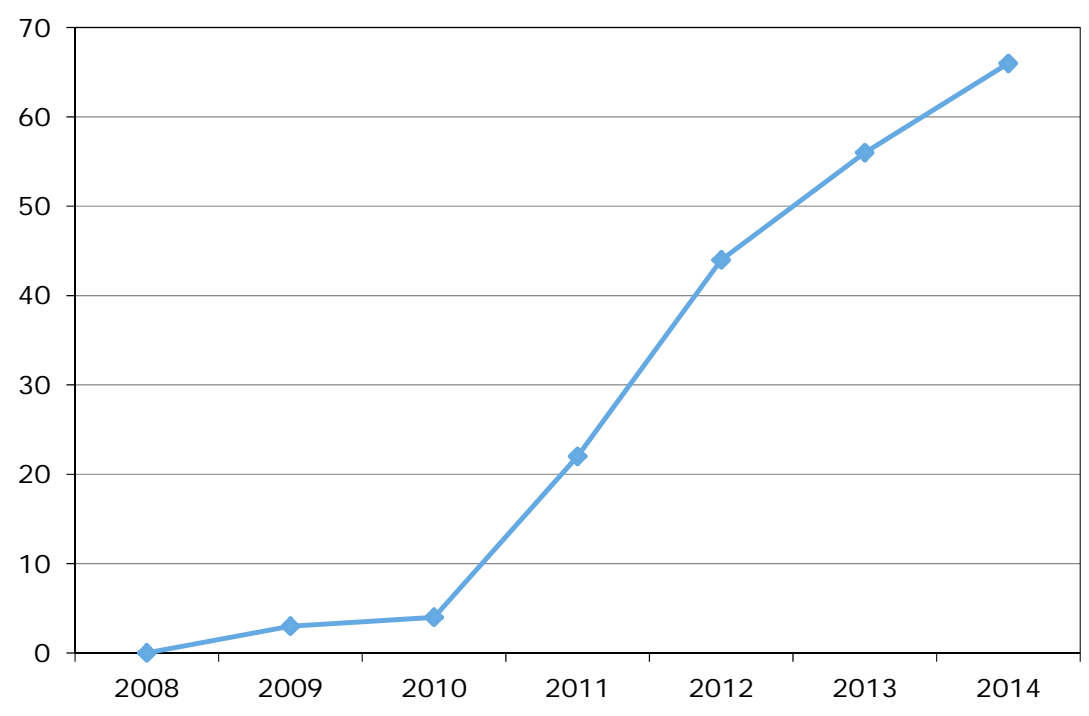

Source: Rainforest Alliance

There are also uncoded leaf collection centres, because the coded centres are sometimes too far away for some farmers. FFSs were not organised in these uncoded centres. Even though farmers supplying these uncoded centres are free to participate in the FFS of nearby coded centres, KTDA staff indicated that this did not often happen as 'farmers selling to uncoded centres do not feel welcome in coded centres'. The expected spillover effects will thus differ between collection centres and areas within a factory catchment, because the share of farmers differs between the centres and no FFSs were implemented at uncoded collection centres.

\footnotetext{
4 Source: Rainforest Alliance
} 
KTDA perceived the upscaling process as a positive experience, though dropout rates have increased and sometimes it suffered from a shortage of demonstration material

The upscaling process has gone well according to KTDA staff. KTDA implemented more than the targeted 3,200 FFSs, and thus implemented on average more than 1 FFS per leaf collection centre. FSCs and TESAs indicated that the quality of the FFS implementation was not negatively affected by the new implementation model in which graduated FFS farmers help the TESAs to organise the FFS meetings. They did, however, notice that fewer farmers graduated per FFS group, and that dropout rates were higher than at the start of the FFS programme. It takes more effort to convince more recent

participants why it makes sense to participate in an FFS compared to the early participants. Nevertheless, they also noticed that many non-participants indicated that they would like to join an FFS, and that they had to disappoint some farmers who were told that they could not participate yet. This has created some tension between participants and non-participants in some areas. Furthermore, demonstration material has not always been readily available because the programme scaled up so quickly and the necessary budgets were not available.

Most farmers are satisfied with the FFSs and how they are set up, and non-participants are lining up to join an FFS

Generally, FFS participants are satisfied or very satisfied with the FFSs and how they are set up. This is the case for both the TESA-led FFSs and the farmer-assisted FFS models, though we found some minor differences between the two. One difference which drew our attention is that farmers from the farmer-assisted FFSs are a little less satisfied with the time required for participation in an FFS than the TESA-led FFS participants.
Figure 1.4 Extent of farmers' satisfaction with farmer-assisted FFS

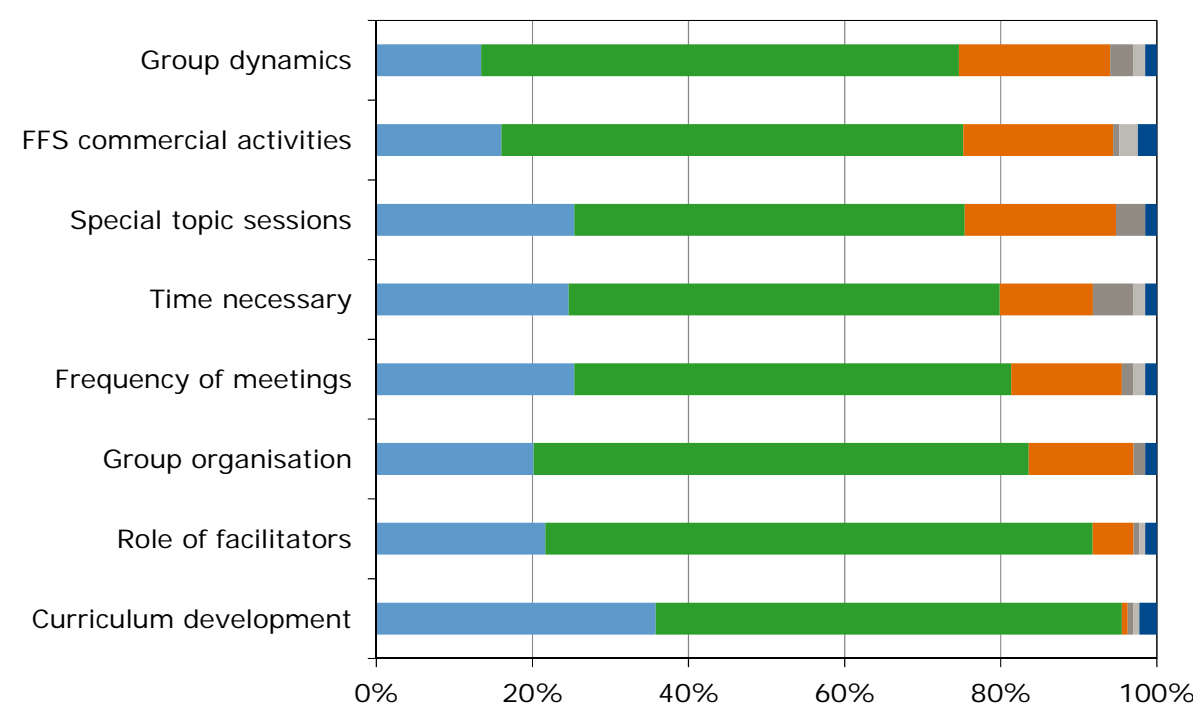

$\square$ Very satisfied $\backsim$ Satisfied $\backsim$ Neutral $₫$ Unsatisfied $\backsim$ Very unsatisfied $\backsim$ Not applicable

Evaluating the impact of the FFS programme, 2006-2016

This study evaluates the impact of the whole tea programme (2006-2016) and tracks changes in adoption, green leaf productivity, profitability and household income. We start by summarising the results of two evaluation studies on the impact of FFS implemented by TESAs between 2009 and 2013 (the TESA-led FFS model). We added to these results an analysis of long-term trends in green leaf productivity of early FFS participants who started with an FFS in 2010. But we specifically focus on the impact of the farmer-assisted FFS model between 2013 and 2015 at the farm level, the results of which we have often compared to the performance of the first two years of the TESA-led FFS (2009-2011). Finally, we assess the embedding and institutionalisation of FFSs at KTDA, including a future outlook for FFS implementation at KTDA. The methodology for the evaluation is described in the next chapter. 


\section{Methodology for measuring the impact of the FFS programme}

Study design to evaluate the impact of the tea programme The overall design employed in this study was a longitudinal impact evaluation using panel data that include baseline data. These baseline data inform about the status of affairs at farm level before farmers participate in an FFS, while follow-up data inform about the state of affairs after a passage of time deemed sufficient for the impact of the FFS to have emerged. The evaluation accounts for differences between the participants and non-participants and therefore combines the difference-in-differences (DiD) approach with propensity score matching (PSM), and regression analysis to control for other factors when assessing net effects.

As illustrated in Figures 2.1 and 2.2, the DiD approach essentially compares the changes among FFS participants (before and after participating in an FFS) and changes among non-participants (the comparison group). Ideally, the comparison group has similar observable characteristics as those from the participants. The similarity was assessed by comparing the status quo of the two groups in the baseline situation on a number of key characteristics and performance indicators using Propensity Score Matching.

Besides being influenced by variations in individual characteristics, the performance indicators of tea farmers are also influenced by other external factors, such as agro-ecological conditions and interventions from other organisations. The influence of these confounding variables on the net-effect estimates were assessed using various regression analyses.

Please consult Appendix 1 for more information on the evaluation methodology.
Figure 2.1 The difference-in-differences approach for the TESA-led Farmer Field Schools (2009-2015)

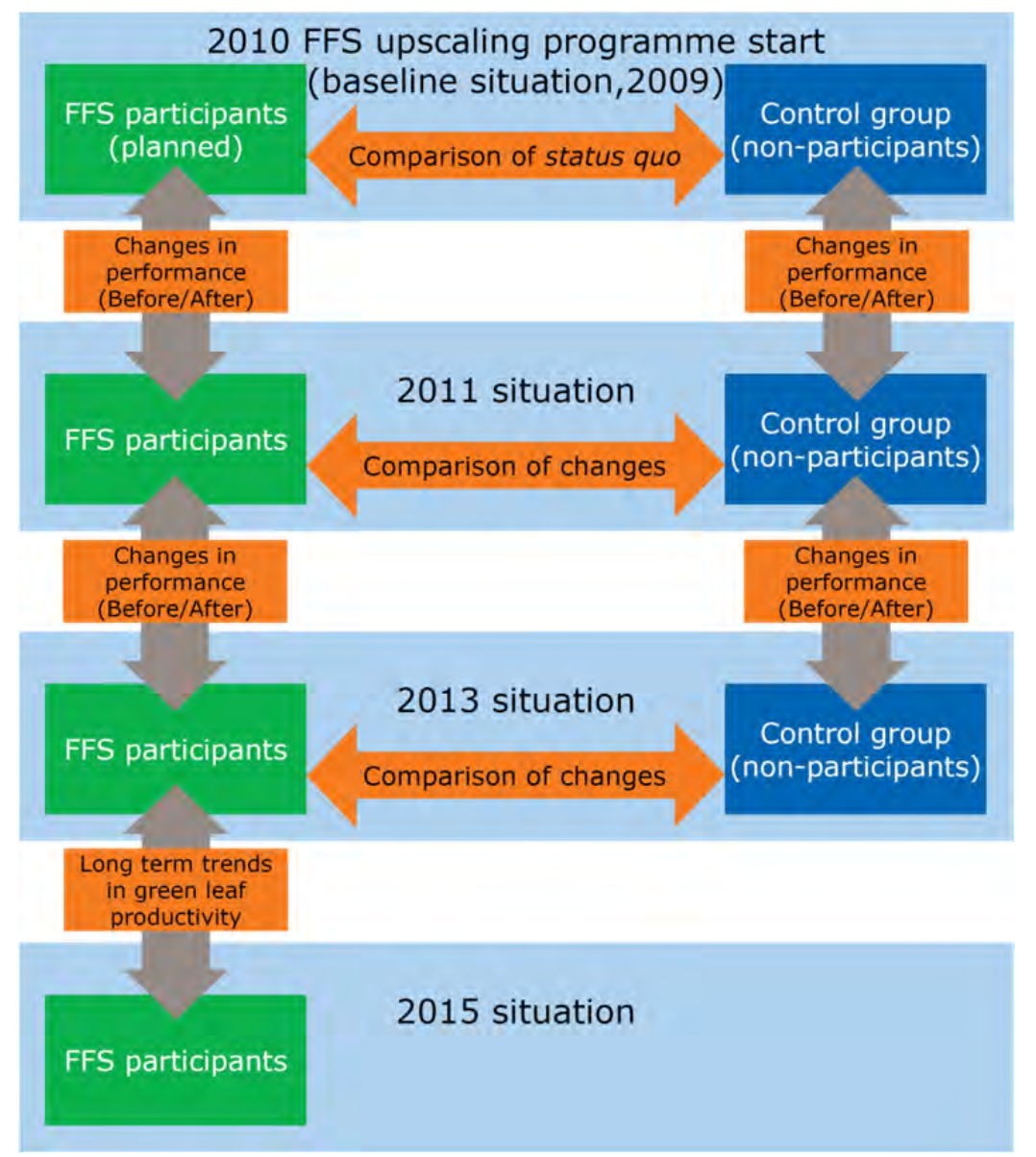


Figure 2.2 The difference-in-differences approach for the farmer-assisted Farmer Field Schools, 2013-2015

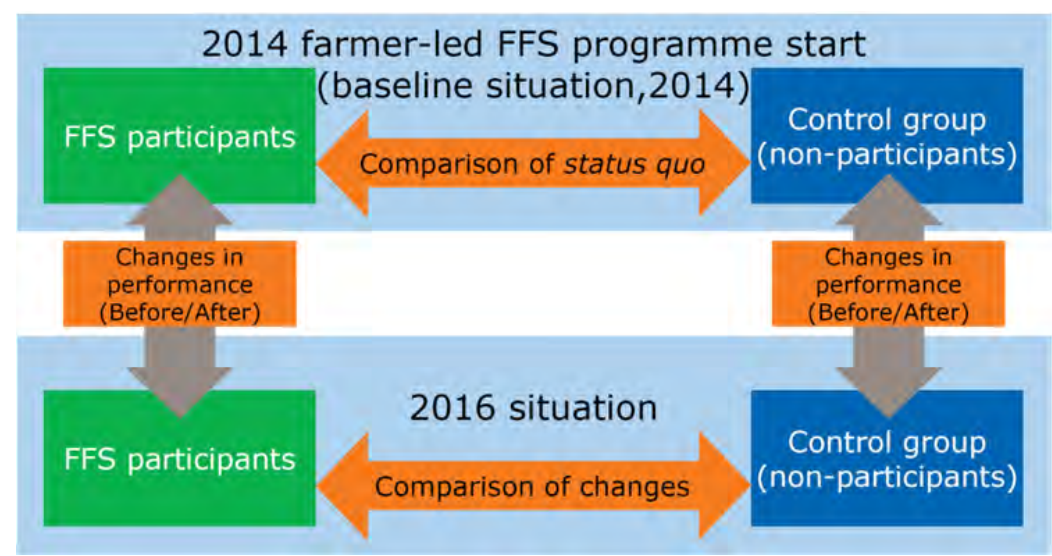

Indicators for programme and impact evaluation

The evaluation examined a range of indicators. The impact logic and tea programme objectives form the basis for the indicators. Indicators are distinguished in output, outcome and impact indicators and range from farm level indicators to programme implementation indicators. Information on some of the indicators is available for the whole period (2006-2016), because they relate to the whole programme period. Other indicators were collected through the baselines and impact evaluation activities, and are thus available for shorter time spans. More information on how the farm level indicators are measured can be found in Appendix 1.
Table 2.1 Indicators

\begin{tabular}{ll} 
Programme-related indicators & Years in this report \\
\hline Successful upscaling & $2006-2016$ \\
\hline Embedding and institutionalisation & $2006-2016$ \\
\hline Attribution & $2006-2016$ \\
\hline Farm level-related indicators & Years in this report* \\
\hline Professionalisation & $2013-2015$ \\
\hline Green leaf productivity & $2009-2015$ \\
\hline Green leaf quality & $2009-2015$ \\
\hline Green leaf profitability & $2009-2015$ \\
\hline Profitability of other crops & $2013-2015$ \\
\hline Income diversification & $2009-2015$ \\
\hline Health and safety & $2013-2015$ \\
\hline
\end{tabular}

* Some of the information was collected for different periods of time for different sets of factories.

Farmers were interviewed from six factories and two programme periods

This study collected primary data using a household survey to interview a sample of farmers associated with 6 KTDA factories and data on green leaf production and FFS activities from KTDA. An overview of farmers interviewed for the household survey is provided in Table 2.2 on page 22 .

We interviewed farmers from two sets of factories:

- 356 farmers from four factories (Kinoro, Litein, Ndima and Nyankoba) for evaluating the impact of the TESA-led FFS model (2009-2015). We interviewed the same farmers in 2009, 2011, 2013 and 2015. In 2015, we mainly interviewed the FFS participants, and only assessed green leaf yield and quality, profitability, income and FFS group continuation.

- 240 farmers from two factories (Gachege and Mudete), for evaluating the impact of the farmer-assisted FFS model (2013-2015).

5 In the 2014 impact evaluation report, the data were presented as 2010-2012-2014. However, although these data were published in 2010-2012-2014, they were collected for the years 2009-2011-2013. In the present document we refer to the data as 2009-20112013-2015. 
In both groups, the numbers of farmers decreased over time because farmers could not participate in the survey anymore for various reasons. Detailed information on the sample and the characteristics of the farmers can be found in Waarts et al., 2014.

Furthermore, farmers' participation in an FFS can change over time as new farmers, including those from the comparison group, may become members of FFSs, and FFS members may stop their FFS activities. ${ }^{6}$ This is quite clear from the number of FFS participants from the factories involved in the TESA-led FFS evaluation.

Complementary qualitative research supported the household survey. This research includes discussions with 8 key stakeholders, focus group discussions with TESAs and FSCs from all six factories, and four focus group discussions with a total of 96 farmers. Please find more information on whom we spoke to in Appendix 1.

Focus group discussions took place in villages that supplied the Gachege and Mudete factories. For each factory two separate discussions took place, one in a village with FFS farmers and one in another village with non-FFS farmers.

Group sizes ranged from 17 to 32 participants. Groups were characterised by considerable female participation (ranging from $32 \%$ to $63 \%$ of participants) and relatively low youth participation (ranging from $0 \%$ to $16 \%$ of participants).

\footnotetext{
6 The FFS membership information is based on the survey response
} 
Table 2.2 Number of farmers interviewed per factory and per FFS group (based on information from the survey)

\begin{tabular}{|c|c|c|c|c|c|}
\hline \multicolumn{2}{|l|}{ Factory } & 2009 & 2011 & 2013* & $2015 * *$ \\
\hline \multicolumn{6}{|l|}{ TESA-led FFS evaluation (2009-2015) } \\
\hline \multirow[t]{3}{*}{ Kinoro } & Non-FFS & 60 & 51 & 0 & 0 \\
\hline & FFS & 0 & 0 & 47 & 47 \\
\hline & Total & 60 & 51 & 47 & 47 \\
\hline \multirow[t]{3}{*}{ Litein } & Non-FFS & 60 & 21 & 6 & 0 \\
\hline & FFS & 58 & 85 & 94 & 58 \\
\hline & Total & 118 & 106 & 100 & 58 \\
\hline \multirow[t]{3}{*}{ Ndima } & Non-FFS & 60 & 35 & 37 & 1 \\
\hline & FFS & 58 & 79 & 67 & 66 \\
\hline & Total & 118 & 114 & 104 & 68 \\
\hline \multirow[t]{3}{*}{ Nyankoba } & Non-FFS & 60 & 60 & 32 & 32 \\
\hline & FFS & 0 & 0 & 25 & 25 \\
\hline & Total & 60 & 60 & 57 & 57 \\
\hline \multicolumn{2}{|c|}{ Total number of farmers interviewed in TESA-led FFS evaluation } & 356 & 331 & 308 & 230 \\
\hline \multicolumn{2}{|c|}{ Farmer-assisted FFS evaluation (2013- 2015) } & & & 2013 (planned)* & $2015 * *$ \\
\hline \multirow[t]{3}{*}{ Gachege } & Non-FFS & & & 60 & 21 \\
\hline & FFS & & & 60 & 91 \\
\hline & Total & & & 120 & 112 \\
\hline \multirow[t]{3}{*}{ Mudete } & Non-FFS & & & 60 & 38 \\
\hline & FFS & & & 60 & 56 \\
\hline & Total & & & 120 & 94 \\
\hline \multicolumn{3}{|c|}{ Total number of farmers interviewed in farmer-assisted FFS evaluation } & & 240 & 206 \\
\hline
\end{tabular}

* We had intended to interview 120 FFS farmers and 120 non-FFS farmers for the farmer-assisted FFS evaluation. The share of FFS farmers interviewed was larger during the survey implementation: more farmers had joined an FFS than expected at the time of sampling, and some farmers, who had participated in the survey in 2013, could not be found for interviews in 2015.

** We interviewed fewer farmers in 2015 from the factories that had started to implement FFS in 2009 , as this survey round was only used to assess the long-term productivity trends of FFS farmers. 
Large differences in the share of FFS participants in total factory population in the six factories studied

By 2015 , between $1 \%$ and $34 \%$ of the factory populations had participated in an FFS in the six factories, percentages that we obtained from factory data on FFS participation. The average participation rate was $9 \%$. The two factories that we added to our research in 2013 had just started with the FFS programme, and showed a steep increase in FFS participants. One of the factories stands out positively; this factory shows a high starting point of $7 \%$ (it was one of the first factories to implement FFS), and in this factory $34 \%$ of the farmers were trained according to the information provided by the factory. It is interesting to note that there are large differences between the factories, and that the average participation rate of $9 \%$ for all six factories in our sample is lower than the $15 \%$ which is reported by KTDA (see Chapter 1 ). It could be that the factories we study are not representative of the whole KTDA population in terms of FFS participation. The large variance is explained by KTDA to be due to the number of farmers registered per coded leaf collection centre and geographical/ecological diversity. 
Figure 2.3 Percentage of farmers who participated in FFS based on KTDA factory information (2008-2014 for four factories, 2012-2014 for two additional factories)

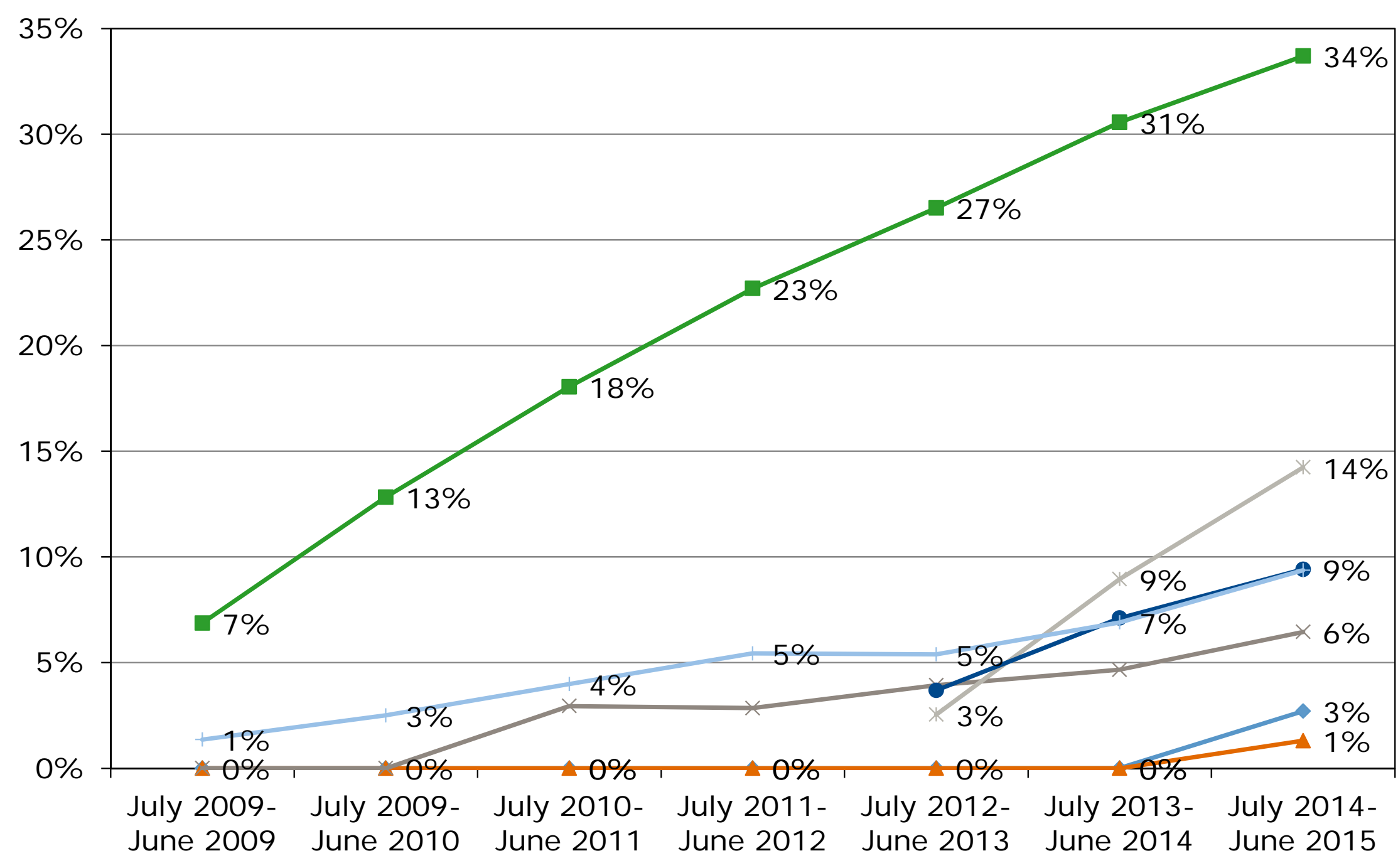

$\rightarrow$ Factory $1 \rightarrow$-Factory $2 \leftarrow$ Factory $3 *$ Factory $4 *$ Factory $5-$-Factory $6 \rightarrow$ All factories combined 


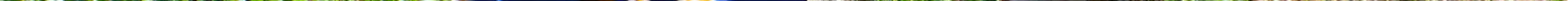




\section{Impact of TESA-led FFS between 2009-2013 and long-term trends in green leaf productivity}

I mplementation of TESA-led Farmer Field Schools 2009-2013 While FFSs were introduced by KTDA in 2006, and piloted between 2006 and 2008 , the FFS programme was upscaled to all 54 KTDA factory companies from 2009 onwards. Fully operational from 2010, the first FFSs in this upscaling phase were implemented by the KTDA Tea Extension Services Assistants (TESA-led FFS). Farmer-assisted FFSs were introduced in 2013, in which FFS graduates helped TESAs organise FFS activities.

Whereas the following chapters will provide insight on the impact of the farmer-assisted FFS model between 2013 and 2015, this chapter provides an overview of the changes in knowledge, adoption, productivity, profitability and income among TESA-led FFS farmers over the period 2009-2013.

This chapter mainly summarises the results from a previous impact evaluation study (Waarts et al., 2015) which included panel data analyses for 2009, 2011 and 2013. At the end of the chapter, we present long-term trends in productivity for early FFS participants compared to non-FFS participants, based on KTDA factory data for the years 2008 until 2015.

Farmers were very satisfied with FFS implementation

The TESA-led FFS training activities were generally well received by the participating farmers. When asked, farmers indicated that they were very satisfied with FFS activities. The majority of FFS participants said that they had benefited from participating in the FFS activities, which was in line with evidence found through quantitative analyses.

FFS participation increased knowledge of Good Agricultural Practices

Over the period 2009-2013, FFS farmers steadily improved their knowledge of Good Agricultural Practices (GAPs). The FFS farmers who had been participating longer showed a higher knowledge increase. Indeed, the knowledge level of farmers who did not participate in an FFS actually decreased during that period.

Figure 3.1 Changes in farmers' knowledge on GAPs over time

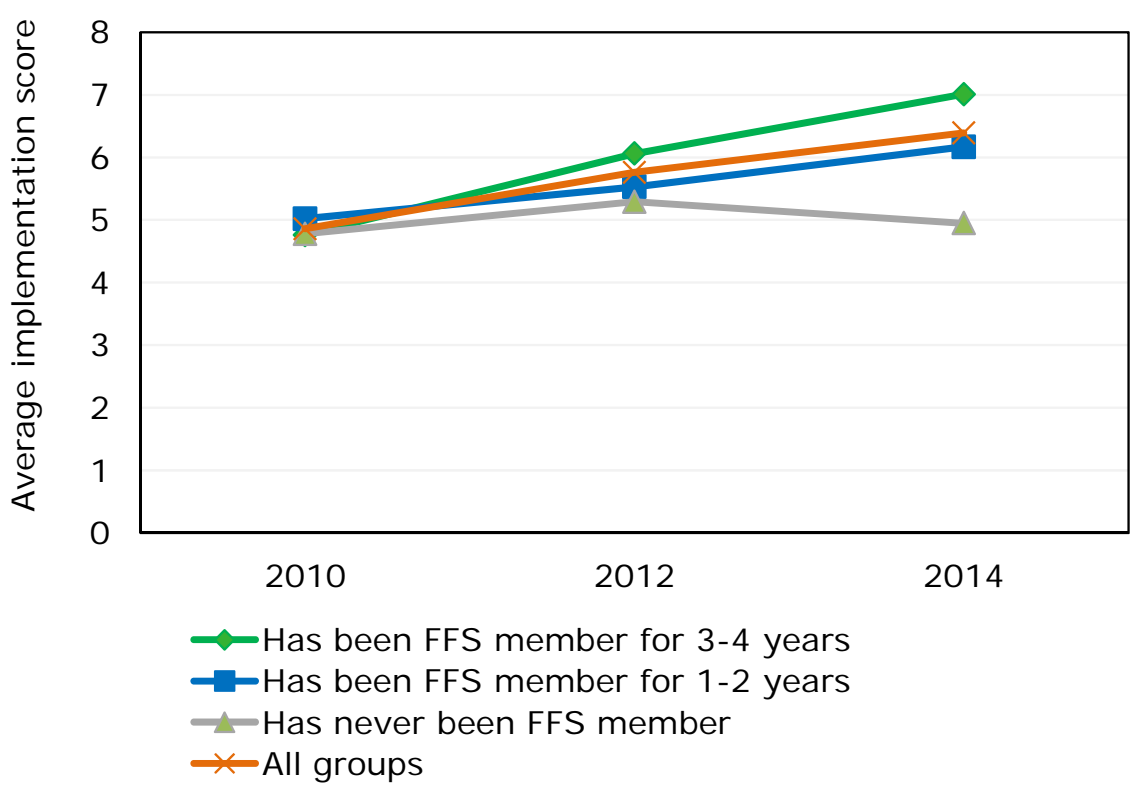

FFS farmers also improved the implementation of GAPs compared to non-participants

As a result of the improved knowledge among FFS farmers, FFS participants improved their production practices significantly more than their non-trained counterparts. Similarly, a significantly larger increase in social and 
environmental practices was evident among FFS farmers compared to nonparticipants. Moreover, FFS participants were significantly more active in experimenting with new agricultural practices and sharing information with others, which are key mechanisms for generating spillover effects occur.

Figure 3.2 Changes in farmers' implementation of GAPs over time

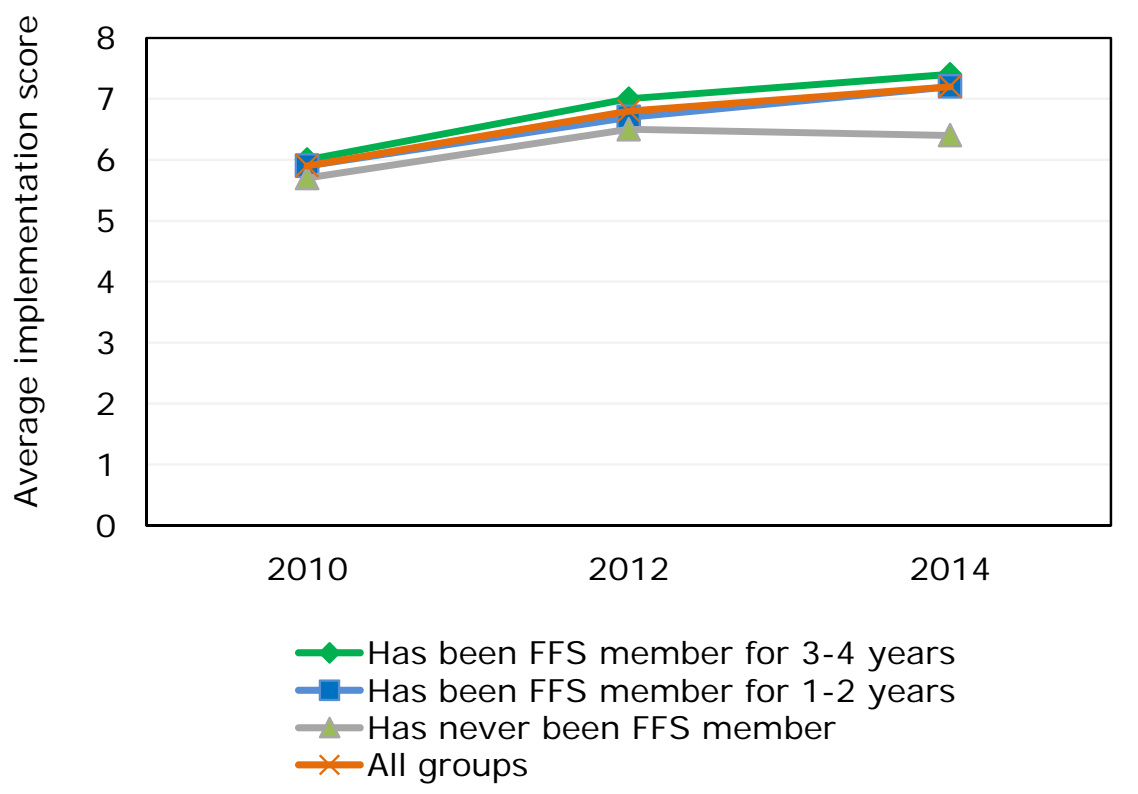

FFS farmers apply more fertilisers, which is considered to be generally beneficial as application rates were previously too low In the period 2010-2012, the use of chemical fertiliser increased among FFS farmers compared to the pre-training situation. This was considered a positive development by KTDA, as farmers generally applied too little fertiliser. The use of crop protection products decreased among both FFS and non-FFS farmers. Moreover, FFS farmers used significantly more hired labour for pruning and for applying fertiliser in the post-training situation than in the comparison group.

Green leaf productivity increases because of FFS participation As a result of the adoption of GAPs and increased use of fertiliser and labour, the average yield of all farmers (both FFS and non-FFS farmers) increased from $1.22 \mathrm{~kg} /$ bush in 2011 to $1.54 \mathrm{~kg} /$ bush in 2013. The increase in yield is significantly higher among FFS participants, with a $30 \%$ yield increase among FFS farmers compared to a $15 \%$ increase among non-FFS farmers.

Figure 3.3 Change in average yield of green leaf among different groups

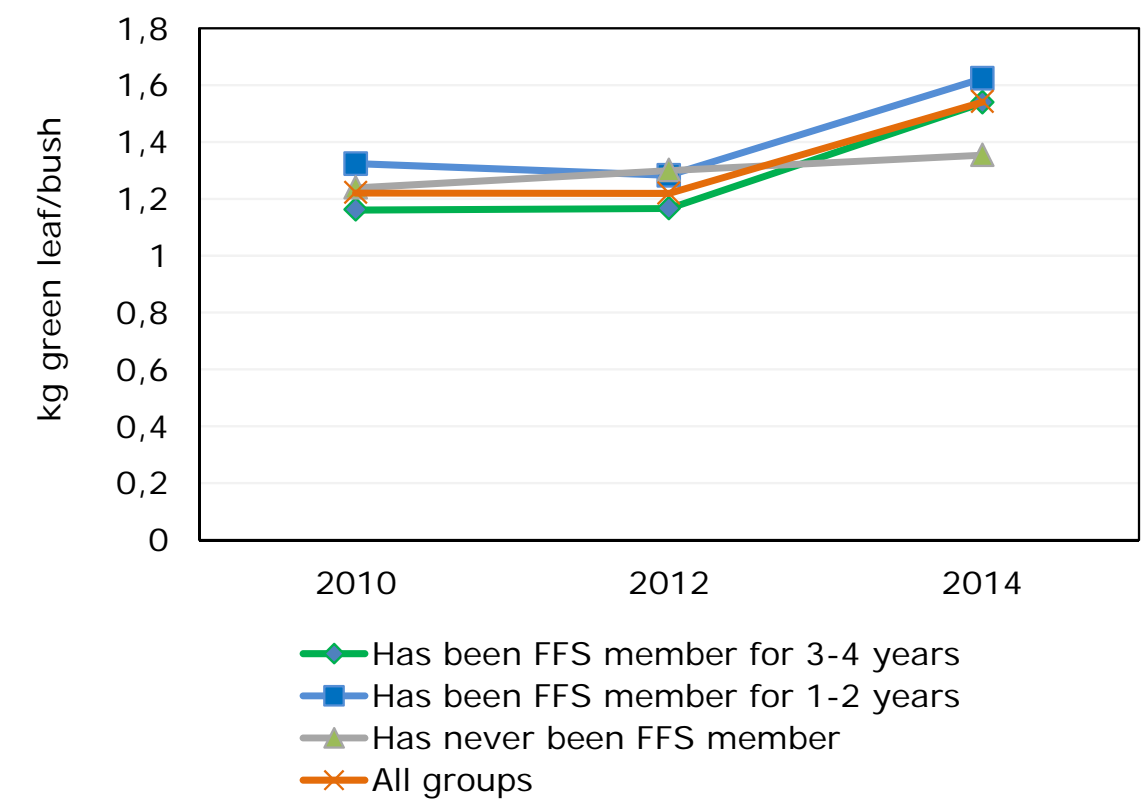

An initial increase in green leaf incomes for FFS farmers, but between 2011 and 2013, incomes decrease for all farmers because of a huge drop in green leaf prices

Between 2009 and 2011 net income increased significantly among all farmers, with higher increases among FFS-trained farmers than among non-FFS farmers. Despite the continuing increase in green leaf productivity, green leaf profitability dropped for FFS and non-FFS farmers between 2011 and 2013, which can be explained by the decrease in bonus payments over that period. The decrease in profitability is slightly lower among FFS participants than among the comparison group, but the difference is not significant. 
However, since the difference-in-difference comparison does not take into account the influence of other factors that differ between the group of FFS participants and non-participants, it might provide only limited insight on the relation between FFS participation and profitability. When controlled for region and factory-specific effects, participation in FFSs shows to have a positive effect on profitability through its interaction with labour costs. This means that FFS farmers experienced less of decrease in profitability per hectare than nonFFS farmers.

Figure 3.4 Changes in income from tea over time among different groups, based on an average number of 1,000 bushes per farmer.

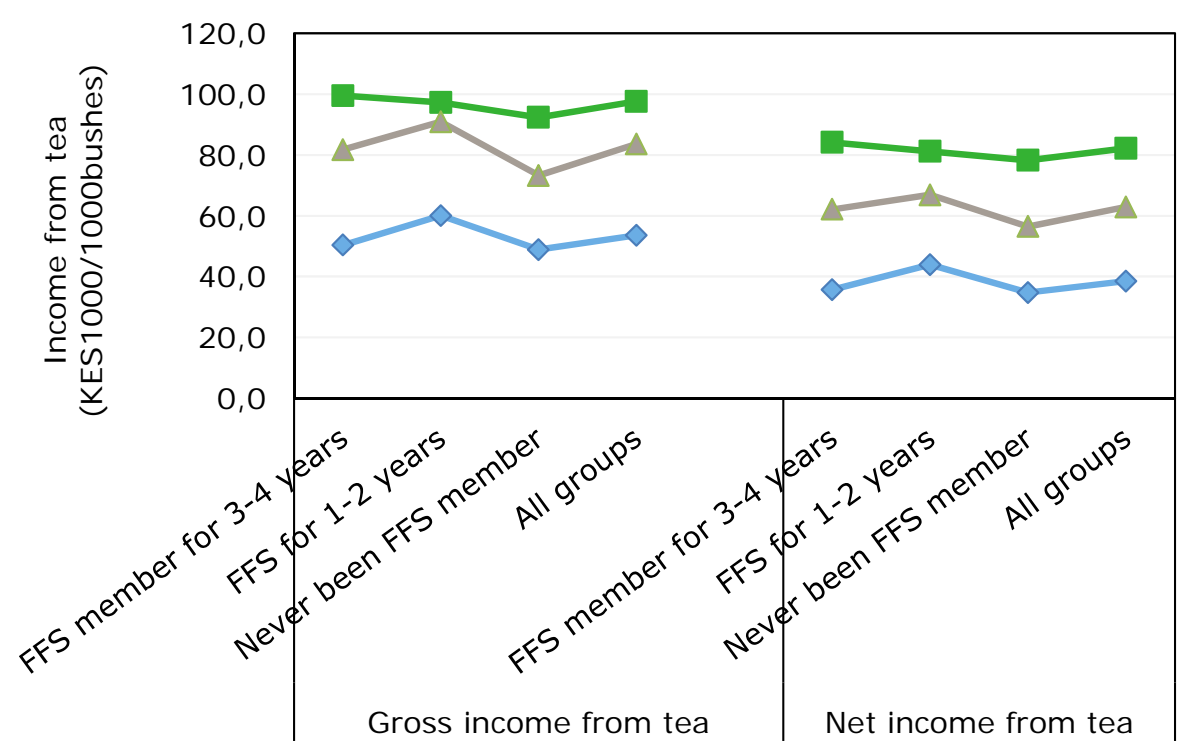

$$
\checkmark 2010-2012-2014
$$

FFS farmers diversify their income sources between 2011 and 2013 The majority of FFS participants have diversified their income sources into other income-generating activities, primarily crop production and livestock production. In 2013, FFS participants reported a significantly higher income from other sources than farmers who did not participated in the FFS.
But household incomes and income earned per person per day remain low

Based on the distribution of farm sizes among farmers of the six factories studied in 2013, more than $80 \%$ of the tea growers have $500-3,000$ tea bushes. Based on average profits per bush, this implies that green leaf income for most households is lower than USD2 per day. This situation creates the necessity to generate more income from other sources.

FFS farmers report livelihood improvements between 2011 and 2013

A self-assessment by FFS farmers, carried out in early 2013, showed significant improvements in the majority of the livelihood indicators measured, such as families' health, welfare, income and homestead as well as the possibility of farmers to send their children to school.

Overall positive results of FFS implementation, though the green leaf price has had a major influence on profitability and incomes, and tea farmers remain poor

From the evaluations conducted between 2009 and 2013, a positive picture emerges regarding the contribution that FFS implementation made to the adoption of GAPs, which increased green leaf productivity and initially also green leaf profitability. Also, FFS farmers diversified their incomes more than non-participants. The decrease in green leaf market prices has had a major impact on green leaf profitability and incomes between 2011 and 2013, which were not offset by an increase in productivity, a reduction in production costs, and/or supplemental incomes from other sources. The typical tea farmer remains relatively poor, with incomes from green leaf generally lower than USD2 per day per family.

In the factory data, we find similar trends in green leaf productivity per hectare between FFS participants and other farmers in their factories. But the early FFS participant has a higher productivity per hectare than the average farmer in their factory catchment Based on factory data from the period July 2008 and J une 2015, we have assessed the long-term trends in green leaf productivity per hectare. We have done so for 101 farmers who started participating in an FFS in 2010. These 101 farmers supply the Ndima and Litein KTDA factories. For the same factories, we have assessed the green leaf productivity for all farmers, 
amounting to a total of 18,199 farmers. Comparing the FFS group with all farmers in their factories, we see similar trends in green leaf productivity for the whole period. Interestingly, factory data covering this longer time period show that FFS farmers had higher productivity levels than the average in their factories. This may indicate a selection bias; better farmers had a higher chance of participating in an FFS. In the impact evaluation studies, we controlled for this bias because we sampled farmers in a comparison group and used matching techniques to get comparable groups.

Figure 3.5 Long-term trends in green leaf productivity per hectare (2008-2015) for farmers who started FFS in 2010 and all farmers in their factories. ( $\mathrm{N}=$ max 101 for FFS farmers, and between 13,994 and 18,199 for non-FFS farmers)

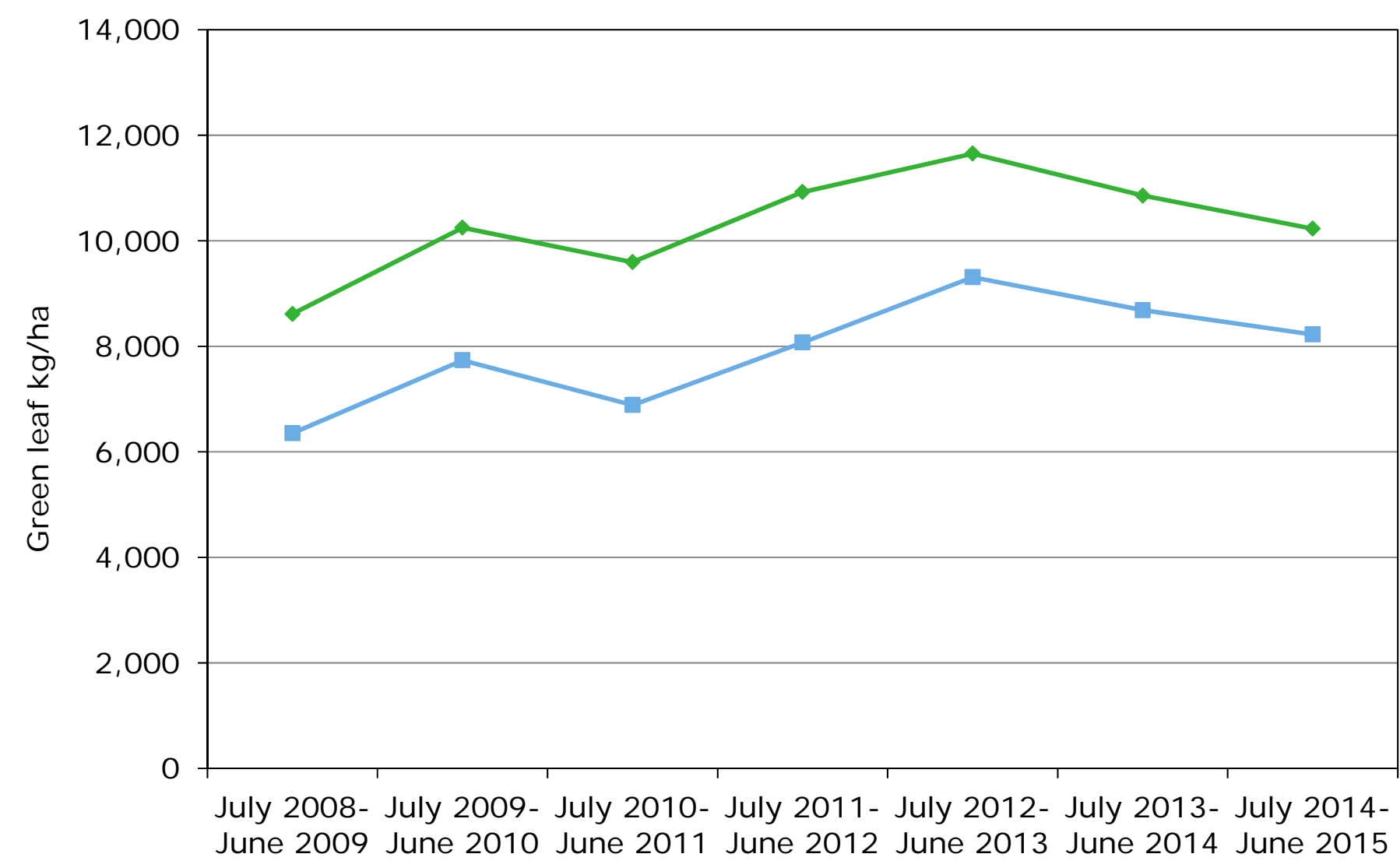

$\multimap$ FFS farmers in Ndima and Litein factories

-All farmers in Ndima and Litein factories 
, 12,1 1. Professionalisation 5 . Ma of tea farmers, $2013-2015$

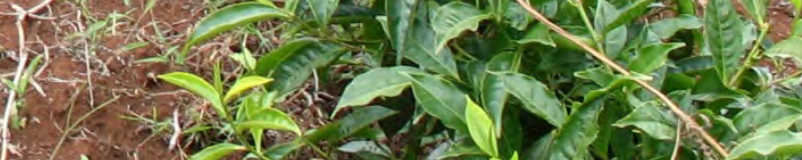

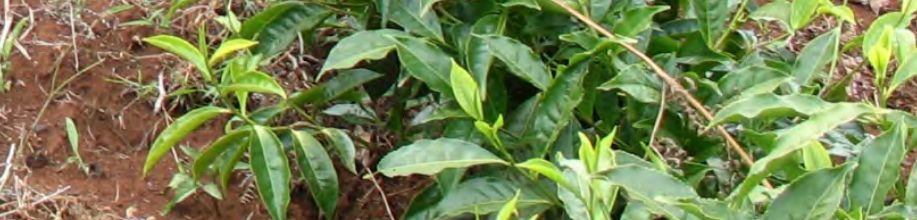

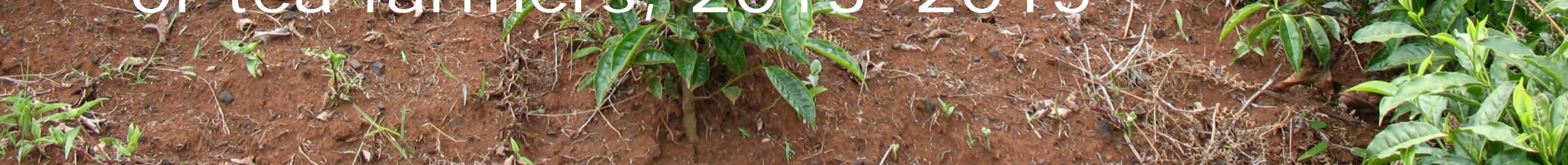




\section{Professionalisation of tea farmers, 2013-2015}

Knowledge of good tea practices increased for both FFS and comparison group farmers between 2013 and 2015

FFS and non-FFS farmers increased their knowledge of good tea practices between 2013 and 2015 , by $22 \%$ and $32 \%$ respectively. This increase is significant for both groups, and there is no statistical difference in the increase over time between the groups. This is surprising, as the level of knowledge of FFS farmers from the earlier evaluation (TESA-led FFS, 2009-2011) did increase significantly compared with non-FFS farmers. And also because KTDA staff indicated that they observed that FFS farmers had increased their level of knowledge compared to non-participants.

Comparison group farmers were also trained by TESAs and all farmers had been trained in order to get Rainforest Alliance certification prior to starting with an FFS

Farmers started with a similar level of knowledge in both FFS implementation models, but the evolution over time was different for the two models. This may be attributable to the fact that non-FFS participants from the farmer-assisted FFS model were also trained by TESAs, including for Rainforest Alliance certification in 2013 (the baseline year) while this was not the case during the TESA-led FFS implementation between 2009-2011. This created similar baseline values in both participant and non-participants, but it may also have led to a similar pattern of improvement in knowledge over time. If this is indeed the case, then knowledge built up through trainings by TESAs and for RA certification could be compared with the additional knowledge gained through FFS participation. In that case, we could assess the additionality of FFS over other trainings by TESAs combined with training for RA certification in terms of farmers' knowledge development.
Older farmers and farmers with larger farms are more likely to increase their knowledge, while there is no difference in the knowledge increase between men and women

Older farmers and farmers with larger farms are more likely to increase their level of knowledge than younger farmers or farmers with smaller farms. But we see no statistical difference in the increase of knowledge between men and women. We suggest that this is partly due to the increased need for complementary income, in addition to the income from green leaf, by younger households that inherit smaller farms.

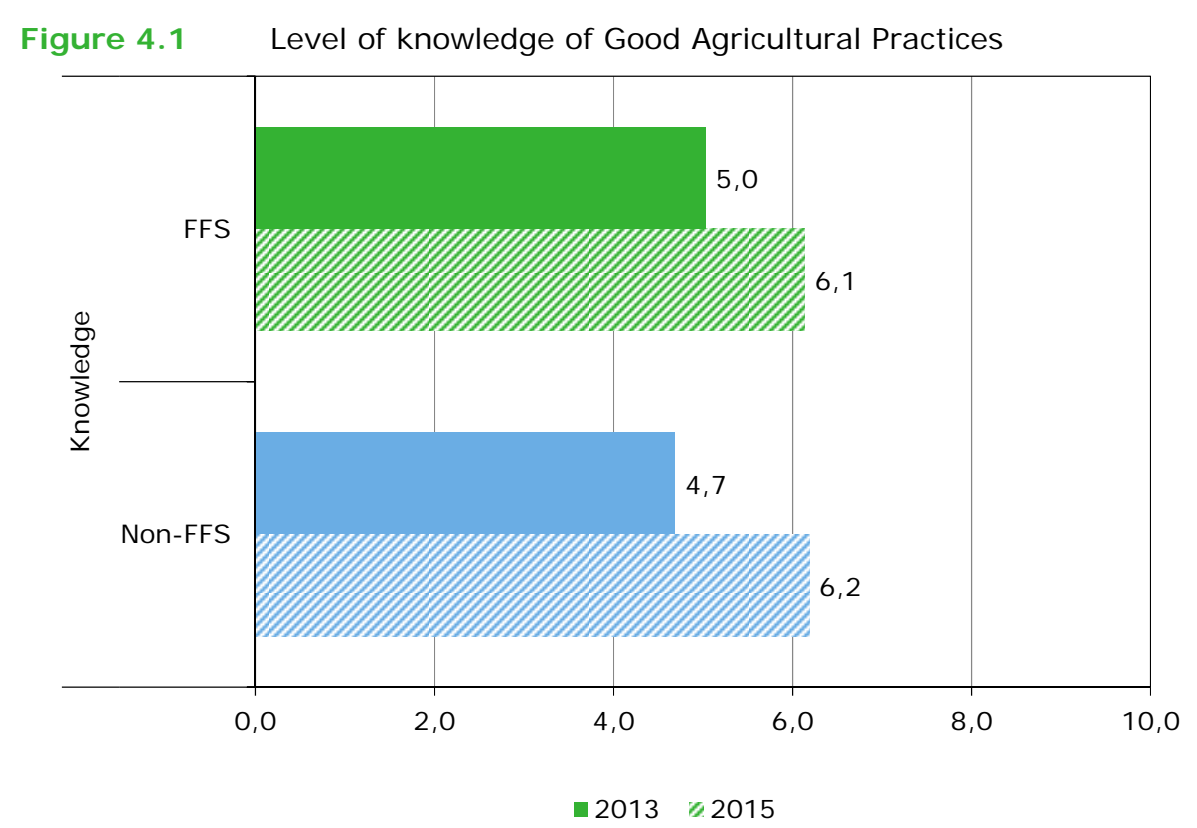


FFS farmers more likely to make management decisions based on what they learn in FFS trainings than the comparison group

We saw some differences over time between FFS farmers and the comparison group with regard to farm management decision-making. FFS participants are more likely to make management decisions based on what they learnt in training compared to 2013, while - logically - the comparison group was less likely to make decisions based on training content. FFS participants are less likely to make decisions based on the state of their tea bushes or advice from family or friends, while the comparison group indicated that they do so more often. Surprisingly, there is a general downward trend when it comes to making decisions on the basis of farm records. This is true for both groups. It could be that farmers see no reason to use records anymore, as they served their purpose foremost at the start of the programme. Comparison group farmers, furthermore, are more likely to make decisions based on routines.

Figure 4.2 Change in decision-making on farm management (percentage change between 2013 and 2015 for the farmer-led FFS group)

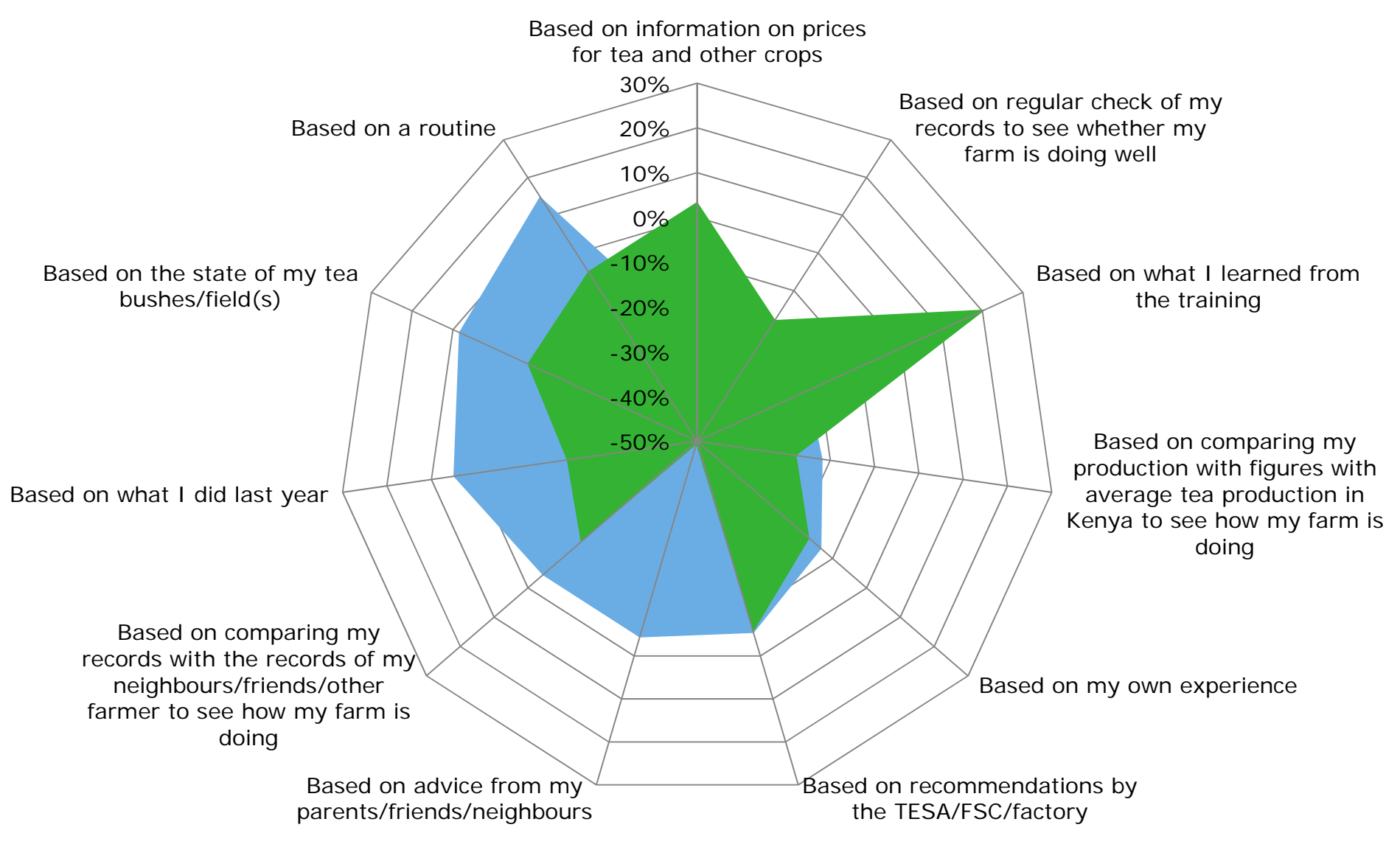

Non-FFS $\quad$ FFS

32 | Wageningen Economic Research | Final impact evaluation of Farmer Field School implementation in the smallholder tea sector in Kenya, 2009-2016 
Farmers value FFS most for learning how to improve tea practices, increase productivity and diversify income

When asked about the perceived benefits of the Farmer Field Schools, farmers listed a wide variety of reasons why they value the FFS training. The largest share of benefits mentioned ( $25 \%$ ) were related to learning how to improve tea practices, such as pruning, plucking and the application of inputs. Almost one fifth of the benefits (19\%) mentioned were related to increases in yield and income. Other frequently mentioned benefits were related to knowledge of income diversification (15\%), soil, water and waste management (14\%) and improved health and sanitation $(10 \%)$. Less frequently mentioned were benefits related to improved nutrition ( $8 \%)$, social benefits $(5 \%)$ and business practices $(4 \%)$.

Figure 4.3 Perceived benefits of FFS by farmers $(n=200)$

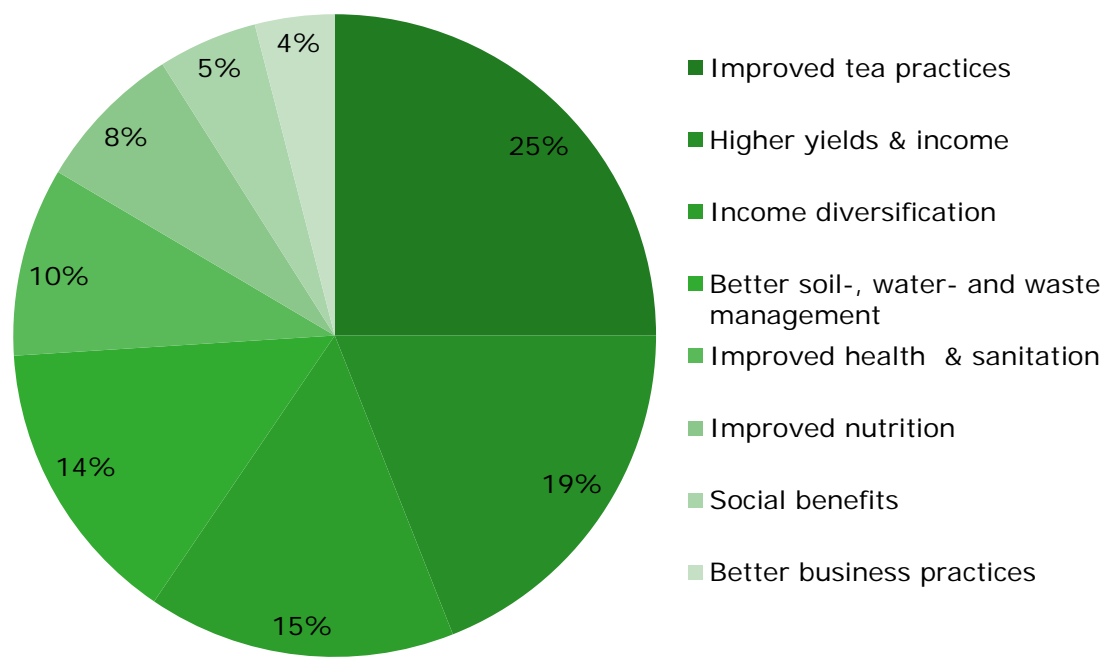

But farmers were already implementing many good tea practices at baseline, and FFS farmers hardly improved

The farmers in the farmer-assisted FFS evaluation started at the same implementation level at the baseline (2013) as the mid-term level of the farmers in the TESA-led FFS evaluation (2011). This is most probably due to the fact that they were already trained by TESAs on good tea practices as well as for Rainforest Alliance certification. The farmers thus began at a high level in terms of implementing good environmental, social and production practices when they started participating in an FFS in 2013. We noticed hardly any change in the implementation of these practices between 2013 and 2015. The most important change was a decrease in the implementation of social practices, which was observed in both groups, but which was larger for the comparison group than for the FFS farmers. Furthermore, there was, surprisingly, an improvement in the implementation of production practices by the comparison group, while the FFS farmers did not significantly increase these practices. As a result, the comparison group ended up with similar production implementation levels as the FFS group in 2015, even though they started at a lower level in 2013.

It seems very difficult for farmers to reach the maximum adoption levels (a score of 10) because the characteristics of farmers (e.g. age, wealth and production goals) and farm resources (farm size and labour) may limit the adoption of some of these practices. Such characteristics and resources mean that not all farmers make the same decisions regarding farm management. For example, the application of fertiliser and the level of pruning might be limited by the wealth and labour access of farmers. This may explain why the FFS group did not improve its adoption level between 2013 and 2015, as this group had already attained the maximum average adoption level, while there was still room for improvement in the comparison group.

This suggests diminishing returns in training and adoption We think there are also diminishing returns in training and adoption. When adoption levels are low, training farmers could change behaviour significantly, which means better implementation of practices. But there is a point where participating in an extra training may not lead to additional behavioural change by the farmer, for instance because he already has a high implementation level. The same is true for investing in ways of adopting certain practices: there is a point where additional investment to improve tea practices will barely reap any clear benefits from the point of view of the farmers. As a result, farmers may stop making additional investments because the expected benefits do not outweigh the cost. 
Figure 4.4 Implementation of good tea management practices

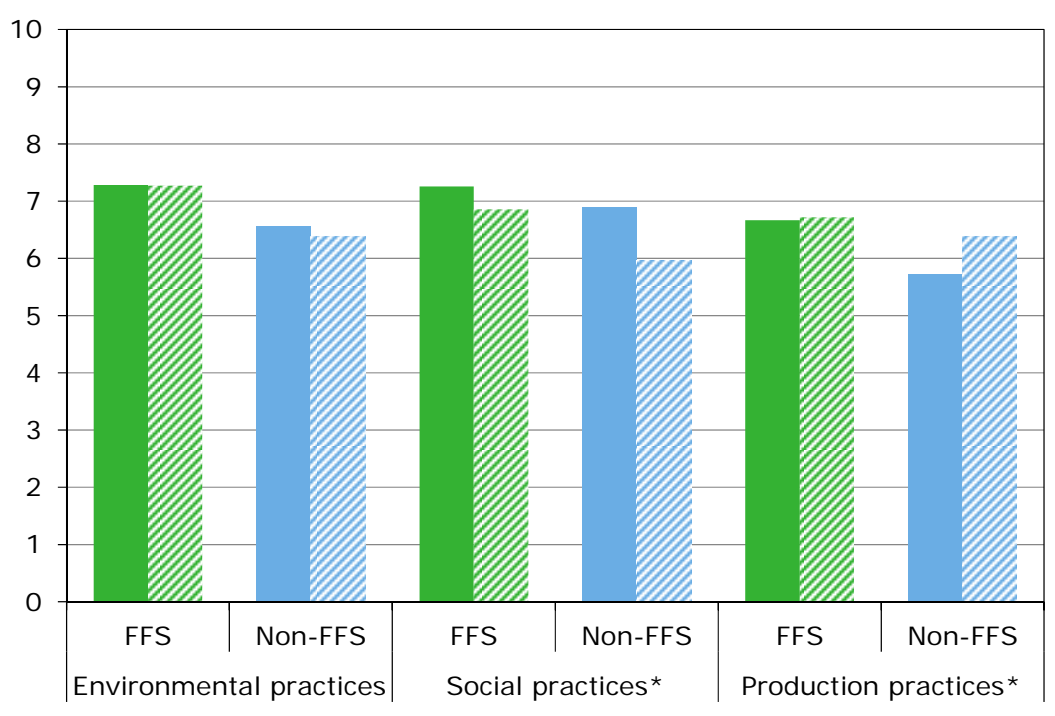

$-2013 \approx 2015$

* Significant difference in evolution over time between FFS and non-FFS farmers based on difference-in-difference analyses.

Other trainings on good tea practices and spillover effects may explain why the comparison group improved without participating in an FFS

We can find two plausible explanations why the comparison group's production practices improved: first, because this group was trained by TESAs on tea management practices, and was also trained for RA certification just before the baseline survey was conducted. These farmers responded well to the training and started implementing recommended practices as a result. Second, they may also have changed their behaviour because they learnt practices from FFS participants (spillover effect). This seems especially relevant for production practices. In contrast, the implementation of social practices decreased over time in both groups.
FFS participants confirm that spillover effects have led them to change tea practices

Both FFS farmers and non-participants indicated that they have shared what they learnt in training with their neighbour farmers, though FFS farmers did so more often at the baseline in 2013 (76\% of FFS farmers compared to 59\% among non-FFS farmers). FFS farmers increased their knowledge sharing with neighbours from $76 \%$ to $90 \%$ between 2013 and 2015 . When farmers shared knowledge, they noticed that their neighbours changed their practices as a result in more than $95 \%$ of the cases. The FFS participants thus confirm the spillover effects that were anticipated by KTDA. We have not been able to establish these effects through quantitative analyses.

Farmers with larger families are more likely to have improved their production and environmental practices, and we also found regional differences in implementation

Farmers with larger families are more likely to have improved their production and environmental practices. A reason for this may be that implementing such practices takes more time, and chances that these will succeed are higher when there is sufficient labour available. We also found that older farmers did improve their production practices more than younger farmers; the same is true for their level of knowledge. We also found significant regional effects for all three types of practices: farmers from the eastern part of the Rift Valley did not implement environmental and production practices at the same rate as farmers in the western part, though they did demonstrate a positive change in social practices. 
Figure 4.5 Knowledge sharing by FFS farmers and perceived change of practices because of such exchanges

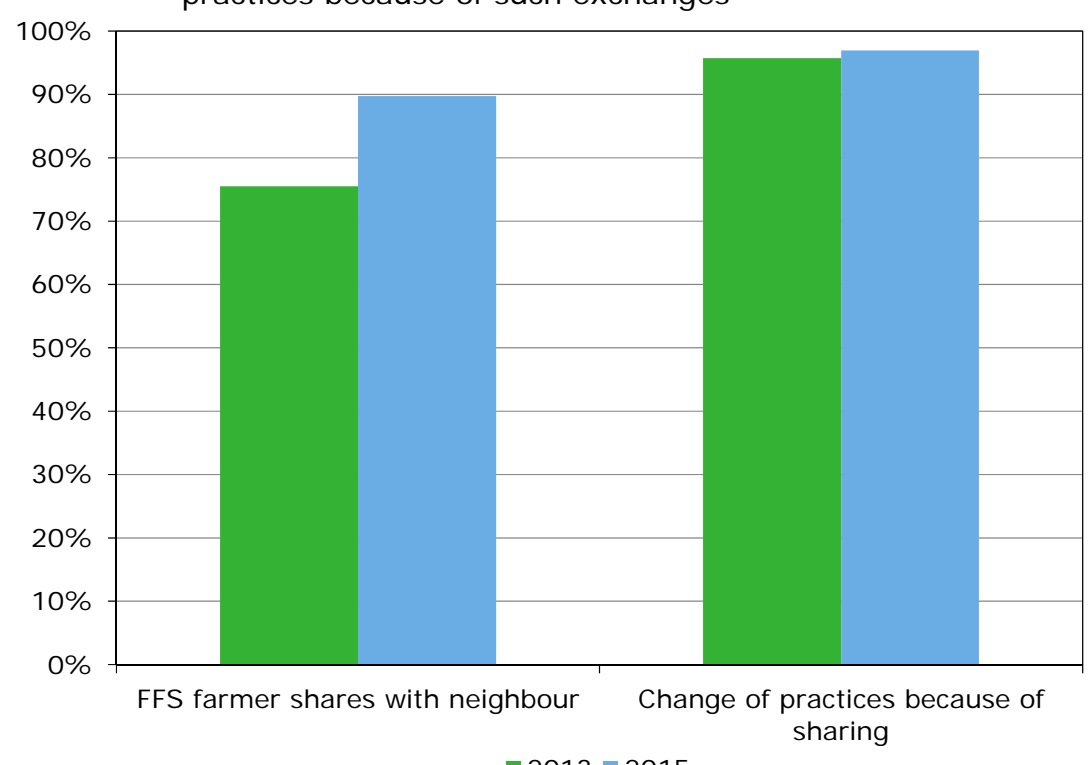

$\approx 2013-2015$

Neighbours of FFS farmers shared information with FFS farmers more often than with the comparison group, but the frequency of sharing decreased slightly over time

At the start of FFS participation, the neighbours of FFS participants already shared information more often with FFS farmers than comparison group farmers. This difference is notable: about one-third of the neighbours of the comparison group farmers never shared knowledge with them (either in 2013 or in 2015), while this percentage was much lower in the FFS group. It is likely that neighbours shared knowledge more often with FFS farmers because these FFS farmers shared knowledge with them more often than the comparison group. The comparison group farmers increased their knowledge-sharing activities over time too: in 2015 they shared knowledge more often compared to 2013 .
Figure 4.6

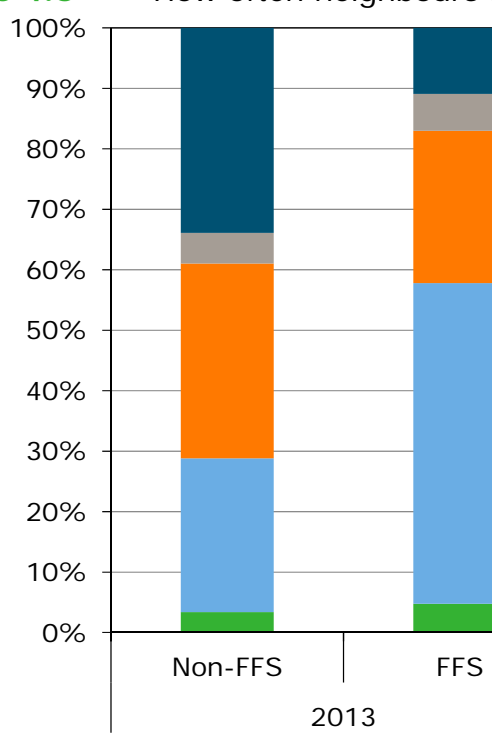

- Daily $\square$ Weekly $\square$ Monthly

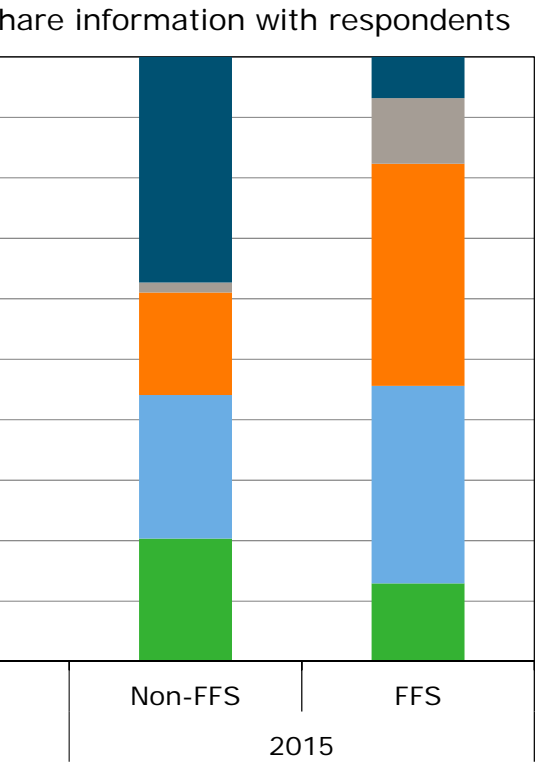

- Never 


\section{Green leaf productivity and quality, 2013-2015}

Green leaf productivity differs between regions and factories: it generally increased between 2010 and 2012, after which it decreased on average

According to the factory data, there were substantial difference in green leaf productivity per hectare $(\mathrm{kg} / \mathrm{ha})$ between factories from 2008 to 2014 . Productivity in the eastern part of the Rift Valley was higher than in the western part, though there were also large differences between the factories in the regions. After 2012, productivity decreased on average for all factories, but the decrease was most obvious in the factories in the eastern part of the Rift Valley (see Figure 5.2 on next page). According to KTDA unfavourable climatic conditions explain these productivity decreases.

Productivity decrease is lower for FFS participants than for nonparticipants of two factories between July 2012 and June 2015 The survey for the two new factories shows that the productivity per hectare decreased between 2013 and 2015 both for the FFS farmers and for the nonFFS farmers ( $14 \%$ for the FFS farmers and $22 \%$ for the comparison group). But the decrease for FFS participants is significantly lower than for nonparticipants. Even we identified these net effects, we cannot explain this fully with reference to the FFS programme, as we did not see a corresponding change in tea management practices. Thus, this could be highlighting some other characteristics of FFS farmers that are not captured by the survey.
Figure 5.1 Green leaf productivity per hectare July 2012-J une 2015

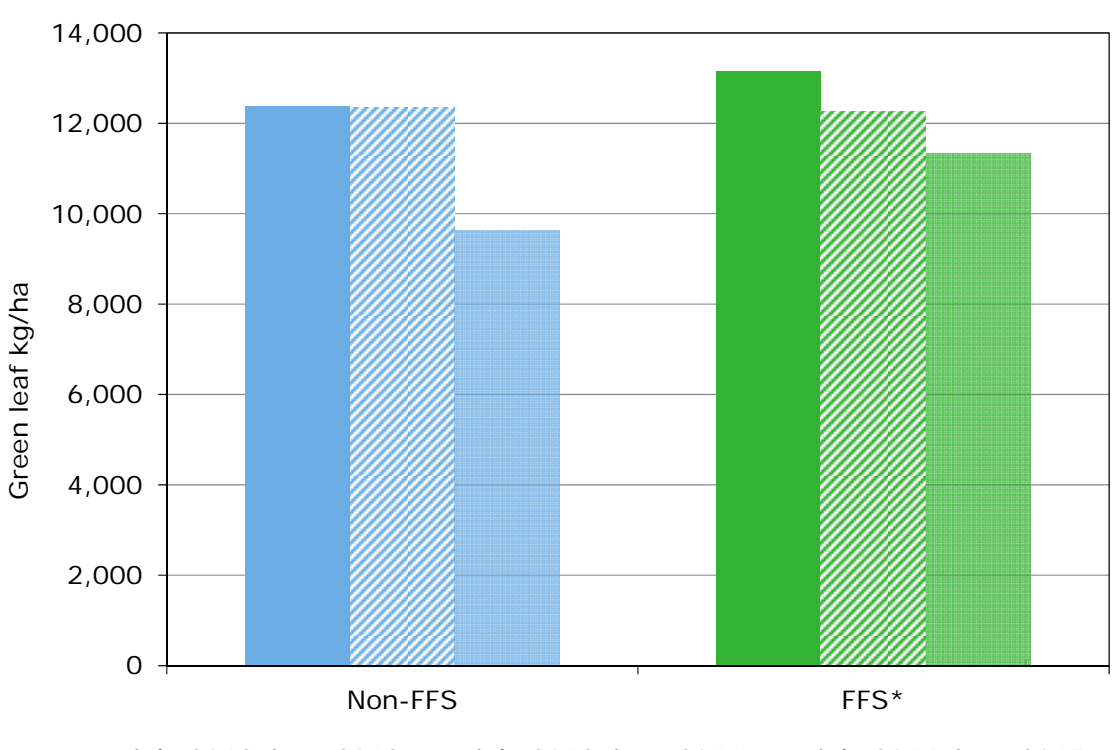

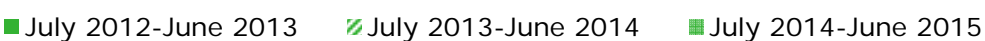

* Significant difference in evolution over time between FFS and non-FFS farmers based on difference-in-difference analyses.

Productivity increase is associated with the region farmers are based in

There are important differences in productivity changes between the two factories we studied. In the Gachege factory in eastern part of the Rift Valley, the productivity decrease for FFS farmers is small, while it is large for the comparison group. In the Mudete factory in the western part of the Rift Valley, both the FFS farmers and the non-participants show a similar decrease over time. We have not found out why these differences occurred between the FFS participants for these two factories. 
Figure 5.2 Trend in green leaf productivity per hectare from factory data, 2008-2015*

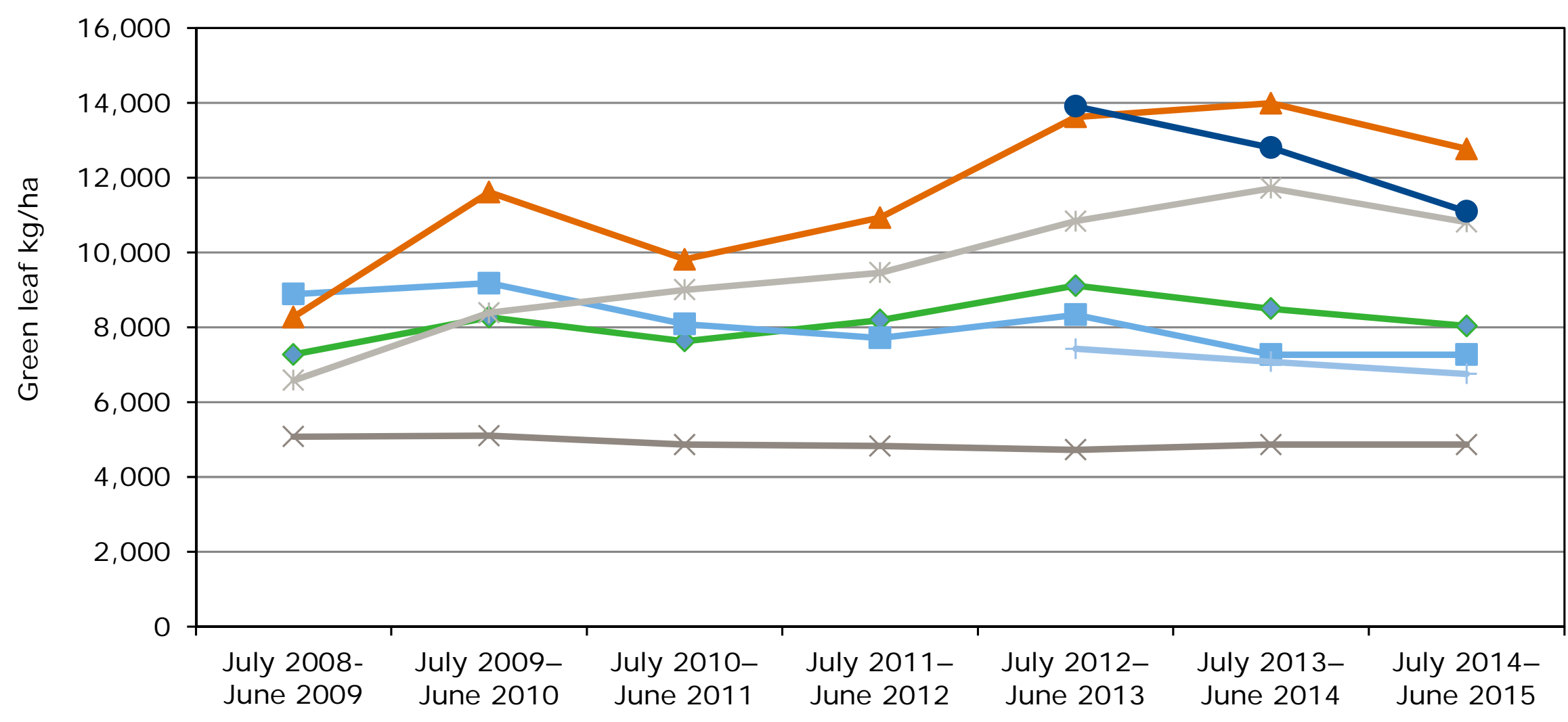

$\neg$ All farmers in 6 factories $\quad-$ Factory 1 (West of Rift Valley) $\neg$ Factory 2 (East of Rift Valley)

* Factory 3 (West of Rift Valley) — Factory 4 (East of Rift Valley) —-Factory 5 (East of Rift Valley)

-Factory 6 (West of Rif Valley)

* $\quad \mathrm{N}=34,955$ in $2008-2009,36,171$ in $2009-2010,37,788$ in $2010-2011,34,453$ in 2011-2012, 51,764 in 2012-2013, 57,188 in 2013-2014 and 57,884 in 20142015. We have data from four factories for the period 2008-2009 to 2014-2015, and from two additional factories for the period 2012-2013 to 2014-2015.

38 | Wageningen Economic Research | Final impact evaluation of Farmer Field School implementation in the smallholder tea sector in Kenya, 2009-2016 
The quality of green leaf decreased slightly in terms of rejected green leaf at leaf collection centres

Contrary to what KTDA staff has indicated in interviews, we found indications that the quality of farmers' green leaf decreased between 2013 and 2015, because their green leaf was rejected slightly more often. A possible explanation could be that KTDA applied stricter quality control measures than at baseline. Rejection rate and volumes were lower in farmers that participated in an FFS.

\section{Figure 5.3 How often a farmer's green leaf was rejected}

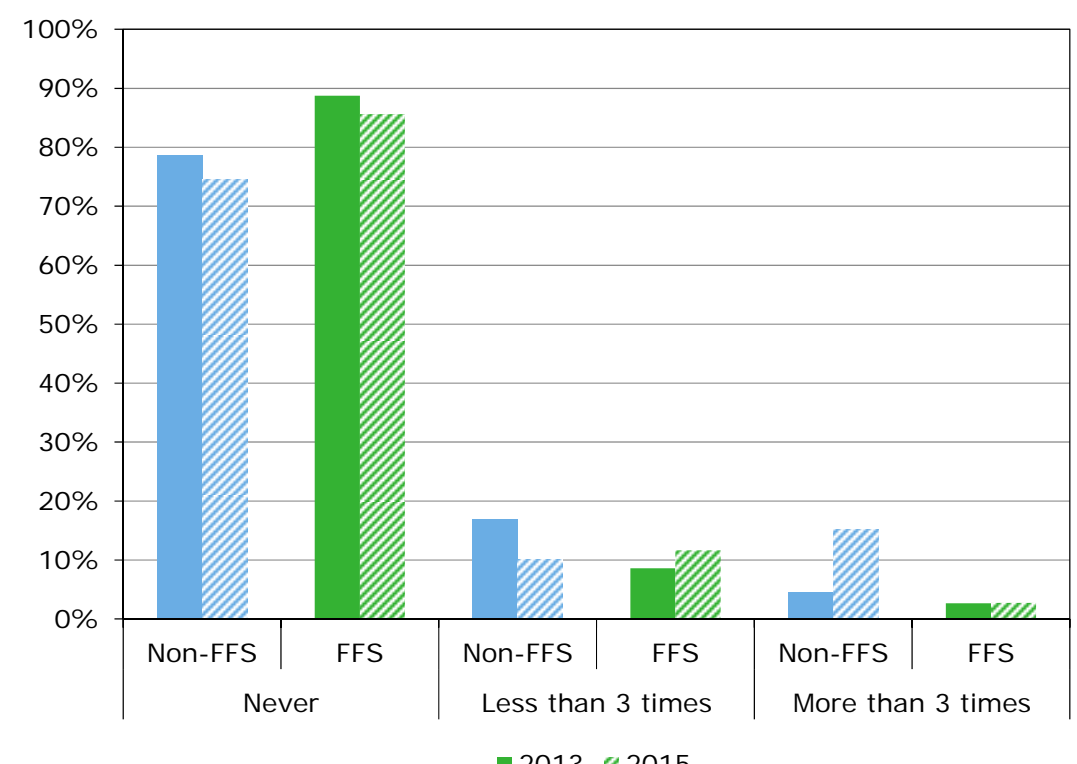

$2013 \% 2015$
Figure 5.4 How many kilograms of green leaf were rejected

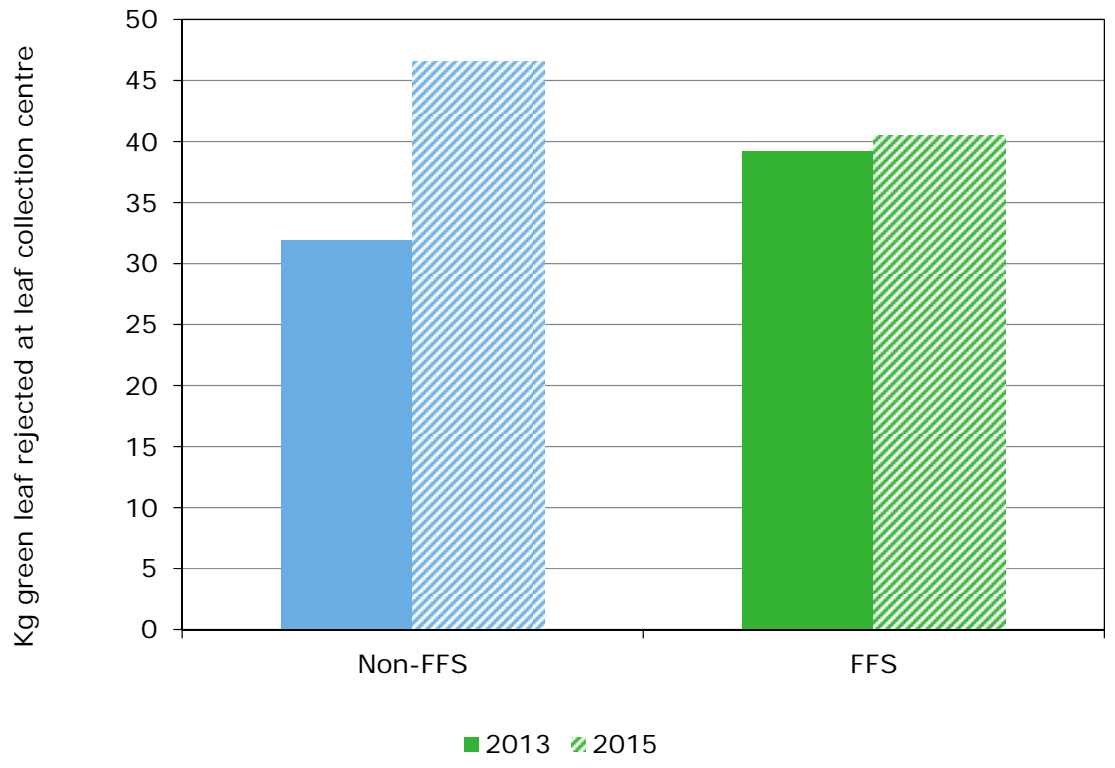

There was little change in the share of different grades of made black tea production between 2008 and 2015

Factory data reveals that the share of different grades of made black tea has slightly changed over time: there was a 3\% decrease in Pekoe Fanning 1

between 2009 and 2015, a 2\% increase in Pekoe Dust and an increase of 4\% in Dust 1. The tea grades have not significantly improved over time. See Figure 5.5 on next page. 
Figure 5.5 Grades of made black tea for six factories over time*

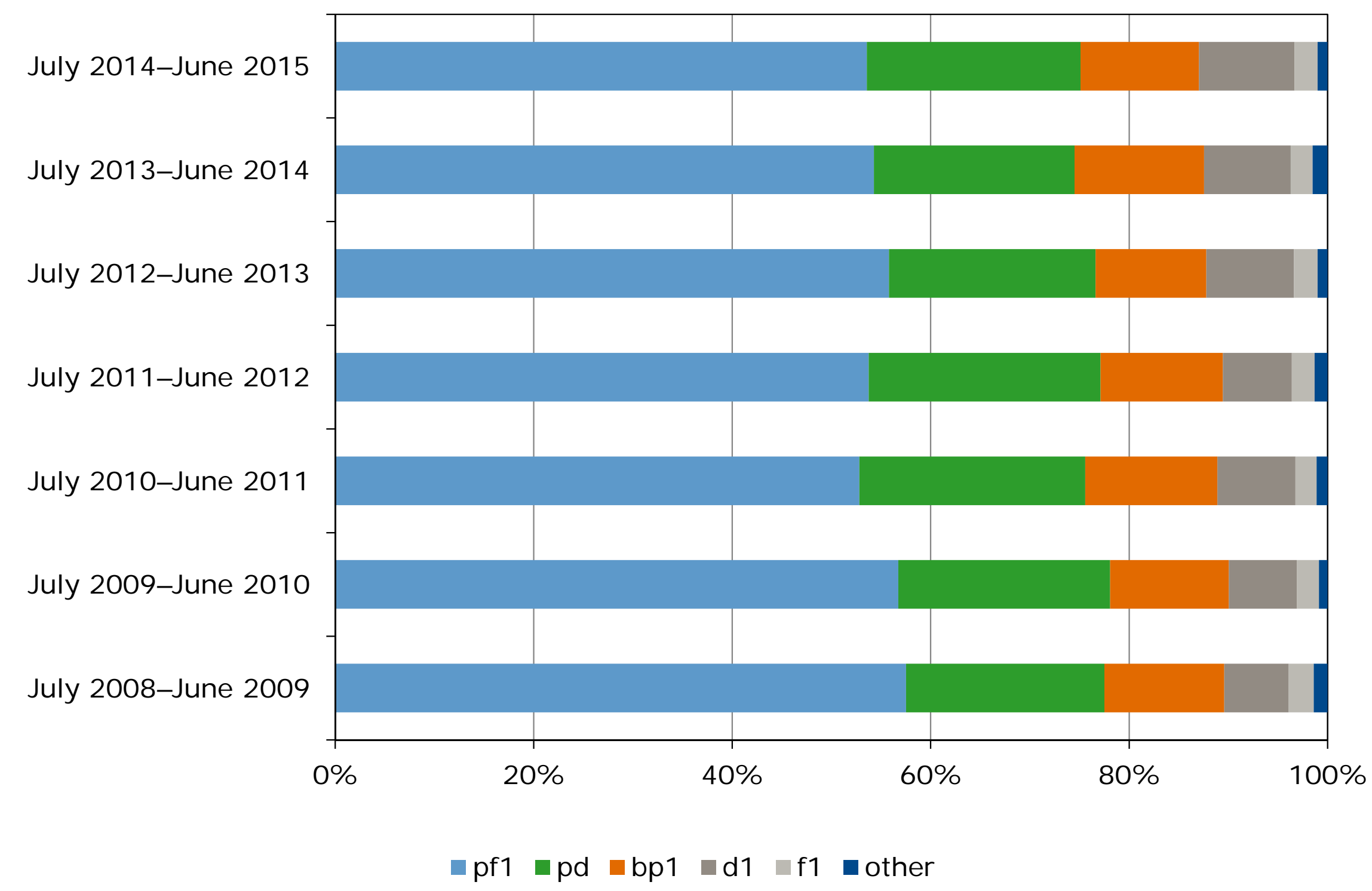

* Based on information from four factories for the years J uly 2008-J une 2015, and for two additional factories between July 2012 and June 2015.

$*$ pf $1=$ Pekoe Fanning 1, pd = Pekoe Dust, bp1 = Broken Pekoe 1, d1 = Dust 1, f1 = Fanning.

40 | Wageningen Economic Research | Final impact evaluation of Farmer Field School implementation in the smallholder tea sector in Kenya, 2009-2016 


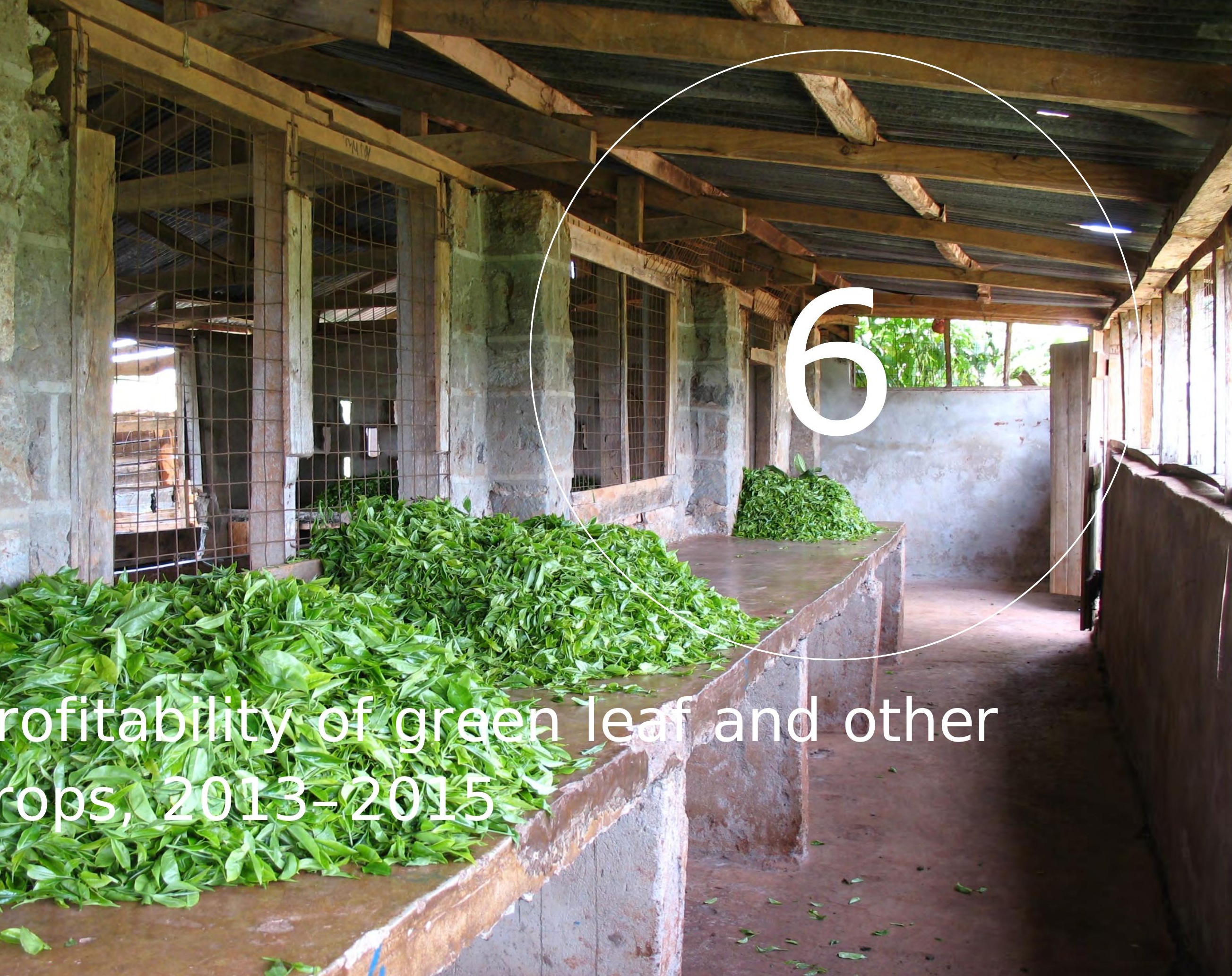




\section{Profitability of green leaf and other crops, 2013-2015}

Green leaf prices dropped in the period July 2011 to June 2014 but increased again after J une 2014

While prices for green leaf tea had rose steadily rise since the KTDA-wide implementation of the FFS approach in 2008, the 2011-2012 season proved to be a turning point, after which the prices for green leaf dropped. The prices rose again in the period July 2013-June 2015, but did not reach their high point from early 2011.

Figure 6.1 Green leaf prices, including first and second payments, between July 2008 and June 2015

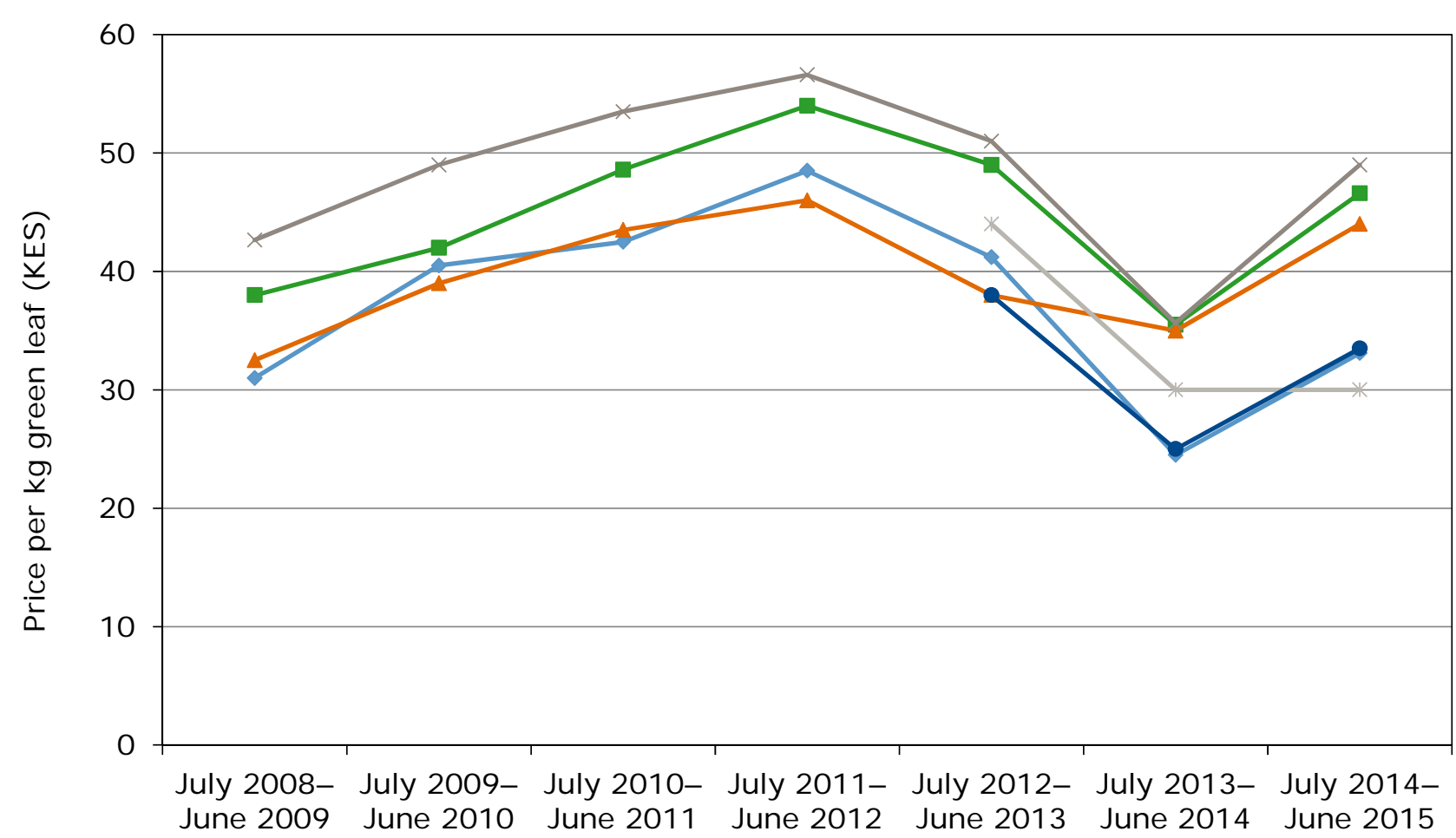

$\rightarrow$ Factory 1 (West of Rift Valley) -F-Factory 2 (East of Rift Valley) $\rightarrow$-Factory 3 (West of Rift Valley) *Factory 4 (East of Rift Valley) *-Factory 5 (East of Rift Valley) - -Factory 6 (West of Rif Valley)

42 | Wageningen Economic Research | Final impact evaluation of Farmer Field School implementation in the smallholder tea sector in Kenya, 2009-2016 
Green leaf profitability: decrease in profitability of tea per hectare, for both FFS and non-FFS farmers

In line with the decline in green leaf productivity between 2013 and 2015, the gross income from green leaf production also shows a steep decline over that period. While the gross income of FFS farmers dropped by $31 \%$ over that period, the gross income of non-FFS farmers dropped by $39 \%$. Over the same period, production costs also decreased. While FFS farmers cut their costs for green leaf production by 15\% between 2013 and 2015, non-FFS farmers cut their costs even more, by $30 \%$. This indicates that the decline in productivity might be explained by tea farmers having reduced their investment in green

Figure 6.2 Green leaf profitability per hectare of FFS and non-FFS participants

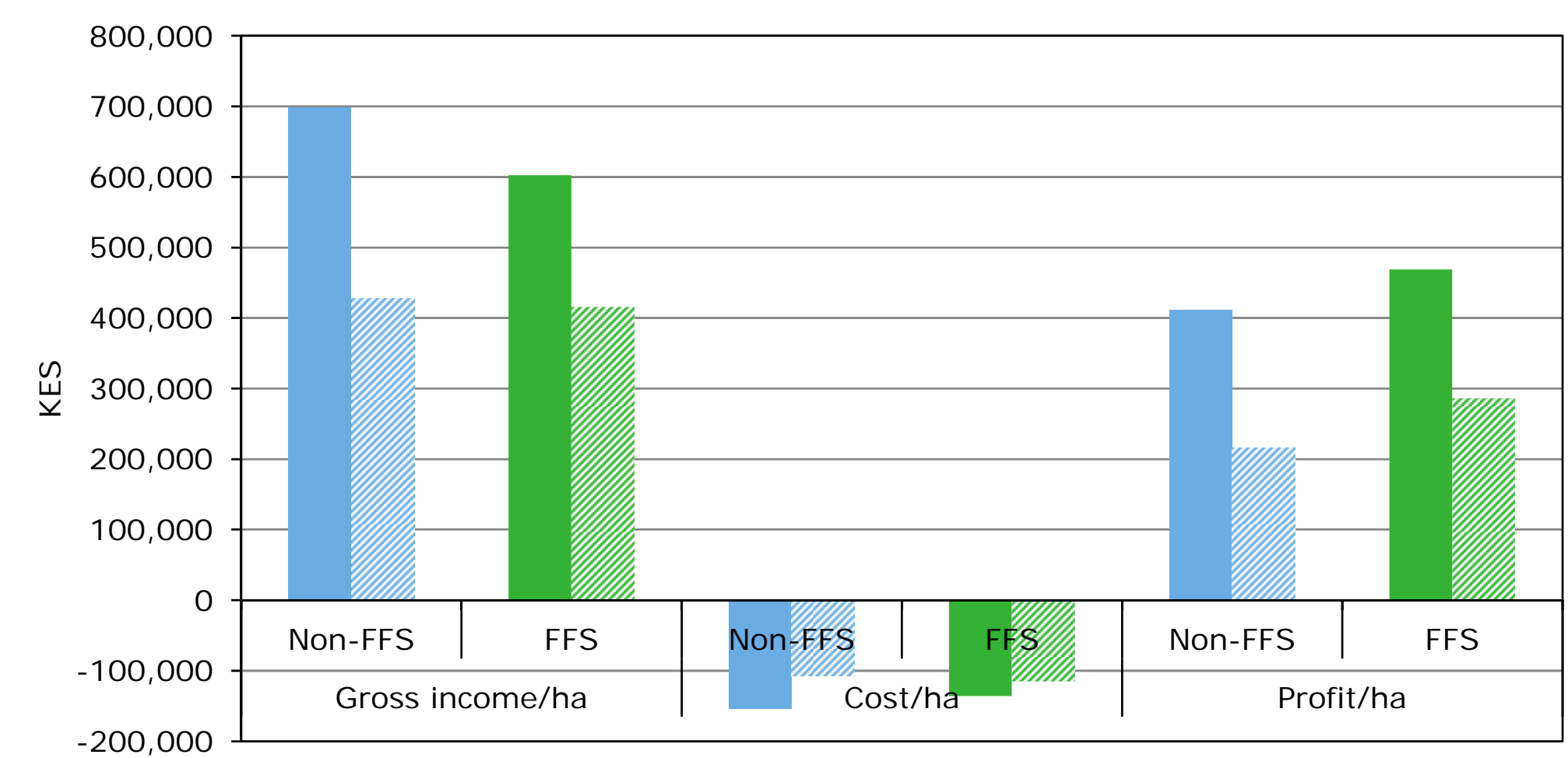

2013 " 2015 leaf production. Nevertheless, the fact that FSS farmers' leaf-related production costs did not decline as much shows that they are slightly more committed to green leaf production than non-FFS farmers.

With a steep decline in gross income, it comes as no surprise that despite the reduction in production costs the overall green leaf profitability also decreased between July 2013 and J une 2015. While FFS farmers saw profitability decline by $39 \%$, non-FFS farmer witnessed a $47 \%$ drop. But the variance between farmers is quite substantial, and this difference is therefore not statistically significant. 
Decrease in production costs mainly caused by reduction of labour used for plucking and pruning

The green leaf production costs consist of two cost categories: input costs and labour costs. Labour costs, especially the cost of plucking and pruning, take up the largest share of the total production costs. The input costs are relatively limited, with fertiliser costing the most. As shown in Figure 5.2, production costs fell during the period J uly 2013-J une 2015, with a bigger decrease for
non-FFS farmers (30\%) than for FFS farmers (15\%). For FFS farmers, this decrease can be mainly explained by a decrease in cost of hiring workers to pluck tea. For non-FFS farmers, the decrease is mostly related to a reduction of labour for pruning. Interestingly, the cost of labour for weeding and planting increased significantly for both FFS and non-FFS farmers. And while the use of pesticides has increased for non-FFS farmers, it has decreased for FFS farmers.

Figure 6.3 Production cost per hectare

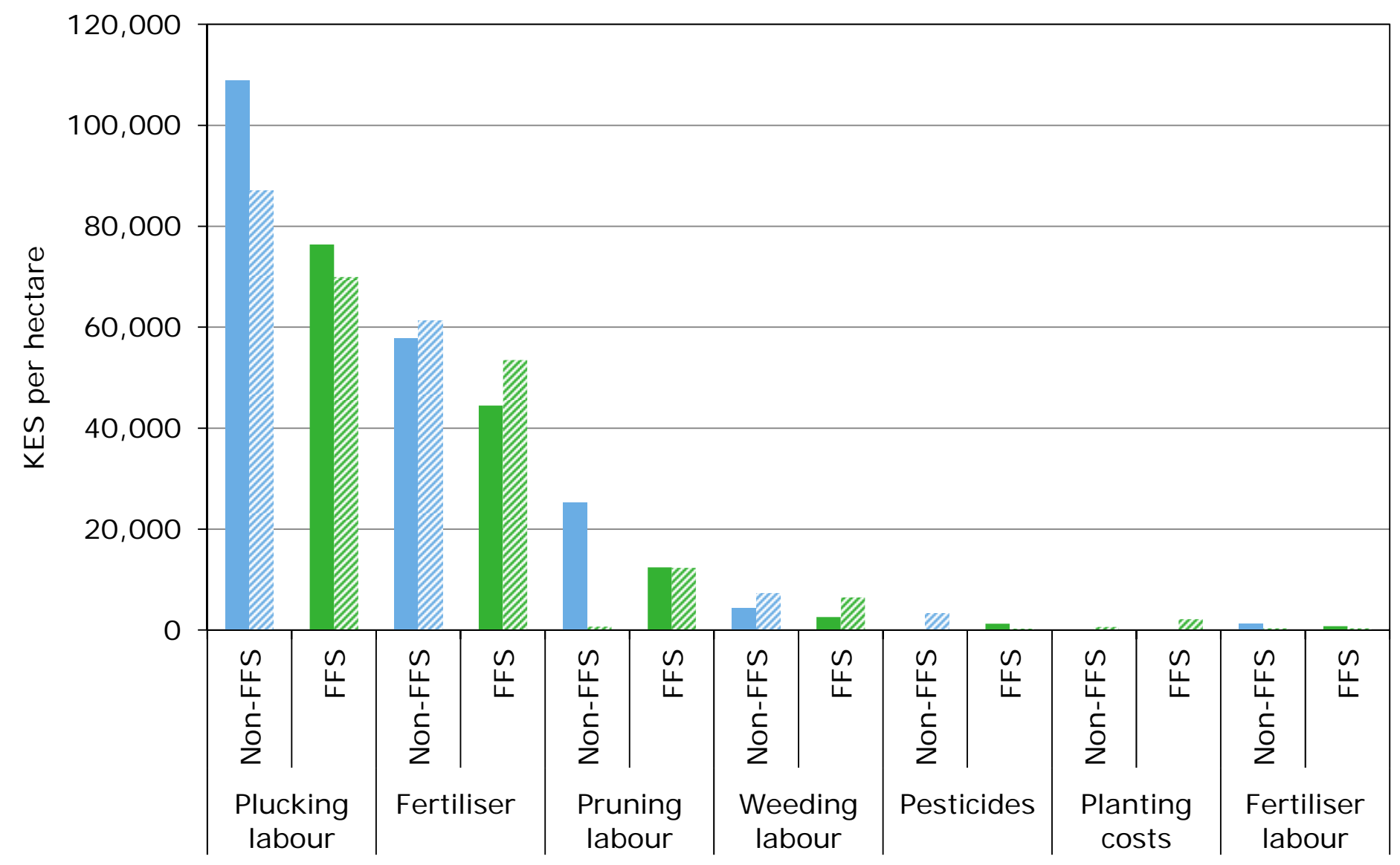

- $2013 \% 2015$

44 | Wageningen Economic Research | Final impact evaluation of Farmer Field School implementation in the smallholder tea sector in Kenya, 2009-2016 
Green leaf profitability per hectare is higher than profitability for maize and beans

A typical farmer earns on average almost KES150,000 with beans per hectare and KES167,000 with maize, compared with KES277,000 for green leaf. This calculation assumes that the farmers sell all the maize and beans they produce. In reality, they eat part or all of the bean and maize produced, so actual cash income per hectare is much lower than depicted here. In terms of crop production, income from green leaf is an important source of cash for the households. Income from sources other than crops will be discussed in the next chapter.

Figure 6.4 Profitability per hectare for bean, maize and green leaf production

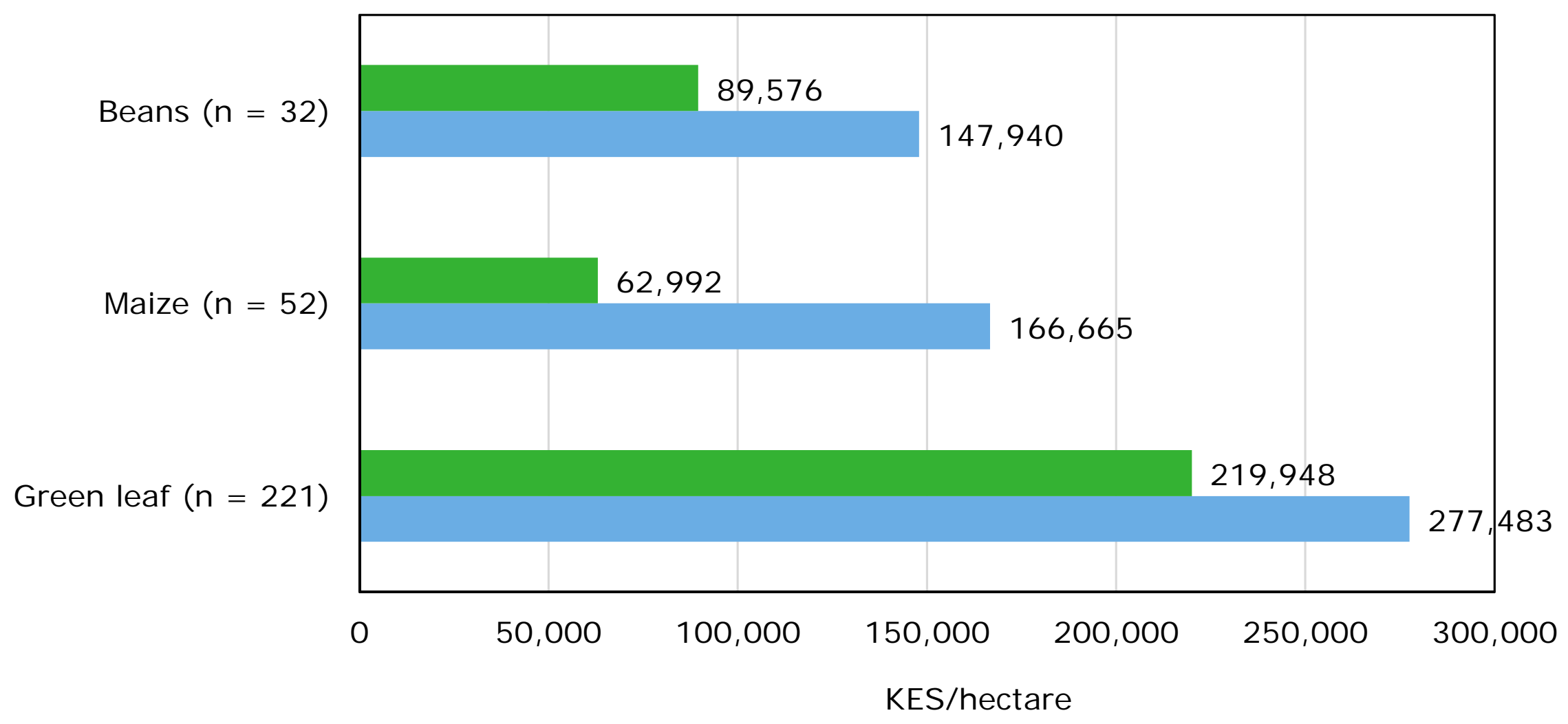

median $\quad$ Mean 


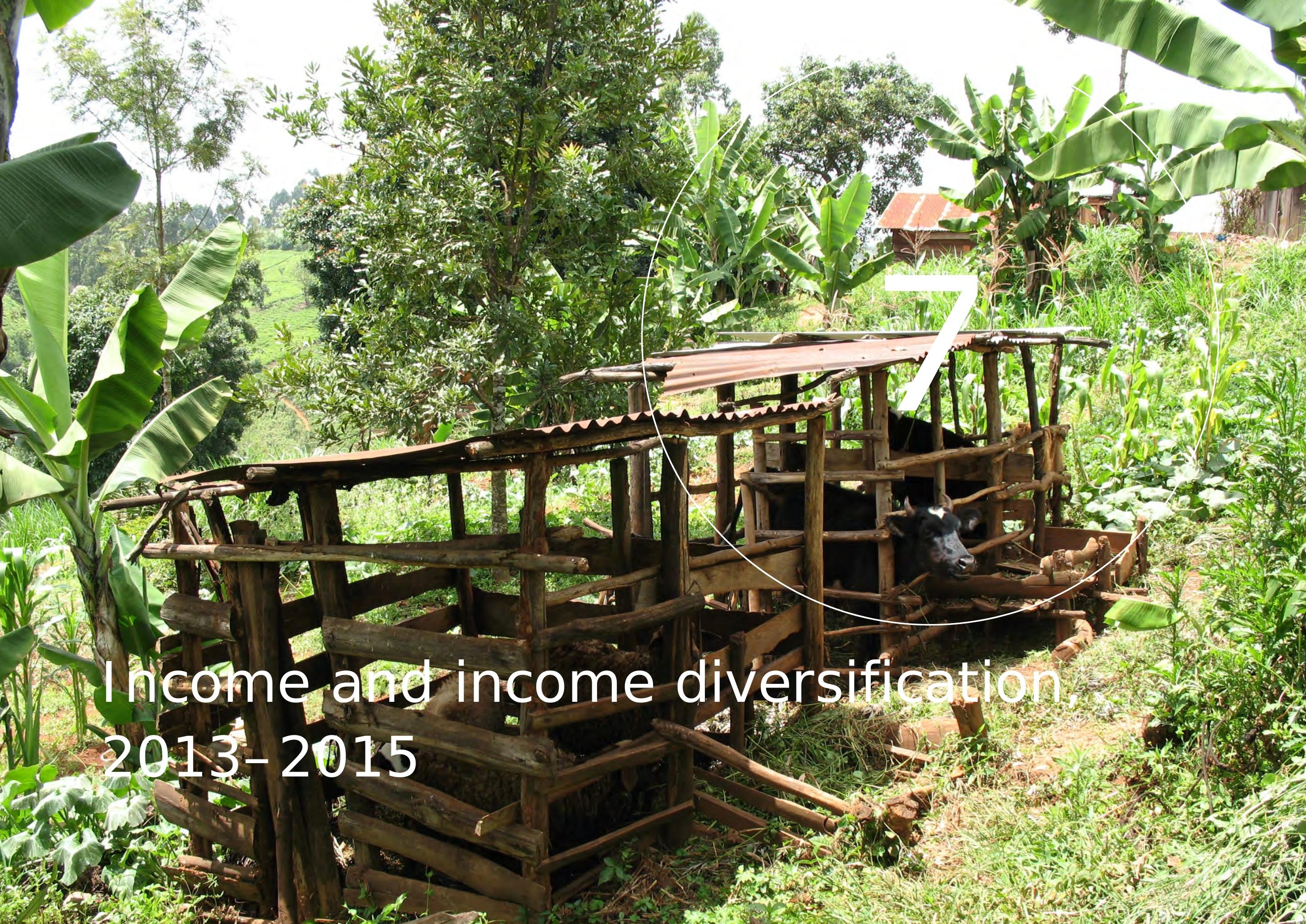




\section{Income and income diversification, 2013-2015}

Household income fell by $25 \%$ over the period 2013-2015 for all farmers, from USD1,099 to USD744 per year, which translates to amounts well below the USD1.25/day poverty line

As a result of the decline of green leaf productivity and the drop in prices for green leaf during the period 2013-2015, the income from green leaf fell by $45 \%$ for non-FFS farmers and $40 \%$ for FFS farmers over that same period. Even though income from other sources increased for all farmers, this did not lead to an overall increase in income. Total household income declined by about $25 \%$ for all farmers, from USD1,099 to USD744 per year. This translates to a decrease of household income per person per day for both groups from USD0.73 to USD0.45 between 2013 and 2015, because families consist of almost six people on average. This is well below the USD1.25/day poverty line.

Figure 7.1 Changes in total household income (2013-2015)

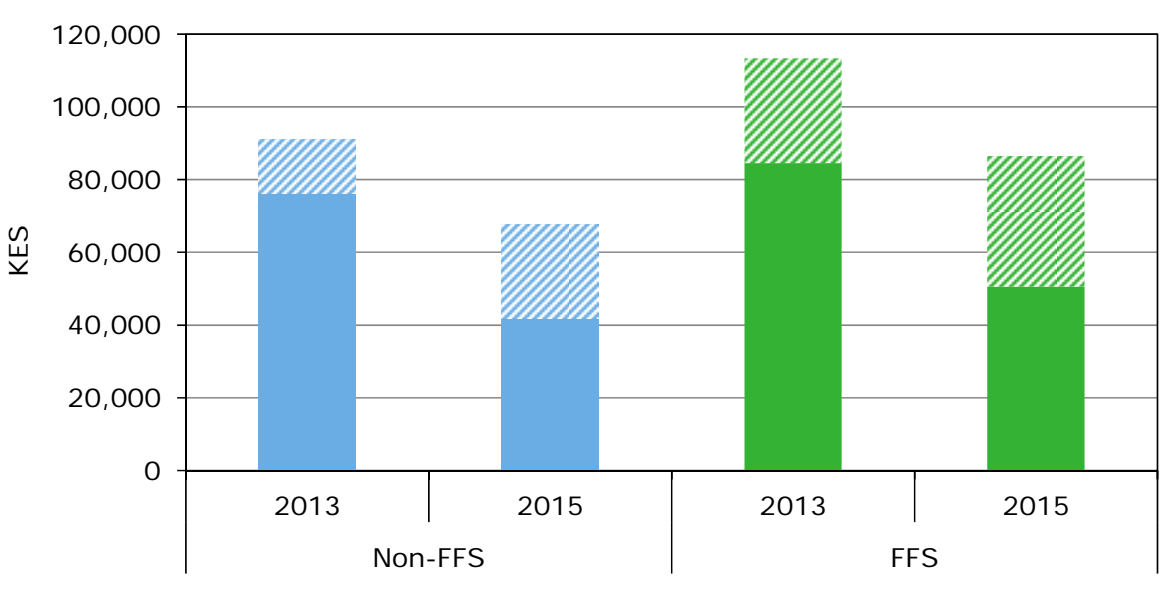

- Income from green leaf $\quad$ Income from other sources
It is a challenge for tea farmers to earn a good income from tea as farm sizes are small, have significantly decreased over time and farmers with smaller-sized farms have lower productivity

An interesting result from the factory data is that farm sizes are small, and have also decreased significantly between 2008 and 2015 (from 0.25 ha to $0.21 \mathrm{ha}$ ). According to KTDA this is the case because plots are being divided among the children when a parent passes away. As a result, new farmers are earning less from green leaf because they have less land to produce green leaf on. Combined with the fact that larger-sized farms are associated with higher productivity per hectare, this means that if the trend of decreasing farm sizes continues, it will be very difficult for tea farmers to earn a good income from tea. To supplement their household incomes, they would thus need to significantly increase their income from other sources.

All farmers increased their income from sources other than tea although not with statistical significance due to a wide variance During the period 2013-2015, both FFS farmers and non-participants increased their income from other sources than tea on average. This increase was however not significant due to a wide variance; half of the farmers solely relied on income from green leaf. Examples given of new income-generating activities were dairy and poultry farming, tomato and cabbage production, and the raising of tree seedlings to sell. FFS farmers indicated that they had diversified their income-earning activities as a consequence of more exposure to these activities and the knowledge and skills that they had acquired in the FFS.

Intriguingly, non-FFS farmers perceived a decrease in diversification of income, which is not in line with our survey data. The main reasons given for this development included high population growth in the area and a corresponding rise in the subdivision of land parcels. Family conflicts over land, a lack of skills and a shortage of funds were other reasons why farmers have been reluctant to diversify their farms over the past two years. 
Figure 7.2 Perceived changes in diversification of income $(\mathrm{N}=36$ for FFS farmers, $\mathrm{N}=60$ for non-FFS farmers)

FFS farmers

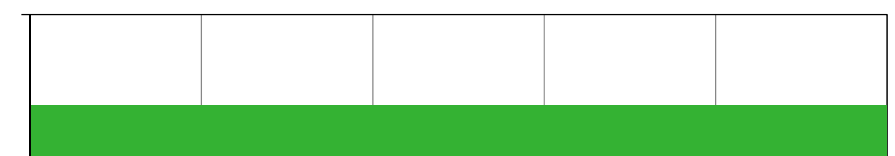

Non-FFS farmers

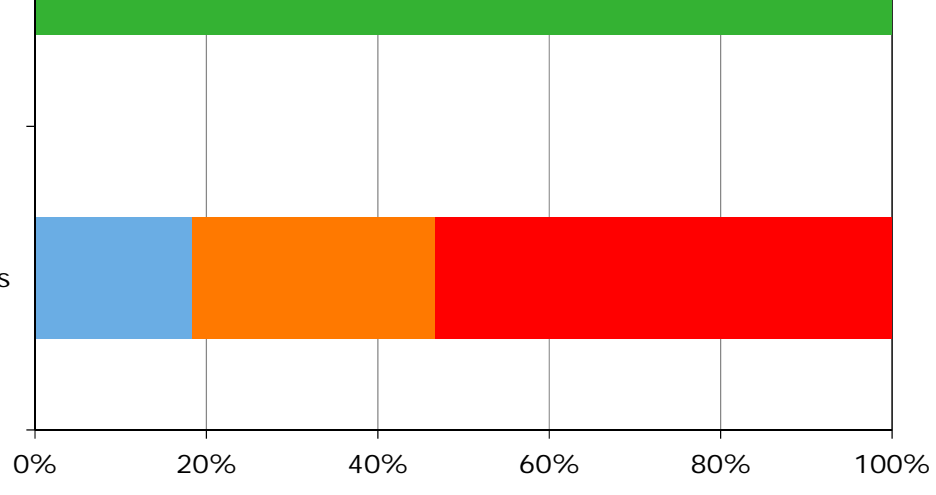

- Increase Constant Decrease
Figure 7.3 Changes in tea dependency among FFS and non-FFS farmers

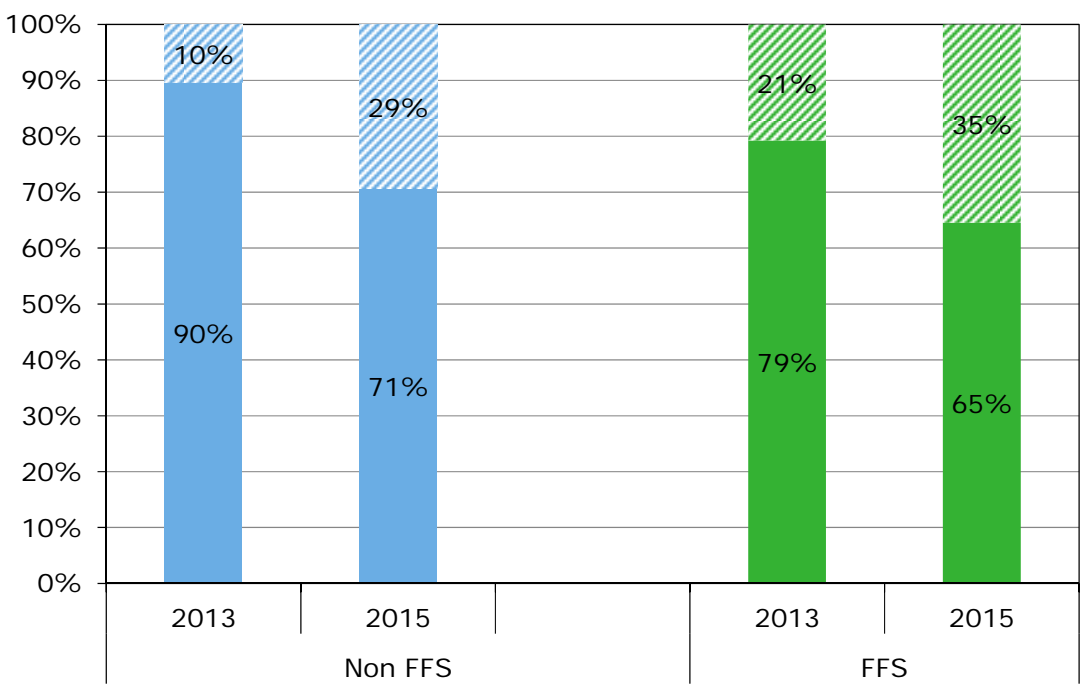

Share of income from green leaf z Share of income from other sources

All farmers reduced their dependency on green leaf for income Between 2013 and 2015, the dependency on green leaf for decreased significantly for all farmers, and we found no difference in this decrease between FFS and non-FFS farmers. Among FFS farmers the share of income from green leaf dropped from $79 \%$ to $65 \%$, while the comparison group decreased its share of income from green leaf from $90 \%$ to $71 \%$. All farmers have thus become less dependent on green leaf for their incomes and improved their resilience to changes in tea prices. 


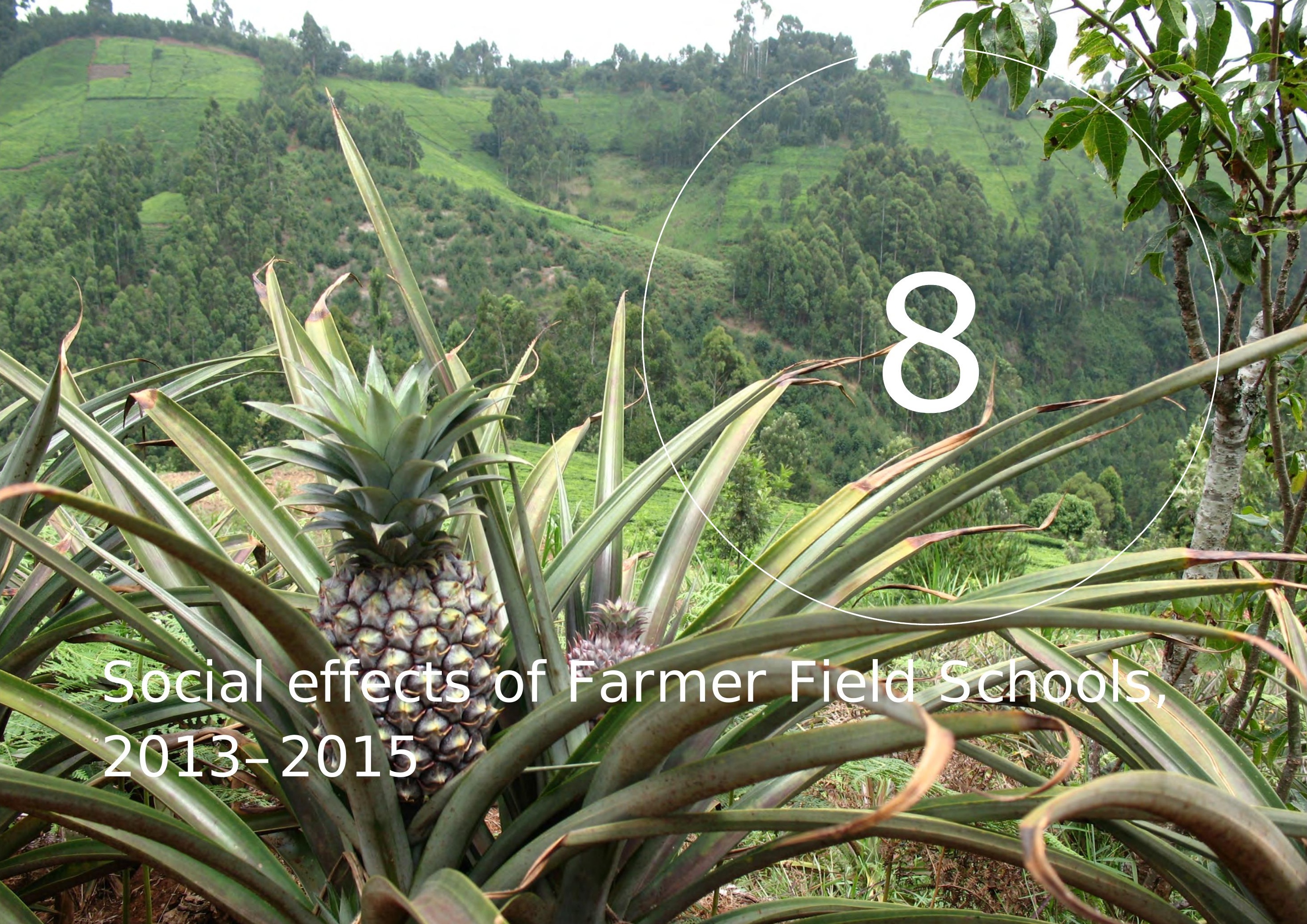




\section{Social effects of Farmer Field Schools, 2013-2015}

The relationship between FFS farmers and KTDA has improved because FFSs allow KTDA to have more in-depth discussions with FFS group members

FFS implementation has improved the relationship between farmers and KTDA, and it has also improved FFS farmers' understanding of tea marketing and the costs involved in KTDA's operations, and thus also how green leaf prices are established. Such knowledge and information has spread in the community thanks to FFS farmers. As a result, the discussions on price setting between farmers and KTDA has abated, as farmers are now better informed. KTDA staff indicated that now that discussions with the FFS groups have become more intensive, compared to the time of the field days, they have become instrumental in increasing farmers' knowledge of these issues, not to mention their appreciation of the work done at the KTDA factories and the related costs.

Women's leadership capacity improved because of the FFS according to KTDA staff. Women in particular bring innovation to food production activities and value addition

KTDA staff has indicated that women have increased their leadership capacity after participating in an FFS. More women are bringing more green leaf to collection centres than before, and they have assumed a stronger role in green leaf production and activities to diversify income. This has reduced conflict and increased domestic harmony. Men were initially a bit resistant to this change, but are now 'okay with it'. Women in particular have been innovative in food production and value-addition activities. This has increased income from sources other than green leaf, for instance from cassava flour, soap, dried bananas and arrowroot chips. According to KTDA, this has also improved nutrition, as farmers now have a more diverse diet than a few years ago (vegetables, eggs and meat).
Better health thanks to improved waste management practices and the introduction of 'central sprayers', which have especially benefited women's health

Pesticides are not often applied by green leaf producers in Kenya. KTDA indicates that when pesticides are applied, it is women who do it in $80 \%$ of the cases. KTDA has introduced 'central sprayers', who are professionally trained people who apply agrochemicals for a fee (KES20-50/USD0.19-0.49 per time) As a result, KTDA indicates that fewer farmers are spraying themselves, which means that the health risk for women in particular has decreased since they are spraying less frequently. This is improving their health according to KTDA staff, who have also indicated that waste management practices have also improved, also contributing to better health at the farm level.

The focus group discussions reveal another beneficial health effect of the FFS: fewer injuries and accidents among people working in the field. While most FFS farmers have witnessed a decrease in the number of injuries and accidents over the past year, many non-FFS farmers experienced an increase. 
Figure 8.1 Perceived changes in number of injuries/accidents in the field (2013-2015) ( $\mathrm{N}=36$ for FFS, and 60 for non-FFS farmers)

FFS

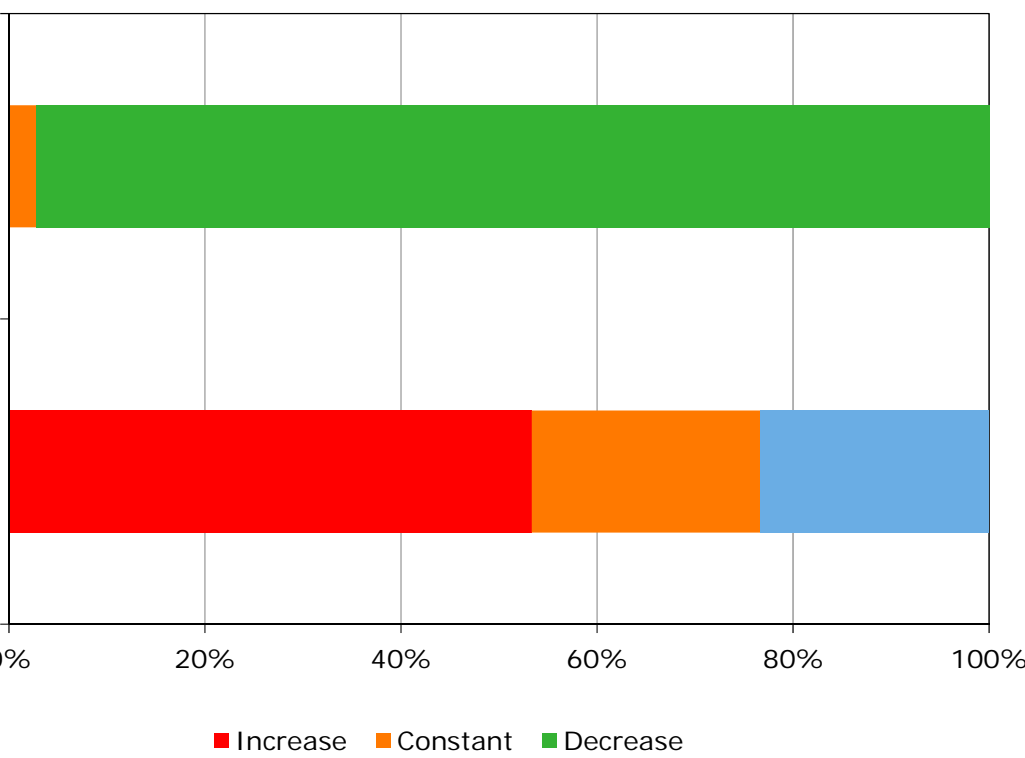

Farmers and KTDA staff report that the FFS programme has had a positive effect on food and nutrition security

When addressing the changes that participants in the focus groups had witnessed in their diets over the past two years, those groups with FFS farmers showed a distinctly brighter picture than those with non-FFS farmers. Both focus groups with FFS farmers indicated that there have been clear

improvements in the quantity of food, due to increased yields from maize, beans and vegetables. Also, FFS famers indicated that the diversity of food in their diets had increased, for example due to a higher intake of vegetables and fruits. KTDA staff has confirmed this trend.
This positive effect of FFS is confirmed by discussions in the focus groups with non-FFS farmers. In the focus groups, only $15 \%$ of the farmers witnessed improvements in the quantity and quality of their diet, while $85 \%$ reported that the quantity and quality had stayed the same in the past two years.

Figure 8.2 Perceived changes in quantity and quality of diet (2013-2015) ( $N=36$ for FFS, and 60 for non-FFS farmers)

FFS

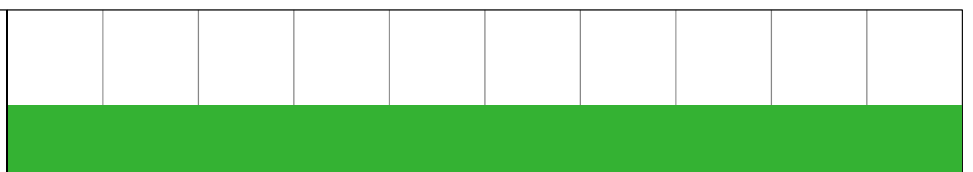

Non-FFS

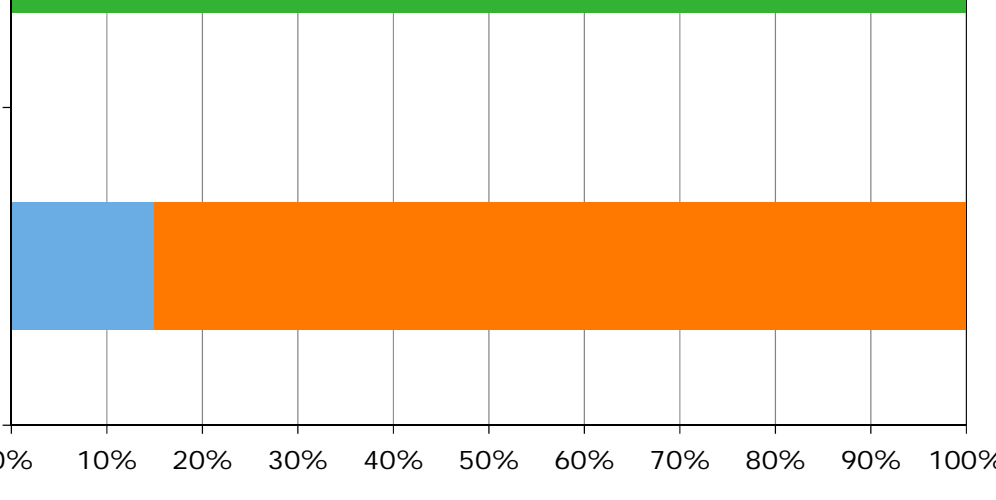

- Improved Constant 

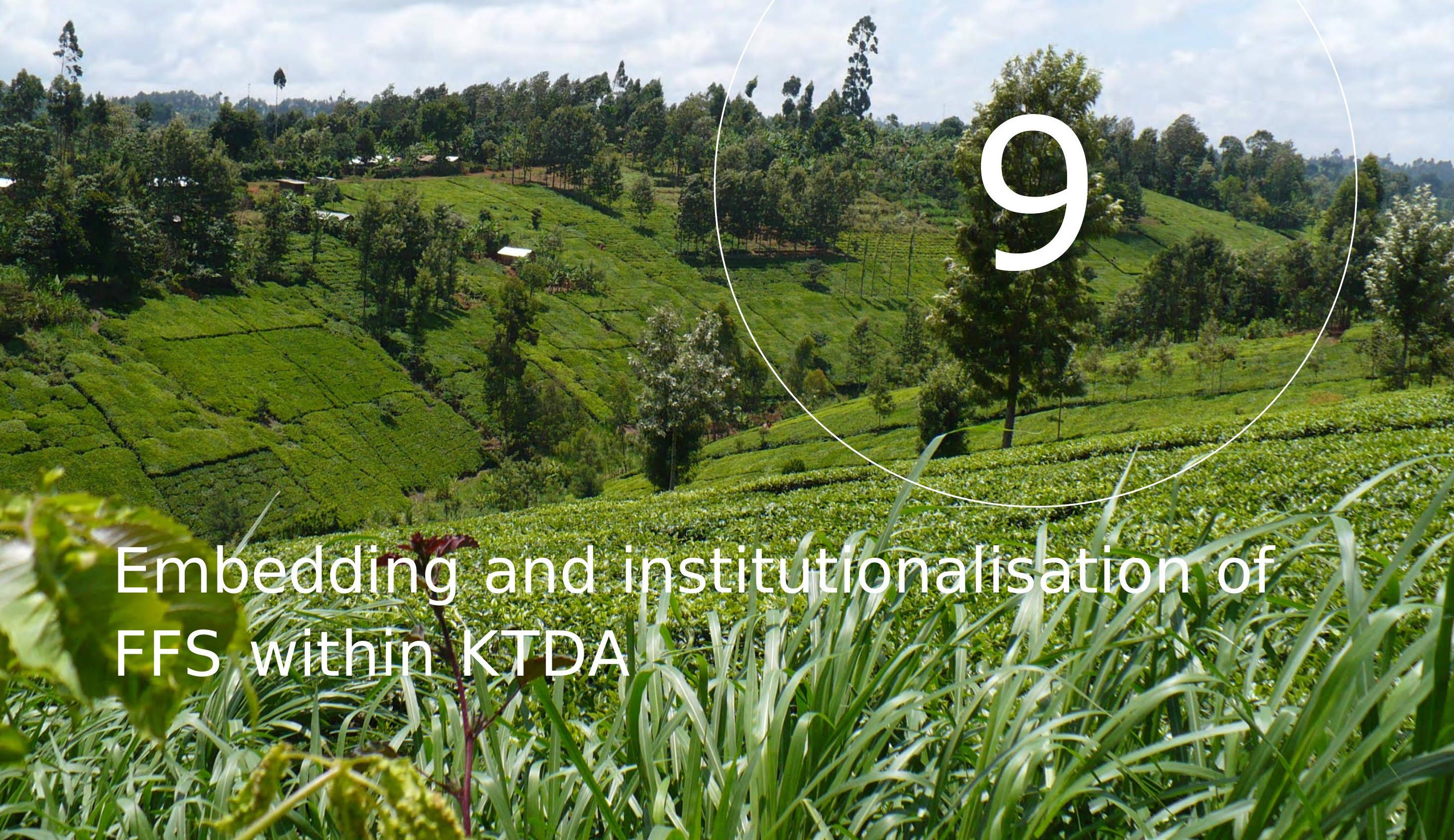


\section{Embedding and institutionalisation of FFS within KTDA}

FFS have been upscaled within the KTDA factory system One of the primary goals of the Embedding Sustainability Programme, which was implemented between 2012 and 2016, was to scale up the number of farmers taking part in Farmer Field Schools. During its implementation, the number of farmers trained through FFS increased from 20,670 in 2012 to 86,020 in 2016 ( $15 \%$ of the entire population). Fifty three percent of FFS participants are women $(45,849)$. At the same time, the amount of FFSs grew from 600 to more than 3,400 , more than the programme's targets of 3,200 FFSs.

All three parties contributed to the programme's results. Funding by IDH and Unilever has led to FFSs being implemented more rapidly than would have been the case without their funding The impact of the Embedding Sustainability Programme can be attributed in large part to the three funders contributing to the programme. The funding of the programme was equally distributed between KTDA, Unilever and IDH. The co-funding of Unilever and IDH played a key role in upscaling the FFS approach. KTDA would also have implemented the FFS without IDH and Unilever support, but at a much slower pace.

The FFS approach has been embedded and institutionalised at the KTDA management level

Interviews with KTDA staff show that FFSs are considered an important and effective extension methodology by all KTDA staff; KTDA management, FSCs, TESAs and regional coordinators. Over the coming years, the FFS implementation will continue. Each factory will implement 12 FFSs per year, for which budget provisions have been made. The implementation of the FFS will be carried out by TESAs, without assistance from FFS graduates. This will slow down the pace in which new FFS are established, but it will bring down the cost of implementation and improve the sustainability of the FFSs that are formed.
At the KTDA management level, Mr. Peter Mbadi, the senior manager of agriculture services, who has been involved in FFS implementation since the FFS pilot in 2006, now has a colleague to assist him in his endeavours. All these changes add to the sustainability of the continued implementation of FFS at KTDA.

However, we did hear about some challenges that may be related to this phasing out of farmer-assisted FFSs, which may need to be addressed to ensure the effectiveness of future FFSs. Ensuring sufficient farmer attendance at FFS meetings and providing the necessary training materials are key areas that KTDA staff say need to be emphasised in the implementation strategy.

Half of the farmers continue with FFS group activities after graduation

About half of the FFS groups continue after graduation. As shown in Figure 9.1, $55 \%$ of TESA-led FFS farmers and $45 \%$ of farmer-assisted FFS farmers continue to engage in FFS activities after their graduation. Among the TESA-led FFS farmers, the most frequently mentioned reasons for not continuing activities after graduation are insufficient planning and commitment in the group and personal constraints in terms of time and money. For the farmerassisted FFS farmers the most important reasons are a lack of coordination and insufficient commitment among the members of the group. 
Figure 9.1 Share of farmers involved in FFS activities after graduation

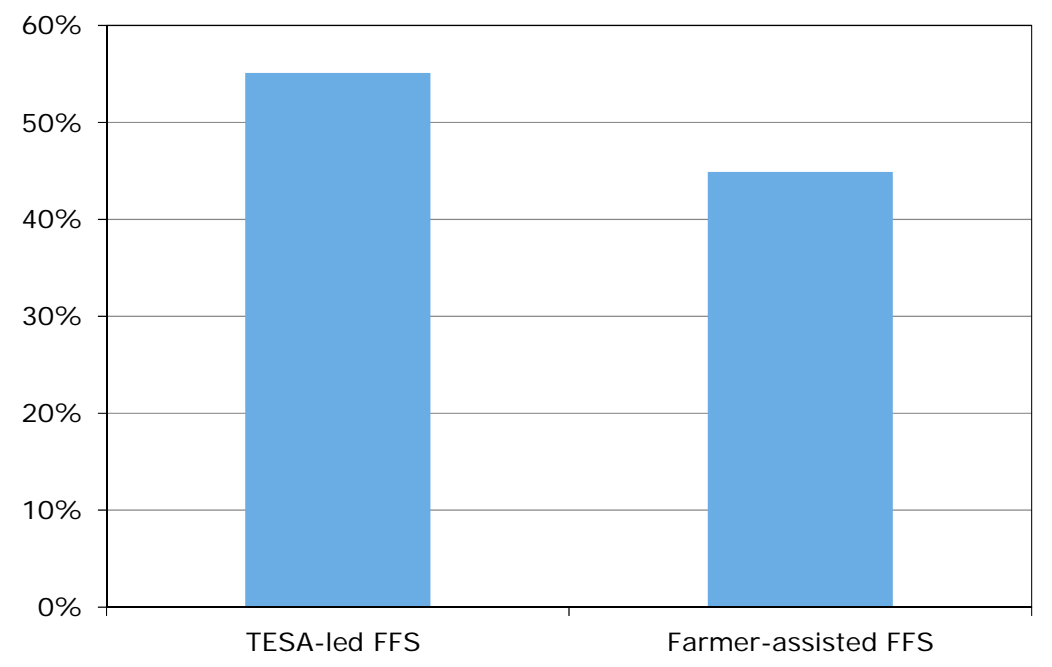

But graduate FFS group activities take place at least monthly in $70 \%-90 \%$ of the cases. Older graduates meet more often than recent graduates

FFS activities take place at least monthly after farmers have graduated from an FFS in $70 \%$ to $90 \%$ of the cases. Surprisingly, the older FFS graduates from the TESA-led implementation model indicate that their group meets more often than more recent graduates.
Figure 9.2 Frequency of FFS activities carried out after graduation, by type of FFS

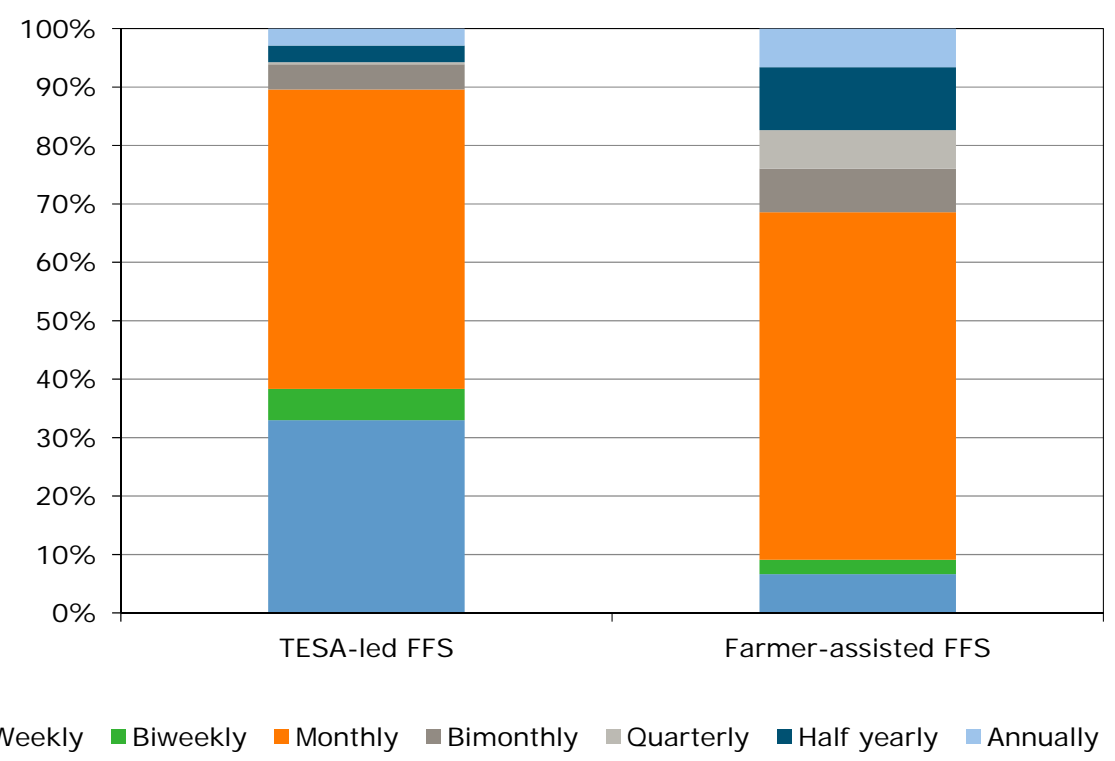

Various activities are carried out by farmers who graduated from FFS groups

The activities carried out by farmers who continued these activities with the FSS after graduation show great variety. Many FFS groups continue carrying out activities to improve tea farming practices. Many activities also organised to grow other (often food) crops and rear livestock, although these are more common among the farmer-assisted FFSs than among the TESA-led FFSs.

So-called merry-go-round groups are organised in both groups, the purpose of which are to save money for making larger expenditures at a future date. Other activities that were mentioned are the planting of trees, environmental activities, farm visits, the formation of farmer groups and meetings with KTDA staff.

Eight per cent of the farmers mention meetings with KTDA staff as activities by the FFS group after graduation, but this most probably underestimates the contact between KTDA and graduate farmers, as we did not specifically asked farmers about their contact with KTDA. 
KTDA indicates that the FSCs and TESAs are in contact with farmer graduates in FFS groups when they have information to pass on to the farmers but also when the farmers contact them for assistance. The FSCs write or call the chairperson of the group, who arranges to convene the FFS group if KTDA has information to convey to the farmers. Furthermore, when any group

undertakes an activity, such as tea seedling propagation, and wants assistance in their factory, they will contact the FSC through their TESA. Finally, the FFS groups are not the only means for contact between factory staff and the

farmers: operational meetings are held quarterly at leaf collection centres in which all farmers participate.
Figure 9.3 Type of activities carried out after graduation, by type of FFS

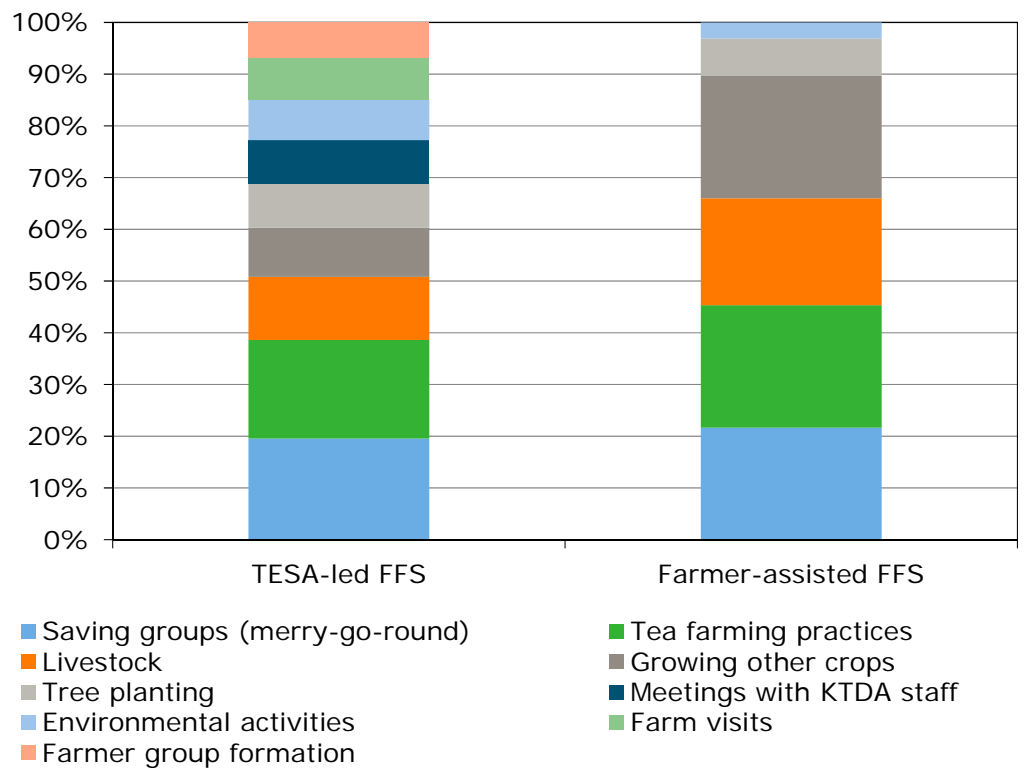




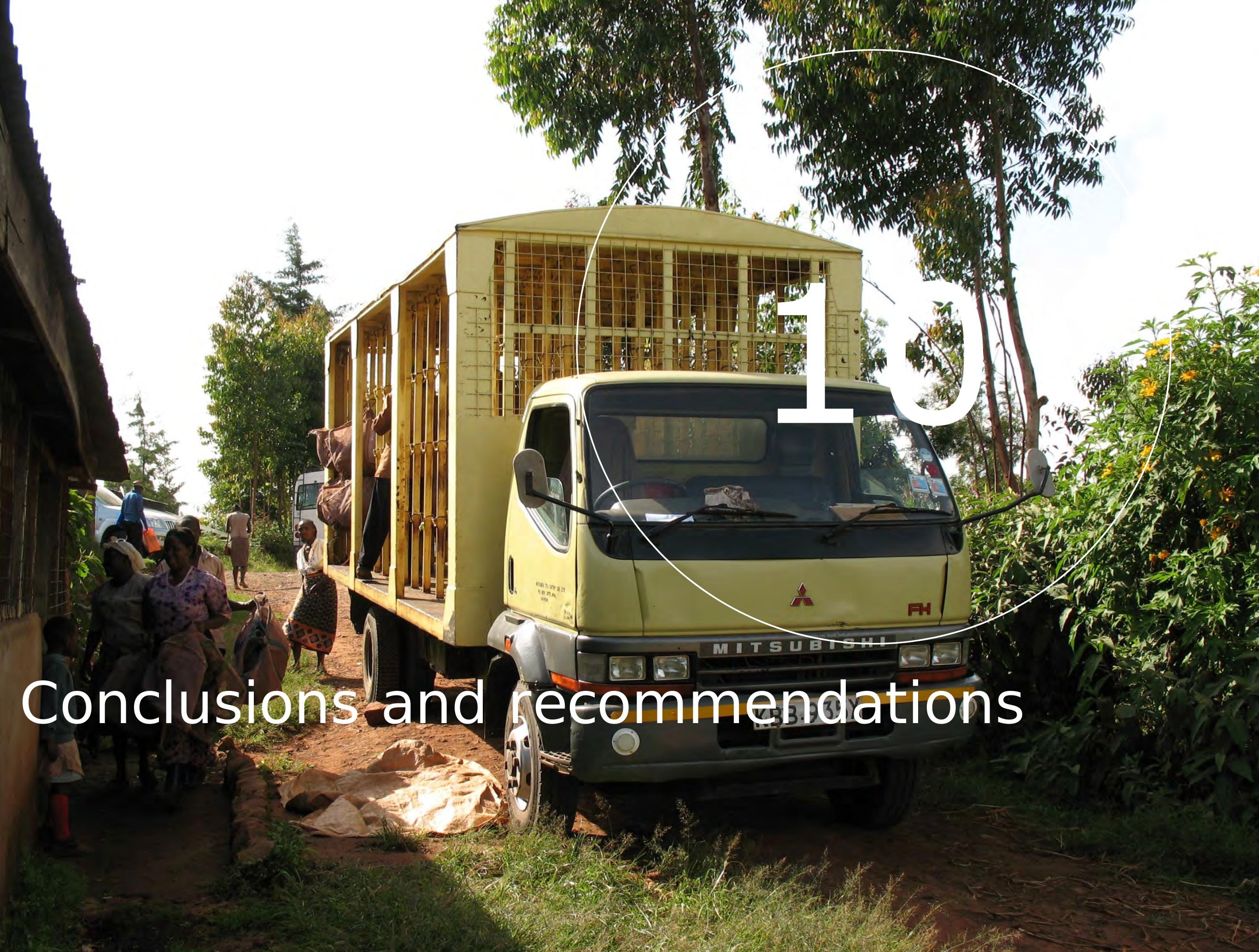




\section{Conclusions and recommendations}

Upscaling FFS implementation between 2009 and 2016

Following the pilots and first implementation in TESA-led Farmer Field Schools, KTDA, Unilever and IDH launched the programme's 'embedding phase' (20122016), in which FFS graduates assisted TESAs in the organisation of FFS, for which they were reimbursed. This enabled the Tea Extension Services Assistants (TESAs) to implement more FFSs per person per year, from two to about six FFSs per TESA. By June 2016, 86,020 farmers had been trained through an FFS, $15 \%$ of all farmers connected to KTDA, including 45,849 women (53\%). This latter model is called the Farmer-assisted FFS, and both KTDA Field Services Coordinators (FSCS) and TESAs have noted that the quality of the implementation of these FFSs is comparable to the first FFS model.

The FFS programme increased green leaf productivity between 2009 and 2013 and increased incomes between 2009 and 2011 Motivated by the good results from a pilot project with 24 FFSs7 in 2008, KTDA introduced the FFS programme to all 54 KTDA factory companies between 2009 and 2016. These FFSs were implemented by the KTDA tea extension staff (called TESA-led FFSs) in the period between 2009 and 2013. Evidence shows the TESA-led FFS trainings improved knowledge and adoption of Good Agricultural Practices (GAPs), which increased farmers' yields and incomes between 2009 and 2011. Moreover, FFS participants actively shared the knowledge they acquired with other farmers, resulting in significant spillover effects.

A decrease in green leaf prices has negatively affected green leaf profitability between 2011 and 2013 and tea farmers remain poor Even though green leaf productivity increased between 2011 and 2013 for FFS participants, a decrease in green leaf prices resulted in lower profitability per hectare and lower incomes from green leaf for all tea farmers. FFS farmers experienced less decline of profitability than farmers in the comparison group. Increases in income from other sources did not offset this green leaf income

\footnotetext{
In partnership with DFiD and Lipton.
}

decrease, so farmers remained poor with a typical income of less than USD2 from green leaf per family per day.

All farmers increased knowledge levels between 2013 and 2015 but adoption did not change, probably because of already high levels at baseline

Over the period 2013-2015, the knowledge of good tea practices increased for both FFS and comparison group farmers. Furthermore, the adoption rates were already quite high at the baseline situation. This may be attributable to the fact that both groups of farmers had been trained by TESAs before the FFSs were implemented, and also to RA certification in 2013. It appears that FFS training on top of these earlier trainings for the group of farmers in question has a limited impact. This could indicate that there are diminishing returns in training and adoption: farmers who already participated in other trainings reach a point where participating in an extra training does not lead to additional knowledge levels or behavioural change by the farmer.

Green leaf quality decreased slightly in terms of rejected green leaf at the leaf collection centres for all farmers (2013-2015)

Contrary to what KTDA staff has indicated in interviews, we found that the quality of farmers' green leaf decreased slightly between 2013 and 2015, because their green leaf was rejected more often. We found no differences in change of green leaf quality between FFS farmers and non-participants.

Green leaf productivity decreased for all farmers between 2013 and 2015, but FFS participants experienced a significantly smaller decrease than non-participants

While the knowledge of GAPs increased and their adoption remained stable, average green leaf productivity decreased between 2013 and 2015 because of unfavourable climatic conditions. Interestingly, the productivity of non-FFS

farmers showed a much steeper decline than the productivity of FFS farmers. This might indicate a higher resilience of FFS farmers to changes in climatic conditions. 
Combined with lower green leaf prices, this resulted in lower green leaf profitability between 2013 and 2015

Green leaf prices dropped in the period 2012-2015, after a steady increase in the period 2008-2013. Combined with declining tea productivity, this resulted in a decrease in green leaf profitability between 2013 and 2015, for both FFS and non-FFS farmers. Interestingly, production costs decreased as well during that period, mainly as a result of a reduction of labour used for plucking and pruning. Apart from climatic effects, the decrease in productivity could be explained in part by farmers reducing their labour investments in green leaf production because of unattractive tea prices.

Average household income fell over the period 2013-2015 for all farmers, from USD1,099 to USD744 per family per year, which is well below the poverty line

As a result of the decline of green leaf productivity and the drop in prices for green leaf during the period 2013-2015, the income from green leaf fell by $45 \%$ for non-FFS farmers and $40 \%$ for FFS farmers in that period. Income from other sources increased for all farmers, though not significantly so. Examples of new income sources were dairy and poultry farming, tomato and cabbage production and nurseries for tree seedlings. Other income sources that contributed to the increased diversification are business and services activities. But the average household income declined for both FFS and nonFFS farmers by $25 \%$, from USD1,099 to USD744 per family per year. This is well below the poverty line, and is largely due to the relatively small size of most farmers' farms (on average 0.21 ha in 2015).

It is a challenge for tea farmers to earn a good income from green leaf as farm sizes are small and have decreased over time, and smaller-sized farms are associated with lower productivity per hectare Farm sizes have decreased significantly from 0.25 ha to 0.21 ha between 2008 and 2015. According to KTDA this is the case because plots are being divided among the children when a parent passes away. These new households earn less from green leaf because they have less land available. Also, smaller-sized farms are associated with lower productivity per hectare, which might explain why households are spending less time on tea as they now need to have additional income-generating activities. It is very difficult for tea farmers to earn a good income from tea if prices do not increase. If the trend of decreasing farm sizes continues, famers will face an even bigger challenge.
KTDA and farmers acknowledge that between 2013 and 2015 the FFSs improved the relationship between KTDA and the farmers, and also improved farmers' health, nutrition and the position of women

The FFS implementation between 2013 and 2015 resulted in a range of social effects according to KTDA staff and farmers that participated in focus group discussions. Regular interaction with the FFS improved relations between KTDA and FFS farmers. In particular, farmers now know how prices are established, and thus complain less that green leaf prices are too low. Also, women's leadership capacity improved due to the FFS activities as women started innovating more in food production and value adding activities.

Moreover, farmers' health improved due to better waste management practices and the introduction of central sprayers, which reduced the number of women applying crop protection products. Farmers and KTDA staff also report that the FFS programme had a positive effect on food and nutrition security. The participants of FFS focus groups indicated that there have been clear improvements in the quantity of food, due to increased yields of maize, beans and vegetables. Also, FFS famers indicated that the diversity of food in their diets had increased, for example due to a higher intake of vegetables and fruits. Non-FFS participants did not indicate any such changes.

All three parties contributed: funding by IDH and Unilever has led to FFSs being implemented more rapidly than would have been the case without their funding

The impact of the Embedding Sustainability Programme can be attributed in large part to the three funders contributing to the programme. The funding of the programme was equally distributed between KTDA, Unilever and IDH. The co-funding of Unilever and IDH played a key role in upscaling the FFS approach. KTDA would also have implemented the FFS without IDH and Unilever support, but at a much slower pace.

The FFS approach has been embedded and institutionalised at the KTDA management level, but half of the FFS farmers discontinue activities after their graduation

KTDA staff in all parts of the organisation consider the FFS to be an important and effective extension methodology. Over the coming years, the FFS implementation will continue, though at a slower pace than in the last few 
years as KTDA fully funds the implementation itself and farmer graduates will no longer assist the TESAs in organising the FFS. KTDA management has gained one extra staff member to implement the FFS programme. This enhances the sustainability of the continued implementation of FFS at KTDA from the KTDA management level.

There is one point that needs to be addressed in order to increase the embeddedness of the FFS within the KTDA extension strategy: about $50 \%$ of the farmers indicated they had discontinued activities since graduation. Time and money constraints, a lack of commitment and insufficient coordination are mentioned as the main reasons for discontinuing FFS activities. A more active way of engaging FFS farmer graduates would perhaps go further in guaranteeing the sustainability of these FFS group graduates. This could also help to address the production problems that many of these FFS graduates are facing.

\section{Recommendations}

Based on the results of this evaluation, we recommend the following.

1. Explore ways of managing the fact that tea plots are getting smaller and smaller plots tend to be less productive. We should learn from similar developments occurring in other sectors.

2. Focus the implementation of FFSs on those farmers who still stand to substantially improve their tea practices. This is likely to have a bigger impact, and would therefore increase the efficiency of FFS implementation because similar investments would generate more impact.

3. Explore which topics and themes can offer added value in addition to previous trainings attended by FFS farmers.

4. Continue the training on nutrition and diversification, as it contributes to resilience and food security.

5. Explore ways of increasing the activities of farmers who have graduated from FFSs with their FFS groups, to address production problems and continue to experiment with innovations. 


\section{References}

Waarts, Y., L. Ge, G. Ton, D. Jansen, 2012. Sustainable tea production in Kenya: Impact assessment of Rainforest Alliance and Farmer Field School training. LEI report. LEI Wageningen UR, The Hague. Commissioned by the Royal Netherlands Embassy in Nairobi (http://edepot.wur.nl/214044).

Waarts, Y., L. Ge, L. Puister-J ansen, D. Onduru, 2014. For all the tea in Kenya: Impact assessment and baseline situation of farmer field schools. LEI Report 2014-007. LEI Wageningen UR, The Hague, The Netherlands

(http://edepot.wur.nl/310209) 


\section{Appendices}

The Appendices to this report can be accessed by following this link: http://dx. doi.org/10.18174/401404 
This study was carried out by Wageningen University \& Research and was financed and commissioned by KTDA, IDH the Sustainable Trade Initiative and Unilever

Author: Wageningen Economic Research, part of Stichting Wageningen Research, 2016

Reproduction of contents, either whole or in part, is permitted with due reference to the source. The user must attribute the work by stating the name indicated by the author or licensor but may not do this in such a way as to create the impression that the author/licensor endorses the use of the work or the work of the user. The user may not use the work for commercial purposes. Wageningen Economic Research accepts no liability for any damage resulting from the use of the results of this study or the application of the advice contained in it. 
Authors

Yuca Waarts, Just Dengerink, Linda Puister-Jansen, Fédes van Rijn, Davies Onduru*

* ETC-East Africa

Citation: Final impact evaluation of Farmer Field School implementation in the smallholder tea

sector in Kenya, 2009-2016, Waarts, Y.R., J. Dengerink. L. Puister-Jansen, F. Van Rijn,

D. Onduru. Wageningen Economic Research, Den Haag, 2016

Wageningen Economic Research Report 2016-044

Project code 2282500141

ISBN 978-94-6343-053-1

This report can be downloaded for free at http://dx.doi.org/10.18174/401403 or at

www.wur.eu/economic research (under Wageningen Economic Research publications).

Layout

MediaCenter Rotterdam

\section{Photography}

Sabine Hiller (p. 26, 54), Andre de Jager (p. 13), Yuca Waarts (cover, p. 19, 31, 37, 43, 48, 51, 58)

Editor

Speer Publications 
Wageningen University \& Research

Wageningen Economic Research

P.O. Box 88

$6700 \mathrm{AB}$ Wageningen

$\mathrm{T}+31(0) 317481875$

$\mathrm{F}+31(0) 703615624$

\section{E yuca.waarts@wur.nl}

www.wur.nl/economic-research 